\title{
ASSESSING ENDOTHELIAL DYSFUNCTION ESTIMATING THE DIFFERENCES BETWEEN 3 MINUTE AND 5 MINUTE \\ REACTIVE HYPEREMIA STIMULI
}

\author{
A Thesis \\ presented to \\ the Faculty of California Polytechnic State University, \\ San Luis Obispo
}

\author{
In Partial Fulfillment \\ of the Requirements for the Degree \\ Master of Science in Biomedical Engineering
}

by

Tamiko Saldin

March 2019 
(C) 2019

Tamiko Saldin

ALL RIGHTS RESERVED 


\section{COMMITTEE MEMBERSHIP}

TITLE: Assessing Endothelial Dysfunction Estimating the Differences Between 3 Minute and 5 Minute Reactive Hyperemia Stimuli

AUTHOR: Tamiko Saldin

DATE SUBMITTED: $\quad$ March 2019

COMMITTEE CHAIR: Michael Whitt, Ph.D.

Assistant Professor of Biomedical Engineering

COMMITTEE MEMBER: David Clague, Ph.D.

Professor of Biomedical Engineering

COMMITTEE MEMBER: Pat Senarith

Principal R\&D Engineer 


\section{ABSTRACT \\ Assessing Endothelial Dysfunction Estimating the Differences Between 3 Minute and 5 Minute Reactive Hyperemia Stimuli Tamiko Saldin}

The purpose of this study was to define a lower standard cuff occlusion time to induce reactive hyperemia in assessing endothelial dysfunction. In this study, strong evidence was found by a novel technique that used oscillometric methods, which supported that 3 minute reactive hyperemia was sufficient to elicit a significant difference in arterial compliance from baseline. Twenty healthy Cal Poly students were assessed, $(n=12$ female, $n=8$ male) aged 22 years old with a standard deviation of 2.04 years. Arterial compliance was estimated by measuring the peak-topeak oscillations for baseline, 3 minute reactive hyperemia, and 5 minute reactive hyperemia tests, with the result being statistical evidence of an increase in arterial compliance after 3 minutes of cuff occlusion compared to baseline. The peak-to-peak mean for the 3 minute reactive hyperemia test was significantly greater than the baseline peak-to-peak mean with p-values less than 0.0001 . These results support that 3 minute reactive hyperemia is sufficient to assess endothelial dysfunction using oscillometry techniques. Endothelial dysfunction is the most significant predictor of a major adverse cardiovascular event, so this test can be used as an early detection tool for cardiovascular disease and allow patients to find treatment before irreversible damage is done to the body. Implementing this test into routine doctor checkups has the potential to have a significant effect on cardiovascular disease, which is the leading cause of death globally. The currently accepted clinical benchmark performed in hospitals uses high-frequency ultrasound with a standard cuff occlusion time of 5 minutes. Although noninvasive, 5 minutes of cuff occlusion causes slight discomfort to the patient and is not desirable. This test was improved and shortened by using a system based on the oscillometric method of blood pressure measurement. By reducing the duration of the test from 5 minute reactive hyperemia to 3 minute reactive hyperemia, this will make the procedure practical for an increased number of patients, providing a noninvasive option to regularly check for early symptoms of cardiovascular disease.

Keywords: endothelial dysfunction, reactive hyperemia, oscillometry, early diagnosis, cardiovascular disease 


\section{TABLE OFCONTENTS}

Page

LIST OF TABLES .............................................................................................................................. vii

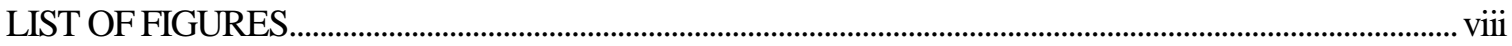

\section{CHAPTER}

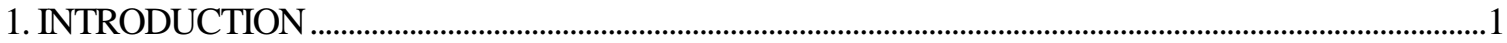

1.1 Prevalence of Cardiovascular Disease ........................................................................................................

1.2 Atherosclerosis

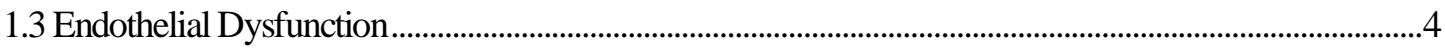

1.4 Imaging Methods for Detection ............................................................................................................

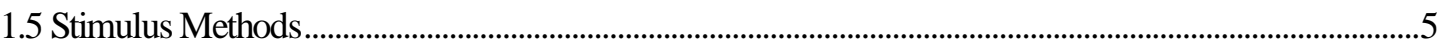

1.6 Arterial Occlusion as a Function of Blood Pressure ..........................................................................................

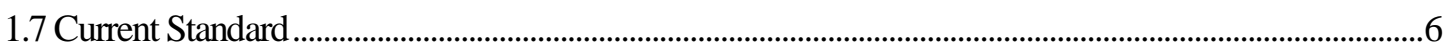

1.8 Flow-Mediated Dilatation .................................................................................................................

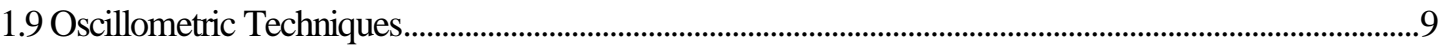

2. THEORY/LITERATURE REVIEW ....................................................................................................... 11

2.1 Endothelial Function and Dysfunction ............................................................................................... 11

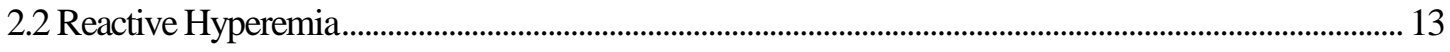

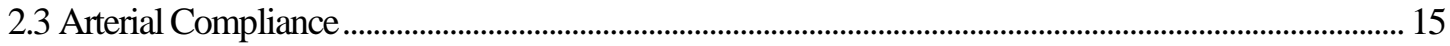

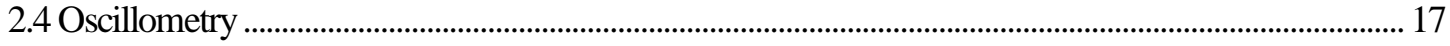

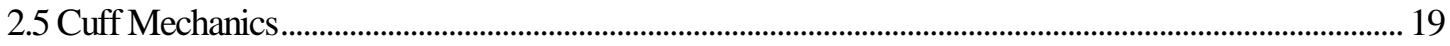

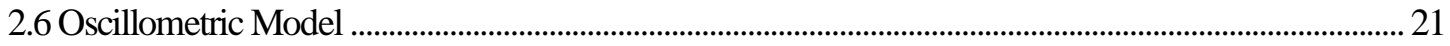

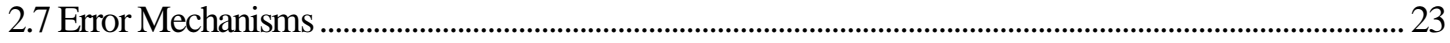

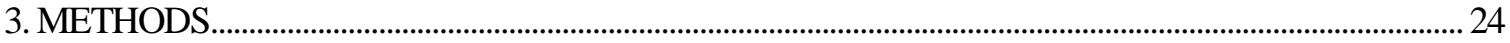

3.1 Experimental Methods............................................................................................................................ 24 
3.2 Software Methods

3.2.1 Baseline Test Analysis .............................................................................................................. 27

3.2.2 Reactive Hyperemia Tests Analysis .............................................................................................. 29

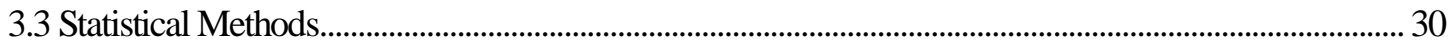

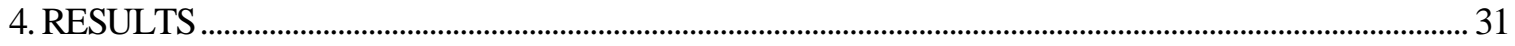

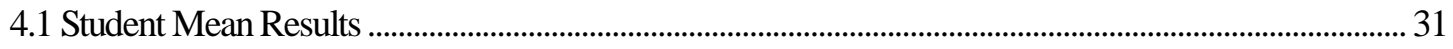

4.2 Individual Results .............................................................................................................................. 33

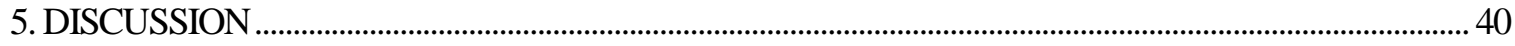

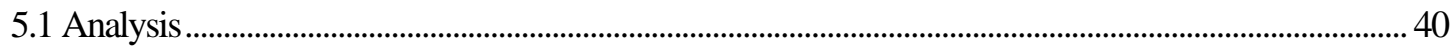

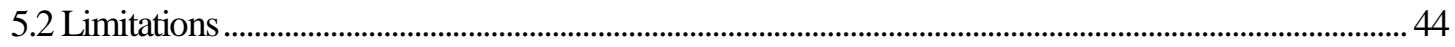

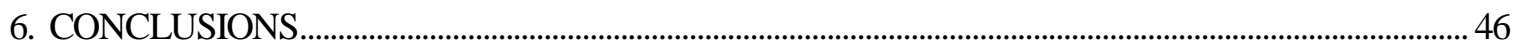

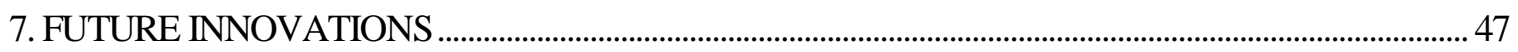

7.1 Improvements to Study................................................................................................................... 47

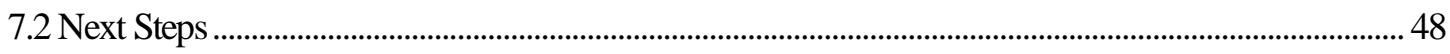

7.3 Benefits of Pushing this Test Forward .................................................................................................. 49

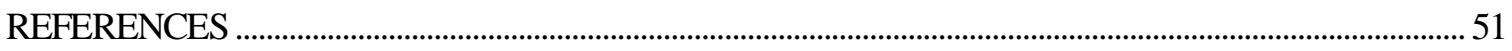

\section{APPENDICES}

A. AcqKnowledge Data..................................................................................................................... 54

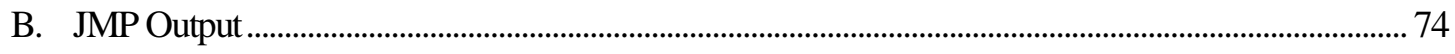

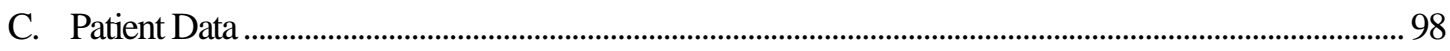




\section{LIST OF TABLES}

Table

1. Ideal, Intermediate, and Poor Cardiovascular Health Definitions ........................................ 3

2. Percent Change in Artery Diameter Following 1, 3, and 5 Min Cuff Occlusion..................... 7

3. Constants to Composite Solution for Cuff Pressure ............................................................. 22

4. Data Acquisition Settings for New Graph Template .......................................................... 27

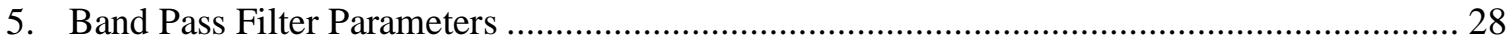

6. Peak-to-Peak Data for the Overall Means of the Students for Each Test .............................. 31

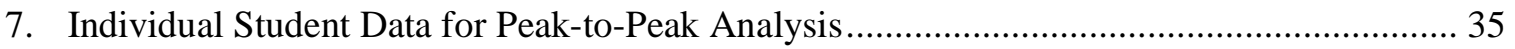




\section{LIST OF FIGURES}

Figure

1. U.S. Age-Adjusted Death Rates for the Leading Causes of Death, 1958-2015...................... 1

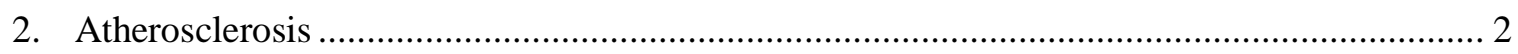

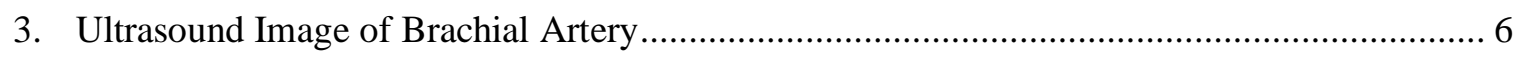

4. Percent Change in Diameter Following Release of 1, 3, and 5 Minutes of Cuff Occlusion ..... 8

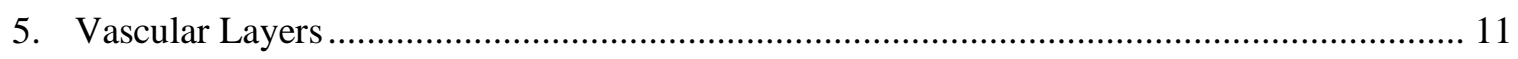

6. Proper Endothelial Cell Function Leads to Vasodilation and Vasoconstriction ..................... 12

7. The Inhibition of NO Leads to Endothelial Dysfunction and Vascular Disease ................... 13

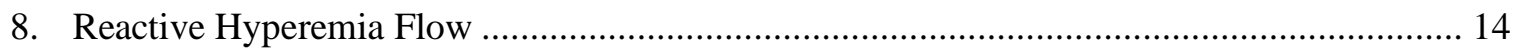

9. Arterial Properties vs. Transmural Pressure ................................................................. 15

10. Critical Buckling Pressure Computed for a Cylindrical Vessel ....................................... 16

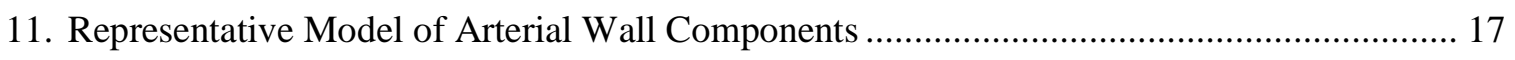

12. Typical Oscillations in Cuff Pressure During a Blood Pressure Measurement by

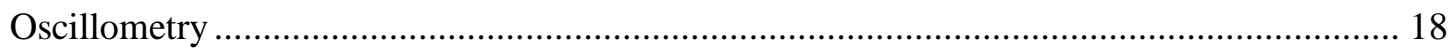

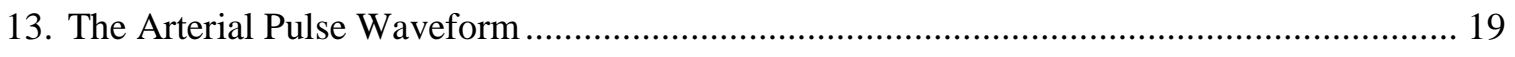

14. Experimental Apparatus to Model Pressure Changes of a Blood Pressure Arm Cuff ........... 20

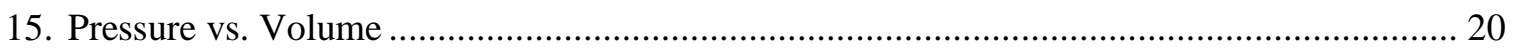

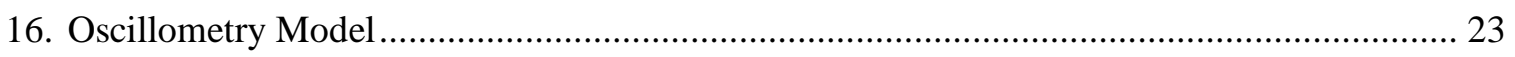

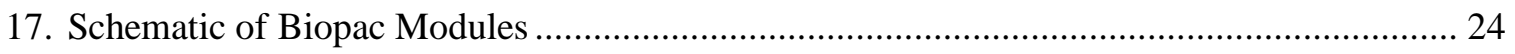

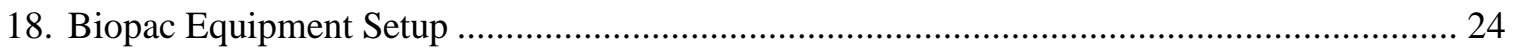

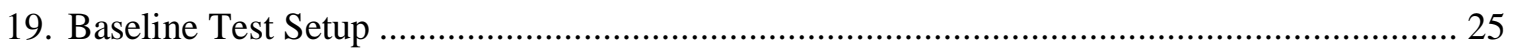

20. Investigator Pumps Pressure to $50 \mathrm{mmHg}$ Suprasystolic to Occlude Blood Flow ................. 26

21. Selected Channel Designated to Measure Peak-To-Peak (P-P) …...................................... 27

22. Example of Baseline Data Before Filtering Using Acqknowledge .................................... 28 
23. Frequency Response from Band Pass Filter on Baseline Data Using Acqknowledge

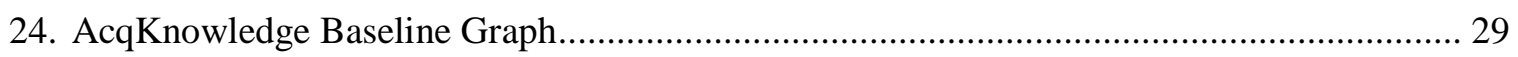

25. Selection of P-P Measurements of Baseline Data Using Acqknowledge …......................... 29

26. Original Data from a 3 Min Reactive Hyperemia Test Using Acqknowledge ...................... 30

27. Selection of P-P Measurement for Reactive Hyperemia Data Using Acqknowledge ............ 30

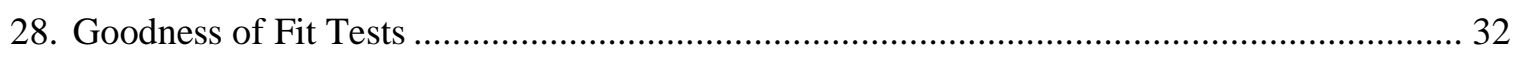

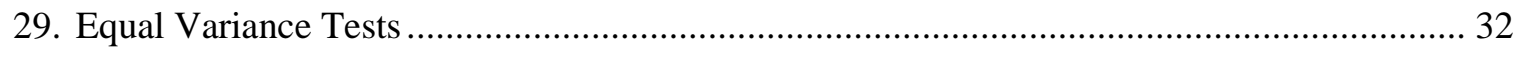

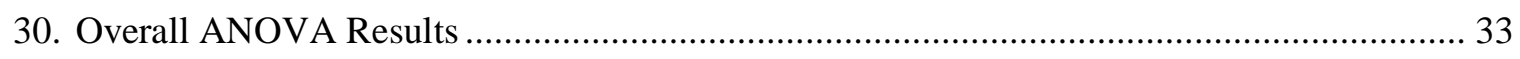

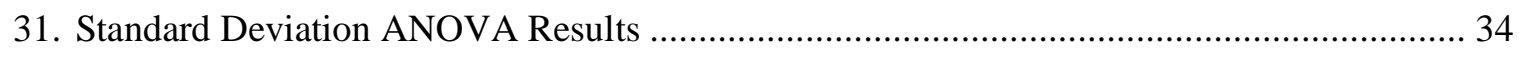

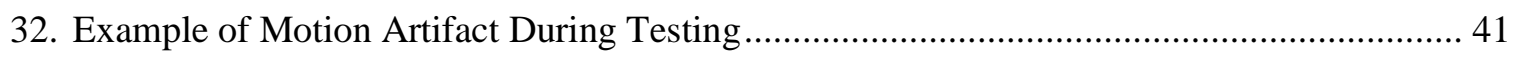


Chapter 1

\section{INTRODUCTION}

\subsection{Prevalence of Cardiovascular Disease}

Cardiovascular disease is the global leading cause of death, and is responsible for about one in every three deaths [1]. Cardiovascular disease includes any disease affecting the heart and/or blood vessels. Of the deaths attributable to cardiovascular disease, coronary heart disease is the leading cause of these deaths (43.8\%), followed by stroke (16.8\%), high blood pressure $(9.4 \%)$, heart failure $(9.0 \%)$, diseases of the arteries (3.1\%) and other cardiovascular diseases (17.9\%) [1]. Shown in Figure 1 are the age-adjusted death rates for the leading causes of death in the United States from 1978 to 2015 [2]. Heart disease is shown as the highest leading cause of death since 1958 and continues to be the leading cause of death today.

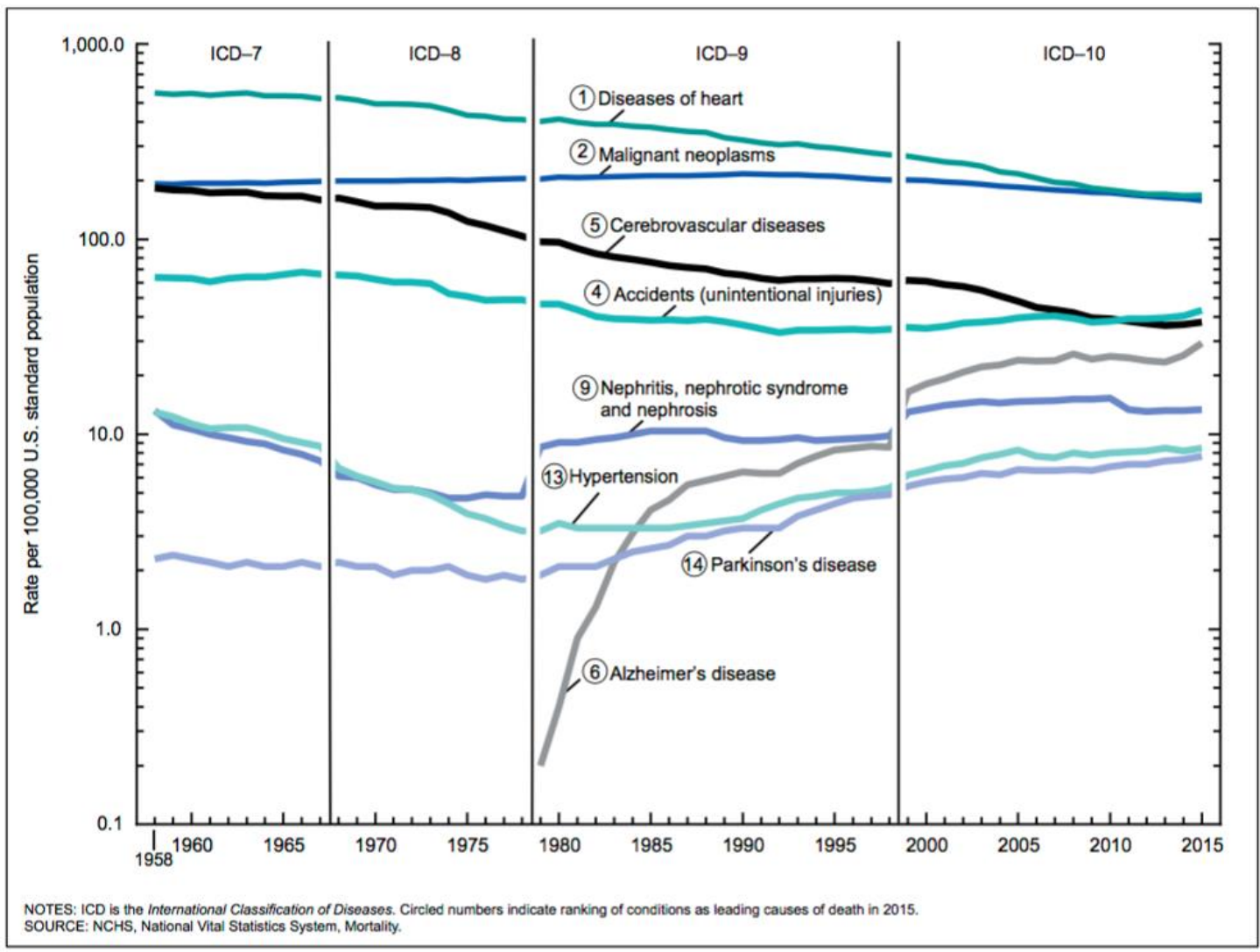

Figure 1 U.S. Age-Adjusted Death Rates for the Leading Causes of Death, 1958-2015 [2] 


\subsection{Atherosclerosis}

The most common type of heart disease is coronary heart disease [3]. Coronary heart disease results from the buildup of fatty plaque in the blood vessels, shown in Figure 2. Plaque buildup, otherwise known as atherosclerosis, causes the arteries to narrow and harden, which can damage the blood vessel, decrease blood flow, and require the heart to work harder to pump blood. If plaque builds up in the arteries supplying blood to the heart, this is known as coronary artery disease and can lead to a heart attack. If the plaque builds up in the arteries supplying blood to the arms and legs, this is known as peripheral artery disease, and if the plaque builds up in the arteries supplying blood to the brain, this is known as carotid artery disease and can lead to stroke. The plaque itself could completely occlude the artery, or a portion of the plaque can embolize and dislodge itself further downstream, causing several complications.

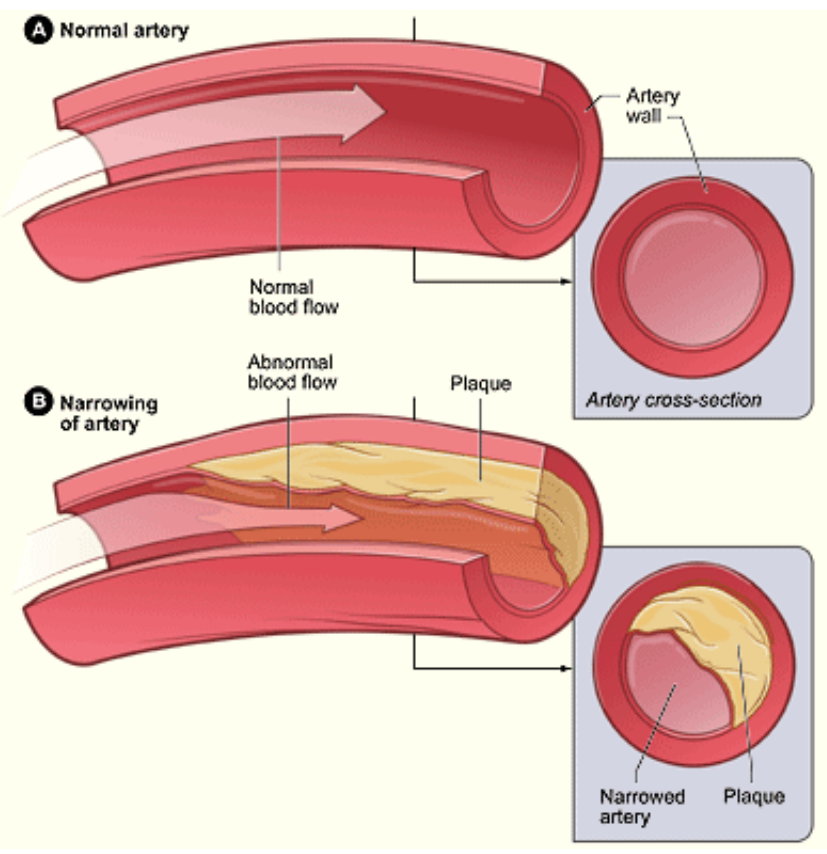

Figure 2 Atherosclerosis. Healthy artery versus artery with atherosclerosis showing plaque buildup and abnormal blood flow. [4]

Atherosclerosis is typically caused by destructive life habits including unhealthy diet, lack of exercise, and smoking [5]. There are currently seven cardiovascular health metrics that have been identified as critical in defining ideal cardiovascular health. The metrics were 
published by the American Heart Association as a goal for 2020, and define poor, intermediate,

and ideal cardiovascular health for adults greater than 20 years old and children between the ages

of 12 and 19, summarized in Table 1 [6].

Table 1 Ideal, Intermediate, and Poor Cardiovascular Health Definitions [6]

\begin{tabular}{|c|c|c|c|c|}
\hline \multirow{2}{*}{ Metric } & \multirow{2}{*}{ Age } & \multicolumn{3}{|c|}{ Cardiovascular health definitions } \\
\hline & & Ideal & Intermediate & Poor \\
\hline \multirow[b]{2}{*}{$\begin{array}{l}\text { 1. Current } \\
\text { smoking }\end{array}$} & $\begin{aligned} & \text { Adults } \\
> & 20 \text { years }\end{aligned}$ & $\begin{array}{c}\text { Never or quit }>12 \\
\text { months ago }\end{array}$ & Former $\leq 12$ months & Yes \\
\hline & $\begin{array}{c}\text { Children } \\
12-19 \text { years }\end{array}$ & $\begin{array}{c}\text { Never tried, never } \\
\text { smoked whole } \\
\text { cigarette }\end{array}$ & & $\begin{array}{c}\text { Tried prior } 30 \\
\text { days }\end{array}$ \\
\hline \multirow{2}{*}{$\begin{array}{l}\text { 2. Body } \\
\text { mass index }\end{array}$} & $\begin{aligned} & \text { Adults } \\
> & 20 \text { years }\end{aligned}$ & $<25 \mathrm{~kg} / \mathrm{m} 2$ & $25-29.9 \mathrm{~kg} / \mathrm{m} 2$ & $\geq 30 \mathrm{~kg} / \mathrm{m} 2$ \\
\hline & $\begin{array}{c}\text { Children } \\
12-19 \text { years }\end{array}$ & $<85$ th percentile & $\begin{array}{l}85 \text { th }-95 \text { th } \\
\text { percentile }\end{array}$ & $\begin{array}{c}>95 \text { th } \\
\text { Percentile }\end{array}$ \\
\hline \multirow[t]{2}{*}{$\begin{array}{l}\text { 3. Physical } \\
\text { activity }\end{array}$} & $\begin{aligned} & \text { Adults } \\
> & 20 \text { years }\end{aligned}$ & $\begin{array}{l}\geq 150 \mathrm{~min} / \text { week } \\
\text { moderate intensity or } \\
\geq 75 \mathrm{~min} / \text { week } \\
\text { vigorous intensity or } \\
\quad \text { combination }\end{array}$ & $\begin{array}{c}1-149 \mathrm{~min} / \text { week } \\
\text { moderate intensity or } \\
1-74 \mathrm{~min} / \text { week } \\
\text { vigorous intensity or } \\
1-149 \mathrm{~min} / \text { week } \\
\text { moderate }+ \text { vigorous }\end{array}$ & None \\
\hline & $\begin{array}{c}\text { Children } \\
12-19 \text { years }\end{array}$ & $\begin{array}{l}\geq 60 \text { min of } \\
\text { moderate- or } \\
\text { vigorous-intensity } \\
\text { activity every day }\end{array}$ & $\begin{array}{c}>0 \text { and }<60 \text { min of } \\
\text { moderate or vigorous } \\
\text { activity every day }\end{array}$ & None \\
\hline \multirow{2}{*}{$\begin{array}{l}\text { 4. Healthy } \\
\text { diet score }\end{array}$} & $\begin{aligned} & \text { Adults } \\
&> 20 \text { years } \\
&\end{aligned}$ & $4-5$ components & $2-3$ components & $\begin{array}{c}0-1 \\
\text { components }\end{array}$ \\
\hline & $\begin{array}{c}\text { Children } \\
12-19 \text { years }\end{array}$ & $4-5$ components & $2-3$ components & $\begin{array}{c}0-1 \\
\text { components } \\
\end{array}$ \\
\hline \multirow{2}{*}{$\begin{array}{l}\text { 5. Total } \\
\text { cholesterol }\end{array}$} & $\begin{aligned} & \text { Adults } \\
> & 20 \text { years }\end{aligned}$ & $<200 \mathrm{mg} / \mathrm{dL}$ & $\begin{array}{c}200-239 \mathrm{mg} / \mathrm{dL} \text { or } \\
\text { treated to goal }\end{array}$ & $\geq 240 \mathrm{mg} / \mathrm{dL}$ \\
\hline & $\begin{array}{c}\text { Children } \\
12-19 \text { years }\end{array}$ & $<170 \mathrm{mg} / \mathrm{dL}$ & $170-199 \mathrm{mg} / \mathrm{dL}$ & $\geq 200 \mathrm{mg} / \mathrm{dL}$ \\
\hline \multirow{2}{*}{$\begin{array}{l}\text { 6. Blood } \\
\text { pressure }\end{array}$} & $\begin{aligned} & \text { Adults } \\
> & 20 \text { years }\end{aligned}$ & $<120 /<80 \mathrm{mmHg}$ & $\begin{array}{c}\text { SBP } 120-139 \text { or } \\
\text { DBP } 80-89 \mathrm{mmHg} \\
\text { or treated to goal }\end{array}$ & $\begin{array}{c}\mathrm{SBP} \geq 140 \text { or } \\
\mathrm{DBP} \geq 90 \\
\mathrm{mmHg}\end{array}$ \\
\hline & $\begin{array}{c}\text { Children } \\
12-19 \text { years }\end{array}$ & $<90$ th percentile & $\begin{array}{c}\text { 90th }-95 \text { th } \\
\text { percentile or } \\
\mathrm{SBP} \geq 120 \text { or } \\
\mathrm{DBP} \geq 80 \mathrm{mmHg}\end{array}$ & $\begin{array}{c}>95 \text { th } \\
\text { percentile }\end{array}$ \\
\hline \multirow{2}{*}{$\begin{array}{l}\text { 7. Fasting } \\
\text { plasma } \\
\text { glucose }\end{array}$} & $\begin{aligned} & \text { Adults } \\
&> 20 \text { years } \\
&\end{aligned}$ & $<100 \mathrm{mg} / \mathrm{dL}$ & $\begin{array}{c}100-125 \mathrm{mg} / \mathrm{dL} \text { or } \\
\text { treated to goal }\end{array}$ & $\geq 126 \mathrm{mg} / \mathrm{dL}$ \\
\hline & $\begin{array}{c}\text { Children } \\
12-19 \text { years }\end{array}$ & $<100 \mathrm{mg} / \mathrm{dL}$ & $100-125 \mathrm{mg} / \mathrm{dL}$ & $\geq 126 \mathrm{mg} / \mathrm{dL}$ \\
\hline
\end{tabular}


The timing of the diagnosis of cardiovascular disease plays a crucial factor in the patient's ability to overcome the disease. Typically, the earlier the diagnosis, relative to the stage of the disease, the easier it will be for the patient to treat this disease. Treatment can be as simple as changing lifestyle habits to healthier options, which may reverse the disease and save the patient's life. If the diagnosis occurs too late in the progression of the disease, treatment may include surgery or life-long medications. The ideal diagnosis would occur even before symptoms may begin. In order to accomplish this, doctors would routinely use noninvasive procedures to check for precursors to cardiovascular disease. To prevent a disease from occurring before serious negative symptoms occur is the ultimate goal for the future.

\subsection{Endothelial Dysfunction}

The human body consists of an extensive vascular system, which must be able to deliver sufficient blood where needed by adapting to changes within the body. A blood vessel consists of multiple layers, with the inner lining being the endothelium. The endothelium sends signals to the smooth muscle cells located in the media to expand or constrict, which changes the lumen diameter and maintains vascular tone. The dominating signal in this pathway is the release of nitric oxide (NO), which causes smooth muscle cells to relax and thus dilate the vessel. Endothelial dysfunction (ED) occurs when the release of NO gets inhibited, and the endothelium is unable to properly maintain vascular homeostasis due to narrowing or stiffening of the arteries. ED has become a widely known precursor to cardiovascular disease.

\subsection{Imaging Methods for Detection}

Detection methods must include an imaging procedure along with a stimulus to induce vascular changes. There are several invasive and noninvasive methods to detect ED [7]. One example of an invasive imaging method would be X-Ray angiography, in which a radiopaque substance is injected into the bloodstream, which may not be desirable for a routine checkup.

The nature of noninvasive imaging methods gives patients a practical option for routine testing to detect early symptoms, which could be a crucial factor for finding treatment. The 
counter-argument for noninvasive methods would be their accuracy. Common noninvasive imaging methods for the detection of ED include ultrasound, MRI, and oscillometry. Although ultrasound and MRI are physically noninvasive, these methods present energy exposure to the body. Using oscillometry poses low risk for the individual because there is no energy exposure and it is the platform behind one method of blood pressure screening. Noninvasive imaging methods must be paired with a stimulus in order to get an effective reading of ED.

\subsection{Stimulus Methods}

A stimulus is used to inflict vascular changes within the body. One example of an invasive stimulus involves directly stimulating the artery by injection of substances into the blood stream that enhance the release of nitric oxide in the endothelium, such as acetylcholine or nitroglycerin [8]. However, invasive methods are high risk, and not suitable for asymptomatic patients.

Noninvasive methods pose low risk for the individual and are therefore more desirable to administer regularly. An example of a noninvasive stimulus is reactive hyperemia. Reactive hyperemia is the body's natural response of increased blood flow following arterial occlusion. During arterial occlusion, blood flow becomes blocked, and the local tissue's oxygen supply depletes. When blood flow is released, the dilated blood vessels result in an increase in blood flow to resupply the local tissue with oxygen. This response is immediate and temporary, and blood flow returns to normal as the tissue's oxygen supply levels out. There is low risk to this procedure and it is a simple method to induce vascular changes in the body.

Reactive hyperemia will be described in this report by the duration that the arm cuff occludes blood flow. For example, 1 minute reactive hyperemia would be describing a test where the patient underwent cuff occlusion for 1 minute. The test will be abbreviated as $1 \mathrm{~min}$ RH.

\subsection{Arterial Occlusion as a Function of Blood Pressure}

Using an arm cuff, arterial occlusion occurs as a function of transmural pressure, which is the difference between the cuff pressure and the pressure felt inside the artery. Cuff pressure is increased by pumping air into the cuff and increasing its volume. To measure blood pressure, an 
arm cuff is typically wrapped around an individual's upper arm to measure the brachial artery pressure. The cuff is increased to a pressure that is high enough to induce a negative transmural pressure that causes the artery to occlude and block blood flow. The cuff pressure is then slowly released. The pressure at which the blood is able to resume blood flow is known as systolic blood pressure. Systolic blood pressure is defined as the pressure in the artery when the heart contracts. Its counterpart, diastolic blood pressure, is defined as the pressure in the artery when the heart is at rest between beats [9]. Systolic and diastolic pressures can be interpreted from Korotkoff sounds, known as the auscultatory method [10], or calculated using specified ratios of mean arterial pressure, known as the oscillometric method. Mean arterial pressure is the pressure at which cuff pressure and arterial pressure are equivalent.

\subsection{Current Standard}

The standard time of cuff occlusion to induce reactive hyperemia (RH) for assessing ED is currently 5 minutes. This standard is based on the 1995 study by Mary Corretti at the University of Maryland [11]. A method known as flow-mediated dilatation was performed, which uses highfrequency ultrasound to measure the change in brachial artery diameter after inducing reactive hyperemia. In this test, 1, 3, and 5 min RH was tested. High-frequency ultrasound uses sound waves to produce real time cross-sectional images of the artery, shown in Figure 3.

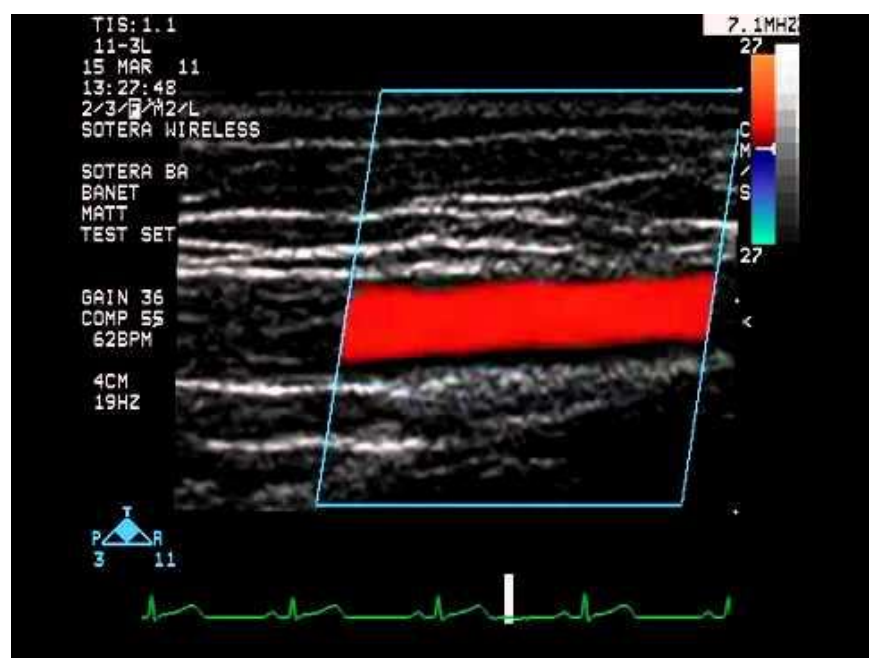

Figure 3 Ultrasound Image of Brachial Artery [12] 
The percent change in artery diameter was calculated by dividing the increase in the dilated vessel diameter by the diameter at baseline. Seven individuals, (female $n=3$, male $n=4$ ) aged 29 to 38 years old (mean $=33 \pm 3$ years), with no known cardiovascular diseases underwent each of the 1, 3, and 5 min RH tests in a random order. To obtain the baseline value, each individual had their brachial artery diameter recorded for 1 minute intervals two times. Each individual had an arm cuff placed around the upper left arm and the operator inflated the cuff to $200 \mathrm{mmHg}$ for the specified duration of occlusion. Brachial artery diameter was imaged immediately after cuff deflation, and continued to be imaged for 20 minutes at 1 minute intervals. An operator blind to the study analyzed the images to obtain the measurements. A baseline test was done before each cuff occlusion test, and the order of the cuff occlusion durations was randomized. A 15 minute rest period was taken between each test. The reactive hyperemia test measurements were compared to their respective baseline measurements. The results for this study are summarized in Table 2 and Figure 4.

Table 2 Percent Change in Artery Diameter Following 1, 3, and 5 Min Cuff Occlusion [11]

\begin{tabular}{|c|c|c|c|c|c|c|c|}
\hline \multirow{2}{*}{$\begin{array}{c}\text { Duration } \\
\text { of } \\
\text { Occlusion } \\
\text { (min) }\end{array}$} & \multirow{2}{*}{$\begin{array}{c}\text { Immediate } \\
\text { Release }\end{array}$} & \multicolumn{6}{|c|}{ Minutes After Release } \\
\cline { 3 - 8 } & $\mathbf{1}$ & $\mathbf{3}$ & $\mathbf{5}$ & $\mathbf{1 0}$ & $\mathbf{1 5}$ & $\mathbf{2 0}$ \\
\hline 1 & $0.8 \pm 6.9$ & $2.1 \pm 6.1$ & $0.1 \pm 5.2$ & $0.3 \pm 4.8$ & $-0.1 \pm 5.4$ & $1.3 \pm 5.3$ & $-0.5 \pm 3.1$ \\
\hline 3 & $5.9 \pm 11.5$ & $7.8 \pm 10.4$ & $4.9 \pm 8.0$ & $0.8 \pm 6.1$ & $0.8 \pm 5.2$ & $-1.7 \pm 4.0$ & $-0.7 \pm 3.2$ \\
\hline 5 & $6.4 \pm 4.9^{*}$ & $12.6 \pm 5.7^{\wedge}$ & $8.0 \pm 6.1^{\wedge}$ & $7.0 \pm 4.9^{\wedge}$ & $4.4 \pm 1.8^{\wedge}$ & $4.1 \pm 3.7^{*}$ & $4.4 \pm 4.3^{*}$ \\
\hline
\end{tabular}

$* \mathrm{P}<0.05$ vs. baseline; ${ }^{\wedge} \mathrm{P}<0.01$ vs. baseline 


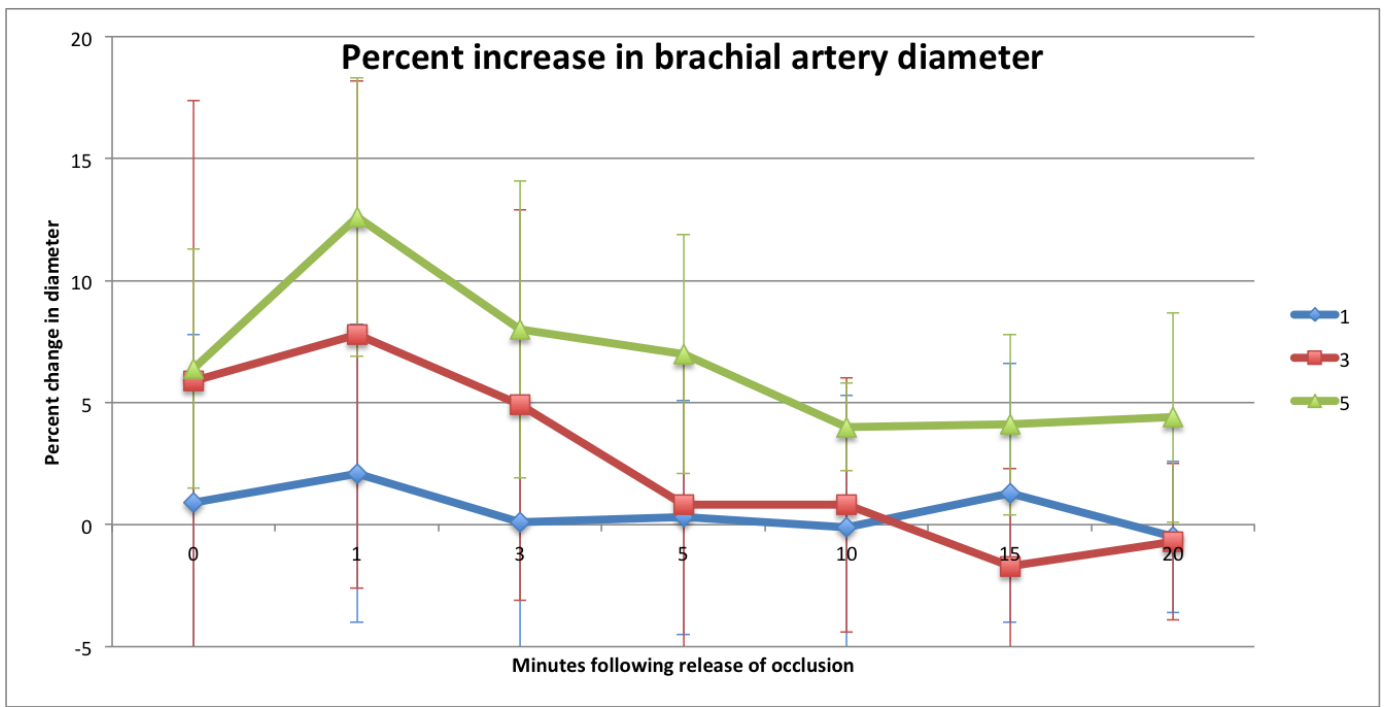

Figure 4 Percent Change in Diameter Following Release of 1, 3, and 5 Minutes of Cuff

Occlusion [11]

According to the results, with each increasing duration of cuff occlusion, the percent change in diameter increased. The $1 \mathrm{~min}$ RH test had the lowest mean percent increase of $0.57 \%$, while the 3 min RH test had a mean percent increase of $2.54 \%$, and the $5 \mathrm{~min}$ RH test had the highest mean percent increase of $6.7 \%$. The 5 min RH test was the only test that produced significant differences from baseline, with a p-value of $<0.05$. The results for the $5 \mathrm{~min} R H$ test remained significantly different from baseline throughout the 20 minutes after blood flow release.

However, in the graph, significant overlap can be seen between the 5 and 3 min RH tests due to the high standard deviation of the 3 minute test. The standard deviation for the 3 min RH test is much higher than the other tests, which raises the thought that if the 3 min RH test had a lower standard deviation, would the results be able to show a significant difference from baseline.

\subsection{Flow-Mediated Dilatation}

Flow mediated dilatation (FMD) is a widely accepted method due to its noninvasiveness and effortlessness for the patient. The accepted standard cuff occlusion time for inducing reactive hyperemia in assessing ED is 5 minutes, based off the results to Mary Corretti's study, as previously described $[11,13]$. Although a widely accepted method, there is subjective error when 
using FMD. The quality of the image is a critical parameter because the edge of the artery must be detected down to a single point. The subjective error associated with this method may arise from different operators with different judgments on the precise edge of the blood vessel, which highlights the importance of training. Critical parameters such as angle, alignment, and depth of the imaging system on the vessel must be kept consistent but are difficult to do so manually. If the alignment differs between tests, the diameter of the artery will be measured inaccurately [13]. This method requires the operator to have a high level of training in image analysis, which presents the possibility for a learning curve associated with this method. Lastly, FMD has only been shown to be optimal for arteries $2.5-5 \mathrm{~mm}$ in diameter [14]. This range limits which artery to measure, and singularizes the brachial artery as the best option for this test, due to over $90 \%$ of the population's brachial artery being less than $5 \mathrm{~mm}$.

\subsection{Oscillometric Techniques}

Oscillometric methods are widely accepted in blood pressure measurement, but have not been used as an ED detection method. An arm cuff is wrapped around an individual's arm, which is inflated using a manual or automatic pump. Data collection software must be used in conjunction to measure the peak-to-peak (P-P) oscillations. By analyzing P-P cuff oscillations, less subjective error is present than in other methods because the software completes the measurements of the peaks objectively. However, there is a need to account for the variability due to the nonlinear pressure-volume sensitivity of the cuff, which increases with increased cuff pressure. The data analysis can be done immediately after completion of the test, allowing the patient to be able to get their results on the same day. Oscillometric methods estimate the arterial compliance by outputting a P-P oscillation amplitude measurement that represents how much the vessel changes in area with pressure. This is an accurate indicator of arterial compliance with a simple and precise analysis.

The use of techniques using oscillometric methods could lead to results with lower standard deviations than FMD. The experimental goal of this study is to demonstrate a statistical 
difference of mean P-P oscillations between the 3 min RH test with baseline. This statistical evidence would support the lowering of the standard cuff occlusion time from 5 minutes using FMD to 3 minutes using the oscillometric technique. 
Chapter 2

\section{THEORY/LITERATURE REVIEW}

\subsection{Endothelial Function and Dysfunction}

The human body consists of an extensive vascular network, which delivers blood and nutrients to every cell in the body. The vascular walls are made up of three distinct layers: tunica adventitia, tunica media, and tunica intima, as shown in Figure 5 [15]. The outermost layer is the tunica adventitia, which is a sturdy fibrous connective tissue that supports and holds the blood vessel together. The middle layer is the tunica media, which is composed of smooth muscle cells in series with collagen. The innermost layer is the tunica intima, or the endothelium, which is a single-celled layer with many functions. Its main function is to maintain vascular tone. In addition, the endothelium provides an anti-thrombotic inner lining to the vascular system and controls the passage of materials in and out of the bloodstream.

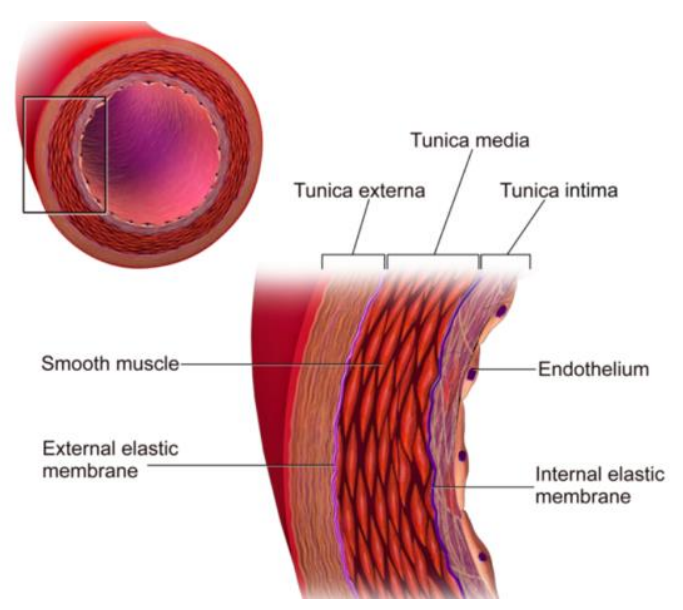

Figure 5 Vascular Layers. Multiple layers of vascular walls: tunica externa, tunica media, and tunica intima. [15]

As seen in Figure 6, endothelial cells respond to shear stress and maintain vascular tone by generating nitric oxide (NO) from L-arginine [16]. NO activates guanylate cyclase (sGC) in the smooth muscle cells of the tunica media. This causes smooth muscle cells to relax, causing the vessel diameter to widen, and thus causes vasodilation. NO also inhibits ET-1 synthesis. ET-1 
is generated by endothelial cells and activates receptors Et-A and ET-B in smooth muscle cells, which causes the cells to constrict, narrowing the vessel diameter, and thus causes vasoconstriction. In summary, vascular tone is maintained by the ability of the endothelial cells to release smooth muscle cell vasodilator NO in response to high shear stresses.

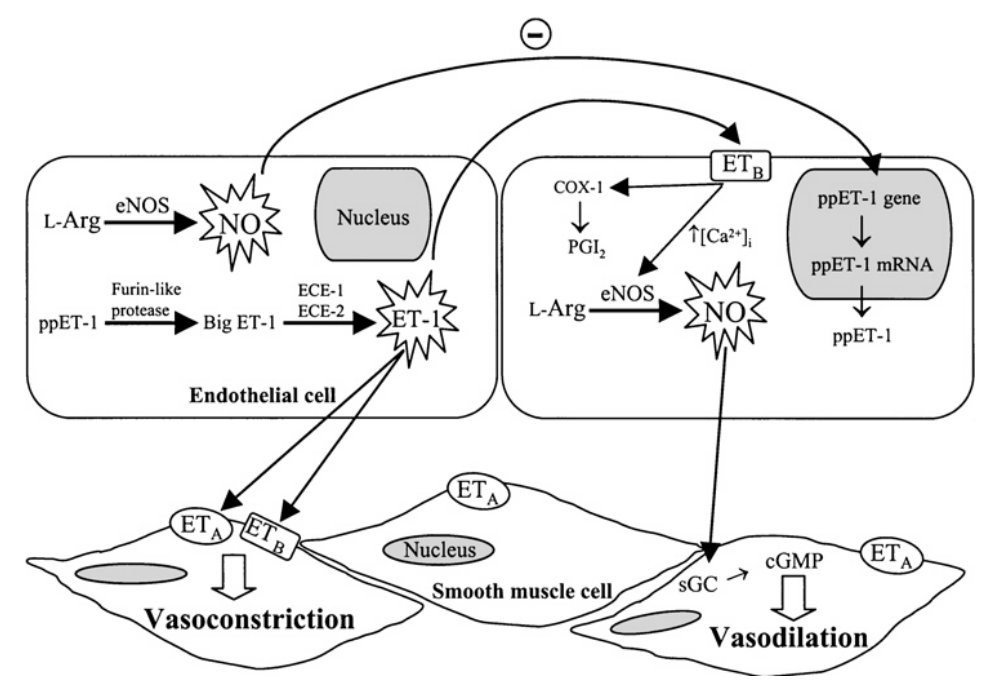

Figure 6 Proper Endothelial Cell Function Leads to Vasodilation and Vasoconstriction.

L-Arg: L-Arginine, eNOS: endothelial nitric oxide synthase, NO: nitric oxide, ppET-1: preproendothelin-1, ET-1: endothelin-1, COX-1: cyclooxygenase-1, $\mathrm{PGI}_{2}$ : prostacyclin, $\mathrm{ET}_{\mathrm{A}}$ : endothelin A, $\mathrm{ET}_{\mathrm{B}}$ : endothelin B, sGC: guanylate cyclase, cGMP: cyclic guanosine monophosphate. [16]

When endothelial cells do not function properly, vascular diseases including atherosclerosis are at risk due to an increase in vasoconstriction. Cardiovascular disease risk factors include smoking, high cholesterol levels, and oxidative stress, which are mediators to ED [17]. Turbulent blood flow has also indicated to lead to ED due to studies showing that turbulent flow exhibited a very low shear stress on vascular walls and unsteady blood flow [18]. Steady, laminar blood flow causes a higher shear stress and has shown to induce cell alignment in the direction of flow, while unsteady flow and low turbulent shear stress induces cell loss and vasoconstriction. These events lead to regions in the vascular wall that are prone to atherosclerosis. In addition, pro-inflammatory cytokines and advanced glycation end-products 
(AGE's) are mediators to ED due to the activation of nuclear factor kappa-light-chain-enhancer of activated $\mathrm{B}$ cells $(\mathrm{NF}-\kappa \mathrm{B})$. NF- $\mathrm{\kappa B}$ is normally inhibited by NO synthesis. With a decrease in NO, there is an increase in endothelial activation, which leads to ED. In this context, endothelial activation is defined as an inhibition of NO secretion. As a result, the risk of vascular disease is increased.

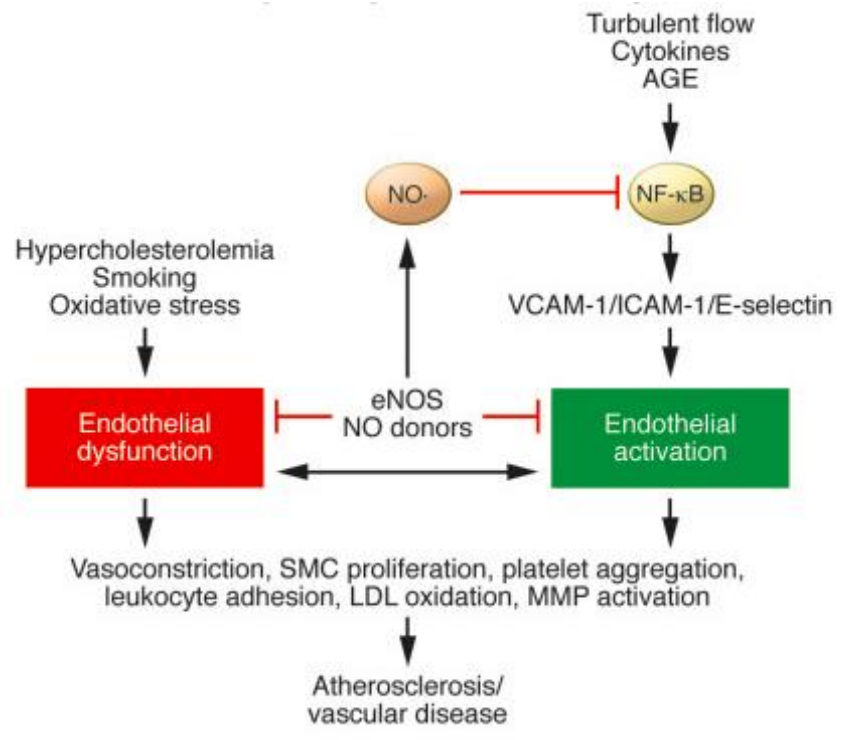

Figure 7 The Inhibition of NO Leads to Endothelial Dysfunction and Vascular Disease.

AGE: Advanced glycation end products, NF- $\mathrm{B}$ : nuclear factor kappa-light-chain-enhancer of activated B cells, VCAM-1: vascular cell adhesion molecule 1, ICAM-1: intercellular adhesion molecule 1, eNOS: endothelial nitric oxide synthase, NO: nitric oxide, SMC: smooth muscle cell, LDL: low-density lipoproteins, MMP: matrix metalloproteinase. [17]

\subsection{Reactive Hyperemia}

Reactive hyperemia is the immediate response of the body following arterial occlusion, including the dilation of blood vessels for the purpose of increasing blood flow and recovering from the loss of oxygen in tissues. Blood flow is closely correlated with tissue metabolic activity because oxygen, a necessary component in aerobic metabolism, is transferred to cells via the hemoglobin on red blood cells travelling through the blood stream [19]. During arterial occlusion, the oxygen supply from blood flow is cut off and local tissue hypoxia occurs downstream. 
Hypoxia occurs when cells have a lower supply of oxygen than normal. Oxygen is needed in the mitochondria of cells during aerobic metabolism. Only in the presence of oxygen, do carbohydrates, amino acids, and fats work to convert adenosine-diphosphate (ADP) to adenosinetriphosphate (ATP) for energy [20]. Along with tissue hypoxia, vasodilatory metabolites including adenosine, potassium ions, carbon dioxide, hydrogen ions, lactic acid, and inorganic phosphates are released, which results in the dilation of arterioles and causes a decrease in vascular resistance [19].

When arterial occlusion is released and blood flow reinitiates, the blood flow is increased due to both the dilation of blood vessels and a decrease in vascular resistance [21]. The longer the duration of occlusion, the stronger the response of increased blood flow is, as seen in Figure 8. Peak blood flow typically occurs within the first minute after release, but the response could last for several minutes depending on the site of occlusion. In the immediate blood flow response, the vasodilatory metabolites are cleared out of the local tissue as the tissue gets re-oxygenated. Since pressure returns to normal when blood flow gets released, vascular resistance increases while blood vessels gradually regain regular vascular tone. Reactive hyperemia is the body's survival mechanism to keep all cells alive. Because of the strong and immediate response, reactive hyperemia is a reliable mechanism in experimentation.
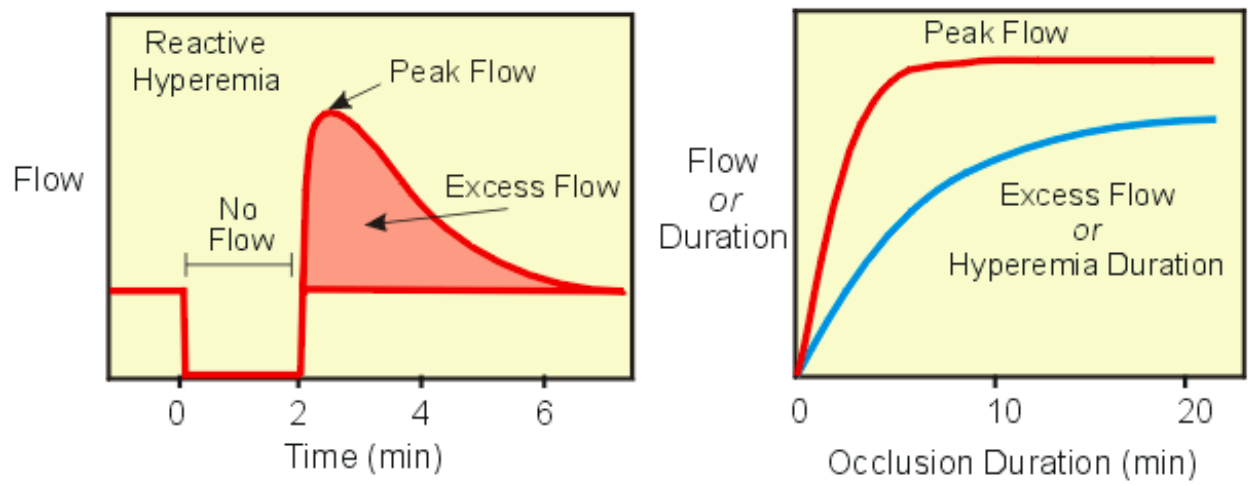

Figure 8 Reactive Hyperemia Flow. Reactive hyperemia demonstrated by the amount of flow versus time and occlusion duration. [21] 


\subsection{Arterial Compliance}

Arterial compliance is the amount that an artery changes in area while changing in pressure [23]. When the cross-sectional area of an artery is graphed versus pressure, compliance is calculated as the derivative of this curve, shown in Figure 9, as the change in area over the change in transmural pressure. Transmural pressure is defined as the difference between the arterial pressure and cuff pressure. When transmural pressure is negative, the cuff pressure is higher than the arterial pressure; and when transmural pressure is positive, the cuff pressure is lower than the arterial pressure. At zero transmural pressure, the cuff pressure equals the mean arterial pressure. According to the graph, with data taken from 13 canine carotid arteries, it can be seen that the maximum slope in the area versus pressure curve, which represents the maximum compliance, occurs around zero transmural pressure.
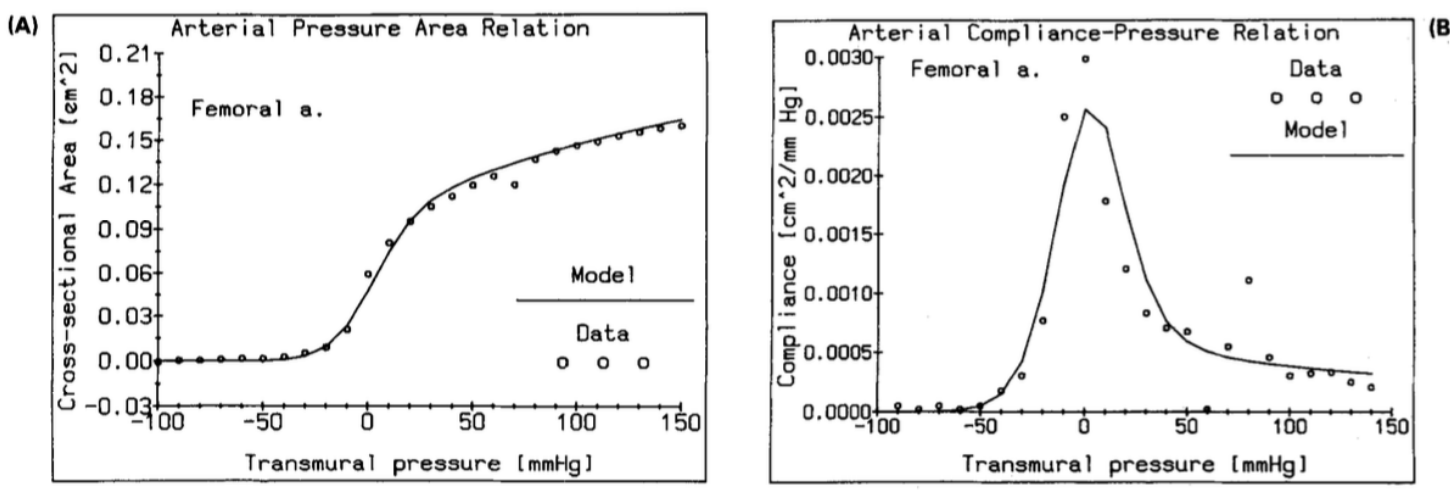

Figure 9 Arterial Properties vs. Transmural Pressure. (A) Lumen area (B) Compliance. [23]

For large positive transmural pressures, the artery is able to retain its circular shape, and slight deviations in area are due to wall stretching by the action of smooth muscle cells and collagen in series in the media. The contractile component is the smooth muscle cell, while the collagen provides structural support. The smooth muscle cells in series with collagen represents the mechanical function of the artery, and is captured during the baseline test. Shown in Figure 11 is a model of the structural layers of the artery. 
When transmural pressure is near zero where compliance is high, the artery is no longer able to retain its shape, and its cross-section collapses to become an elliptical shape. This critical point is known as the buckling pressure. According to the Von Mises Buckling Theory [22], when the artery buckles, it is less capable at supporting external loads, which leads to geometric and elastic instability, and thus the largest changes in volume can be found here because changes in area are due to both wall bending and wall stretch [23]. The critical pressure can be described as: $P_{\text {crit }}=-E h^{3} \frac{\left(m^{2}-1\right)}{\left[12 r^{3}\left(1-\mu^{2}\right)\right]}$, where $\mu$ is Poisson's ratio and equal to 0.5 for a blood vessel, $\mathrm{m}$ is the buckling mode and is equal to 2 , and $\mathrm{E}$ is wall elasticity and equal to $\frac{3 \pi r^{3}}{2 h C}$. With the assumption that the cross-sectional area is circular, the radius equates to $r=\left(\frac{A}{\pi}\right)^{1 / 2}$, where $\mathrm{A}$ is the lumen area, $\mathrm{h}$ is the wall thickness, and $\mathrm{C}$ is arterial compliance, based on Noordegraaf's derivation [24]. The critical buckling pressure is not relevant when transmural pressure is below the critical buckling pressure, so the critical pressure is determined from Figure 10 where the dashed line, which is the equivalence of transmural pressure and critical buckling pressure, meets the solid line, which is the critical buckling pressure. According to Figure 10, the critical buckling pressure occurs near zero transmural pressure.

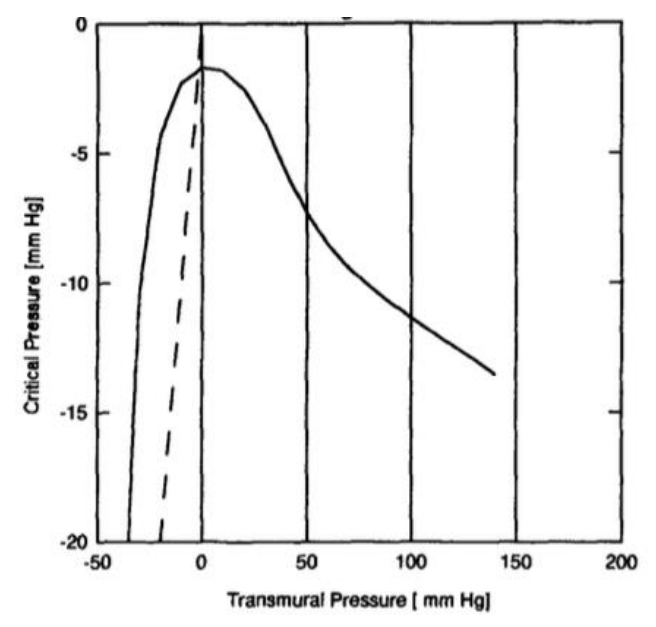

Figure 10 Critical Buckling Pressure Computed for a Cylindrical Vessel [23] 
When transmural pressure is below $0 \mathrm{mmHg}$, wall stretch is negligible, and changes in shape are due to wall bending from the recruitment of elastin and collagen in parallel in the intima $[23,25]$. Smooth muscle cells are inhibited at this point. As the transmural pressure becomes increasingly negative, the artery collapses further until flat and blood flow is occluded. A cuff pressure of $50 \mathrm{mmHg}$ greater than systolic pressure, or suprasystolic, is typically sufficient for the patient. The elastin in parallel with collagen represents the structural function of the artery and is captured during reactive hyperemia testing.

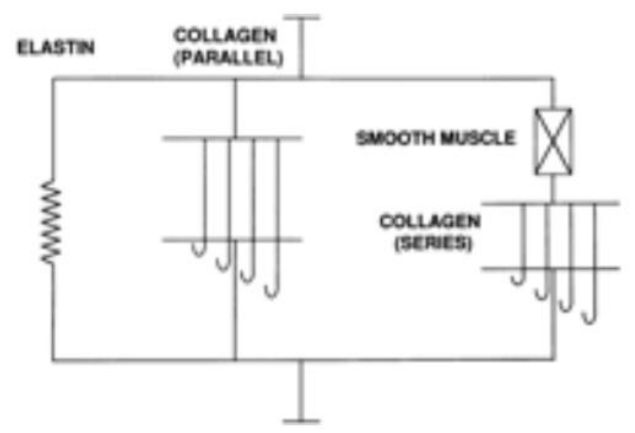

Figure 11 Representative Model of Arterial Wall Components [26]

\subsection{Oscillometry}

Oscillometry relies on the theory that cuff oscillations directly correspond with arterial compliance, and that maximum cuff oscillations occur around zero transmural pressure, which is at mean arterial pressure (MAP). Several mathematical models of oscillometry were created to determine systolic and diastolic values using defined ratios of MAP. One example of the ratio for systolic and diastolic is 0.593 and 0.717 , respectively [23]. Another example found was 0.55 and 0.82 for systolic and diastolic, respectively [27]. These ratios were established by experimentation; however, no standardized ratio has been published. The discrepancy between the ratios helps explain the inaccuracy in blood pressure measurements.

For blood pressure measurements, the oscillometric method utilizes an arm cuff and analyzes cuff oscillations to determine MAP and calculate systolic and diastolic values. The arm cuff is connected via an air tube to a release valve, pump, and pressure transducer. The cuff is typically 
inflated to $20-30 \mathrm{mmHg}$ above systolic $(150 \mathrm{mmHg}$ average $)$ and deflated at a rate of 2 $\mathrm{mmHg} / \mathrm{sec}$ using the release valve [23]. A pressure versus time graph is high-pass filtered at 0.5 $\mathrm{Hz}$ to reveal clearly the oscillations, typically of $1-5 \mathrm{mmHg}$, shown in Figure 12 . The point of maximum oscillation corresponds with MAP and the desired corresponding ratios of MAP are taken to obtain systolic and diastolic values.

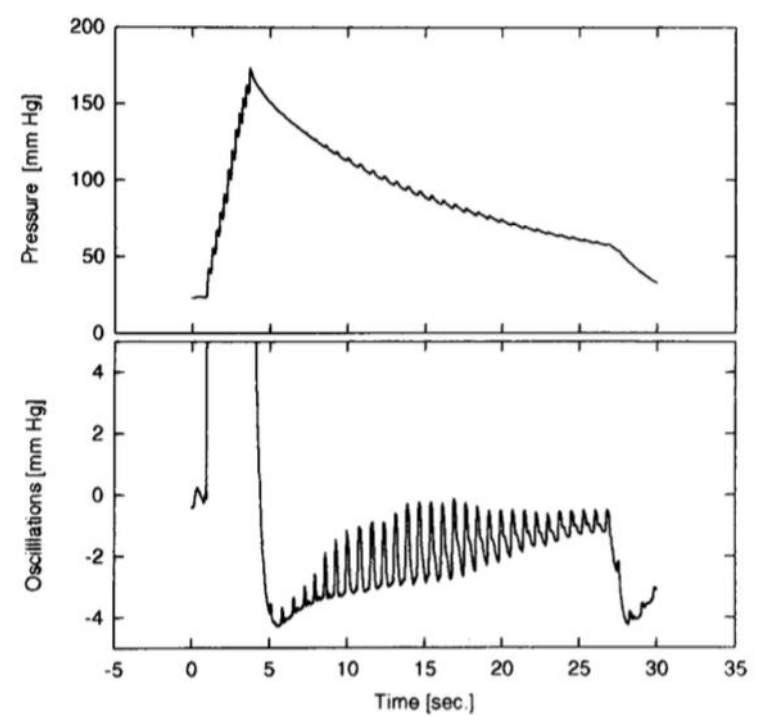

Figure 12 Typical Oscillations in Cuff Pressure During a Blood Pressure Measurement by Oscillometry [23]

The arterial waveform elicits a defined curve based on the mechanics of the blood flow, shown in Figure 13. The initial peak represents the opening of the aortic valve and left ventricular ejection into the aorta. This is the beginning of the systolic period. The pressure drops as it travels through peripheral vessels. When this pressure becomes lower than the aortic root pressure, the aortic valve closes, and the diastolic period begins. This event occurs at the dicrotic notch. The pressure continues to fall until it reaches its lowest point, known as end diastole. At this point, the left ventricle would refill with blood, contract, and repeat the cycle [28]. 


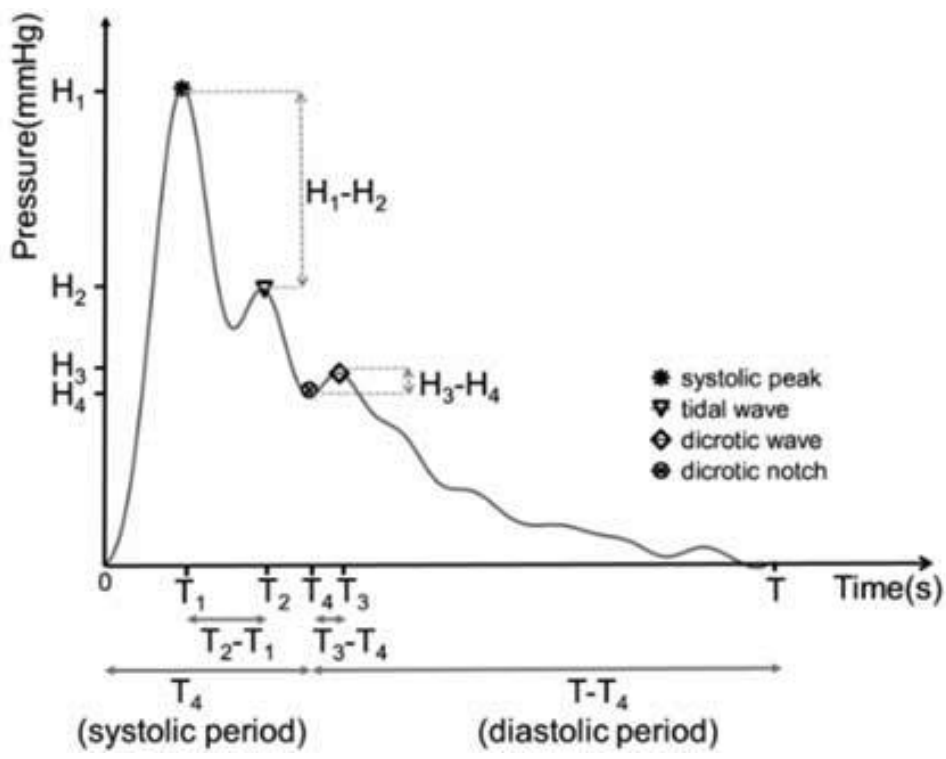

Figure 13 The Arterial Pulse Waveform [28]

\subsection{Cuff Mechanics}

In 1993, a group in the Department of Biomedical Engineering at Rutgers University worked to explain cuff mechanics [29]. Pressure-volume relationships were created through experimentation to come up with a widely accepted mathematical model for cuff mechanics. Two parameters were necessary to the model: cuff stretch, which was modeled by a nonlinear pressure-volume function, and air compression, which was represented by Boyle's Law. A physical model was created for experimentation purposes.

A glass cylinder $31 \mathrm{~cm}$ in circumference was used to represent a fixed-volume arm to allow cuff volume to be the only varying volume. An arm cuff was wrapped around the cylinder with a water-filled balloon placed between the cuff and the cylinder to represent the brachial artery, and two syringes filled with water and air were used to adjust the volume. A pressure transducer was used to measure pressure changes in the cuff. A schematic of the apparatus is shown in Figure 14. 


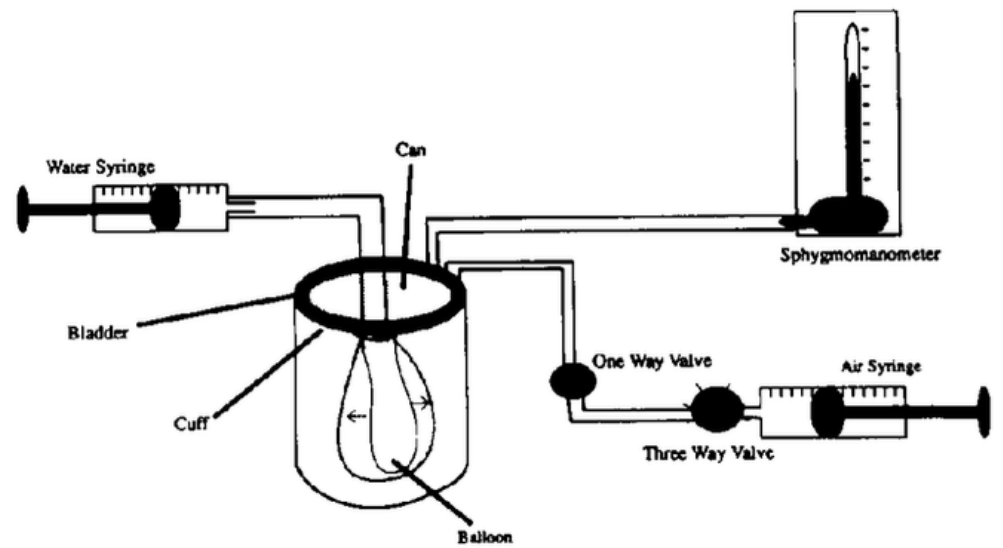

Figure 14 Experimental Apparatus to Model Pressure Changes of a Blood Pressure Arm Cuff [29]

The water inside the balloon was withdrawn until empty. Next, the air syringe injected air in increments of $10 \mathrm{~mL}$ while recording pressure and stopped when pressure reached $300 \mathrm{mmHg}$. Over the course of this experiment, the water syringe injected $5 \mathrm{~mL}$ of water in $1 \mathrm{~mL}$ increments, with the pressure being recorded for each $1 \mathrm{~mL}$ increment.
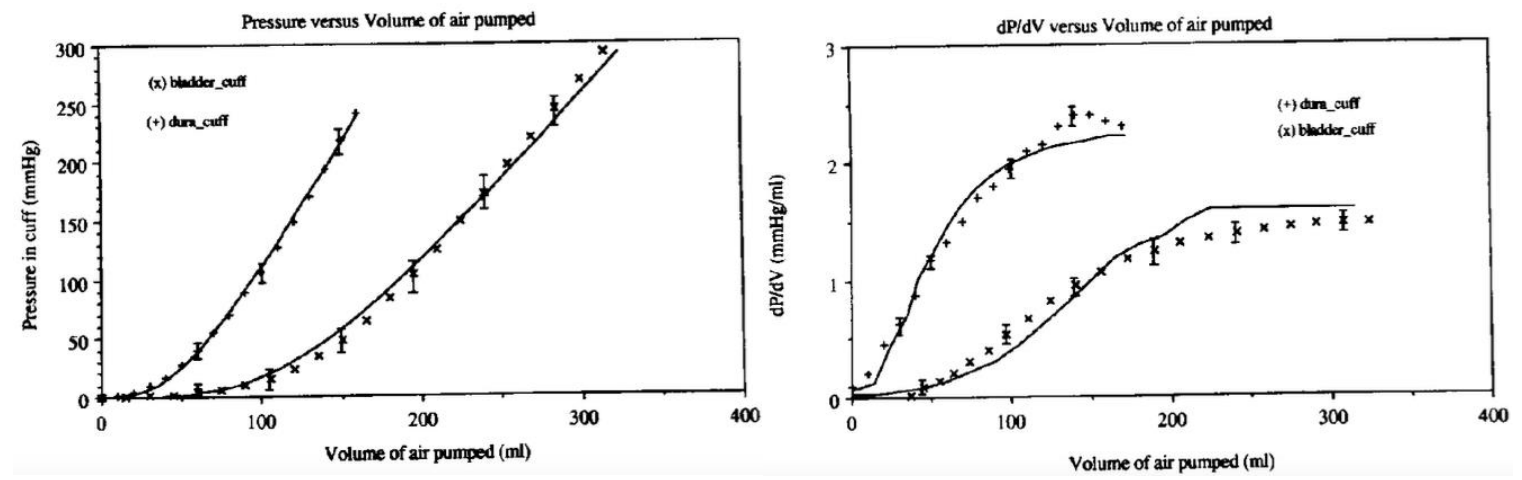

Figure 15 Pressure vs. Volume. Pressure versus volume curves (left) and its derivative dP/dV (right). [29]

A pressure versus air volume curve and its derivative, distensibility $(\mathrm{dP} / \mathrm{dV})$, were generated, showing the sensitivity of the cuff to the injected air volume. The graphs show that the pressure contained within the cuff is due to equilibrium between the compression of air and the stretch of the cuff. At high cuff pressures, the cuff sensitivity is increased, and a small change in pressure 
yields a high volume change. The graph shows the cuff is volume sensitive up until about 150 $\mathrm{mmHg}$, to which it becomes constant.

\subsection{Oscillometric Model}

The article also discussed a mathematical model for the oscillometric method. $\mathrm{V}_{\mathrm{i}}$, the constant arm volume, is represented as $V_{i}=V_{i o}+A L_{c u f f}$, where $\mathrm{A}$ is the arterial lumen area, $\mathrm{L}_{\text {cuff }}$ is the length of the cuff, and $\mathrm{V}_{\text {io }}$ is the arm volume for the collapsed brachial artery. The elastic volume of the cuff, $V_{e}$, is subject to change and stretch. The difference between $V_{e}$ and $V_{i}$ represents the cuff volume, $\mathrm{V}_{\mathrm{c}}$. The cuff is initially at atmospheric pressure $\mathrm{P}_{\mathrm{a}}$, and contains an initial volume $\mathrm{V}_{\mathrm{co}}$. The total volume of air, $\mathrm{V}_{\mathrm{p}}$, is pumped into the cuff with pressure $\mathrm{P}_{\mathrm{c}}$. Following Boyle's Law, $P V_{c}=k$, where $k$ is a constant, the following equation applies: $\left(P_{c}+P_{a}\right) V_{c}=P_{a} V_{c o}+P_{a} V_{p}$. The cuff volume changes as the cuff is filled, and is linearly proportional to pressure changes at high pressures. The slope of this change represents the elastic stretch of the cuff. Maximum cuff elastance, $\mathrm{E}_{\mathrm{c}}$, is calculated by $E_{c}=P_{c} /\left[\left(\frac{V_{e}}{V_{e o}}\right)^{1 / n}-1\right]^{n} \cdot \mathrm{V}_{\mathrm{eo}}$ represents the volume of the cuff with zero stretch and $\mathrm{n}$ is a constant. The difference between $\mathrm{V}_{\text {eo }}$ and $\mathrm{V}_{\text {co }}$ is the additional air found in the connector tube that is included in $\mathrm{V}_{\text {co. }}$.

With $\mathrm{n}=1$, the cuff would function as a linear device. However, from experimentation, it is evident that the pressure-volume relationship is nonlinear, yielding a value for $\mathrm{n}$ that is greater than 1 . The model was best fit to the experimental data to obtain values of each parameter, shown by the solid lines in Figure 15, and recorded in Table 3. The mathematical models for arterial compliance and the cuff are combined to determine a composite solution for cuff pressure with an arterial pressure pulse being the input to the model [23]:

$$
P_{a}(t)=M A P+A_{0} \sin \left(\frac{2 \pi f_{h r}}{60}\right)+A_{1} \sin \left(\frac{4 \pi f_{h r}}{60}+\phi_{1}\right)
$$


Table 3 Constants to Composite Solution for Cuff Pressure [23]

\begin{tabular}{|c|c|c|c|c|}
\hline Name & Quantity & Value & Units & Role \\
\hline Atmospheric pressure & $\mathrm{P}_{\mathrm{a}}$ & 760.0 & $\mathrm{mmHg}$ & \multirow{7}{*}{$\begin{array}{c}\text { Occlusive } \\
\text { cuff constants }\end{array}$} \\
\hline $\begin{array}{l}\text { Initial air volume in cuff and } \\
\text { tubing }\end{array}$ & $\mathrm{V}_{\text {co }}$ & 1311.0 & $\mathrm{~mL}$ & \\
\hline Zero stretch volume of cuff & $\mathrm{V}_{\text {eo }}$ & 1316.9 & $\mathrm{~mL}$ & \\
\hline $\begin{array}{c}\text { Collapsed brachial artery arm } \\
\text { volume }\end{array}$ & $\mathrm{V}_{\text {io }}$ & 1200.0 & $\mathrm{~mL}$ & \\
\hline Constant of nonlinearity & $\mathrm{n}$ & 4.0836 & N/A & \\
\hline Maximum cuff elastance & $\mathrm{E}_{\mathrm{c}}$ & $2.121 \times 10^{8}$ & $\mathrm{mmHg} / \mathrm{mL}$ & \\
\hline \multirow[t]{5}{*}{ Length of cuff } & $\mathrm{L}_{\text {cuff }}$ & 13.0 & $\mathrm{~cm}$ & \\
\hline & $\mathrm{a}$ & 0.03 & $\mathrm{mmHg}^{-1}$ & \multirow{4}{*}{$\begin{array}{c}\text { Brachial } \\
\text { artery } \\
\text { constants }\end{array}$} \\
\hline & $\mathrm{b}$ & 3.30 & N/A & \\
\hline & $\mathrm{c}$ & 0.10 & $\mathrm{mmHg}^{-1}$ & \\
\hline & $\mathrm{d}$ & 0.08 & $\mathrm{~cm}$ & \\
\hline \multirow[t]{4}{*}{ Mean arterial pressure } & MAP & 95.0 & $\mathrm{mmHg}$ & \multirow{5}{*}{$\begin{array}{c}\text { Arterial } \\
\text { pressure } \\
\text { waveform } \\
\text { constants }\end{array}$} \\
\hline & $\mathrm{A}_{0}$ & 10.0 & $\mathrm{mmHg}$ & \\
\hline & $\mathrm{A}_{1}$ & 9.0 & $\mathrm{mmHg}$ & \\
\hline & $\Phi_{1}$ & 1.2 & radians & \\
\hline Heart rate & $\mathrm{f}_{\mathrm{hr}}$ & 75 & beats/min & \\
\hline
\end{tabular}

The complete oscillometry model was graphed, shown in Figure 16. Since the cuff pressure oscillations are small compared to cuff pressure, the data was high-pass filtered with a cut-off frequency of $0.5 \mathrm{~Hz}$. The oscillations are shown along with the original curve in the left graph. The P-P oscillations were measured and displayed in the right graph. It can be seen that the maximum oscillation occurs at $95 \mathrm{mmHg}$, which would determine MAP for this case. Using MAP, systolic and diastolic ratios can be used to obtain systolic and diastolic pressures. 

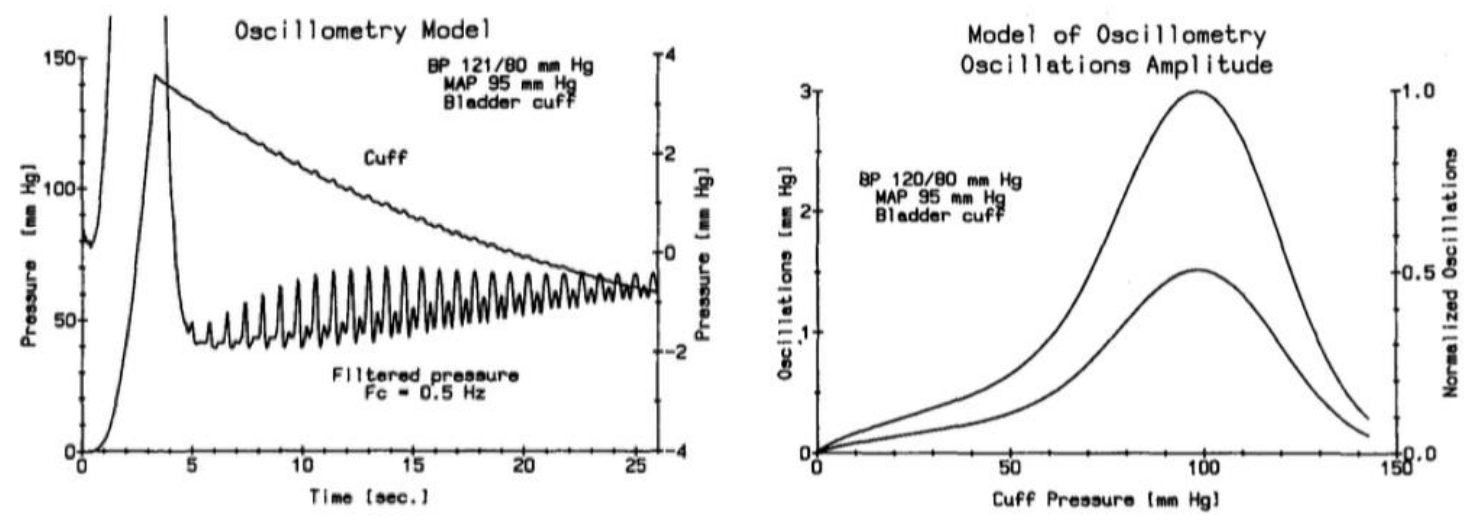

Figure 16 Oscillometry Model. Cuff pressure and oscillations in cuff pressure computed from the complete oscillometry model (left). P-P oscillations in cuff pressure obtained from left graph. Upper curve represents normalized oscillations and lower curve represents computed oscillations (right). [23]

\subsection{Error Mechanisms}

Techniques using the oscillometric method are widely used, so it is important to understand the error mechanisms of this method. It was found using a parametric sensitivity analysis of the model that the leading parameters that caused the highest error were the following [30]:

- Systolic and diastolic errors were sensitive to the brachial artery stiffening around zero transmural pressure.

- Systolic and diastolic values were overestimated and underestimated, respectively, when pulse pressure declined.

Due to the high compliance of the artery around zero transmural pressure, there are high variations in compliance due to each heartbeat. This variation alters the amplitude of the oscillation that is sensed in the cuff. At zero transmural pressure, the pulse pressure, which is an indicator of how hard the heart is pumping, has a large effect on systolic and diastolic errors. In addition, limitations to the oscillometric method include not providing explicit systolic and diastolic pressures, but instead calculated values. It is important to understand the error mechanisms of the model when using oscillometry. 
Chapter 3

METHODS

\subsection{Experimental Methods}

This study obtained IRB Approval on April 13, 2018. Testing was done in a quiet classroom with temperature of $23^{\circ} \mathrm{C}$ over two consecutive days. Students volunteered to participate based off email and flyer advertisement around the campus. The Biopac MP160, HLT100C, and DA100C units, were connected to the laptop via USB with the pressure transducer and cuff connected to the Biopac DA100C unit.

\section{HLT100C \\ Transducer module}
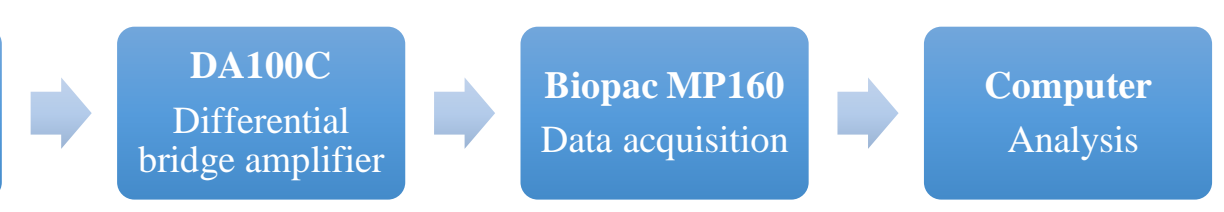

Figure 17 Schematic of Biopac Modules

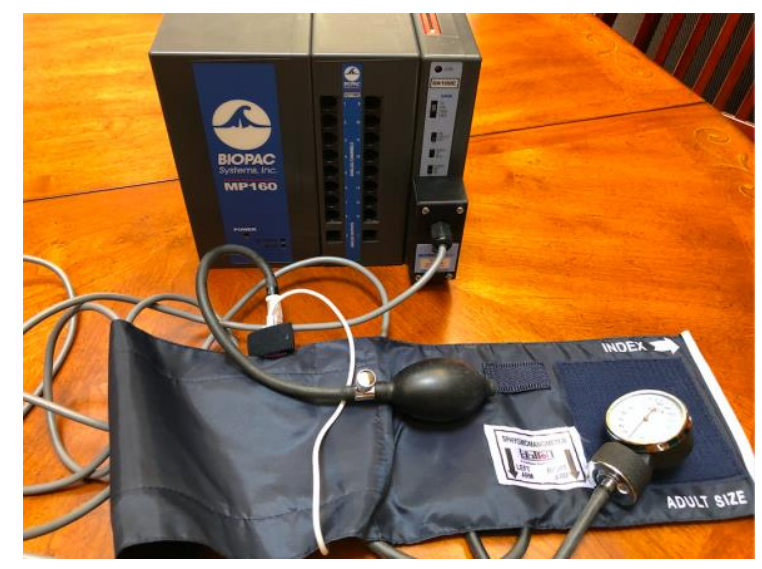

Figure 18 Biopac Equipment Setup. Biopac units connected to pressure transducer and arm cuff.

The consent form was presented to each student before testing. The student's name, age, and gender were recorded on a data sheet only viewable to the investigator. The student sat with their right arm facing palm up on a table. The Omron BP742 Automatic Blood Pressure Monitor was used to take the student's blood pressure. The student was informed to keep feet flat on the 
ground, sit still, and relax during the test. The student's systolic and diastolic blood pressures were recorded. The purpose of this blood pressure measurement was to get the $50 \mathrm{mmHg}$ above systolic value to occlude blood flow for the reactive hyperemia tests. The student then chose blindly from an envelope to determine which reactive hyperemia test would be performed first and proceeded with the baseline test.
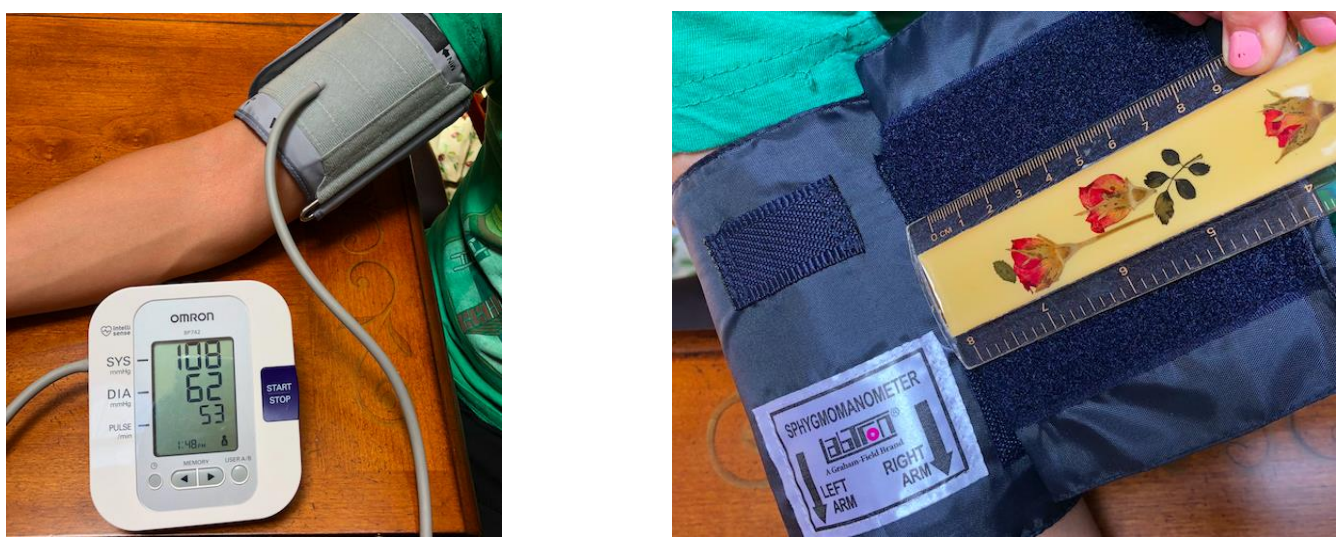

Figure 19 Baseline Test Setup. Omron unit measuring blood pressure on individual. Arm cuff placed on upper right arm with palm face up rested on table (left). Measurement of the arm cuff flap to ensure consistent tightness of arm cuff (right).

For the baseline test, the Biopac arm cuff was wrapped around the individual's upper right arm. To keep the tightness of the cuff consistent between the tests, the arm cuff flap was measured in centimeters with a ruler, shown in Figure 19, and documented on the data sheet. A marker was used on the student's arm to mark the location of the cuff to keep the position of the cuff consistent as well between each test. The student was instructed to keep feet flat on the ground, sit still, and relax during the test. The pump was pumped to $50 \mathrm{mmHg}$ suprasystolic and the investigator started recording data through the AcqKnowledge software. The pressure valve was released to slowly allow the arm cuff to deflate. Data recording was stopped when the cuff was fully deflated and cuff pressure reached about $0 \mathrm{mmHg}$. 


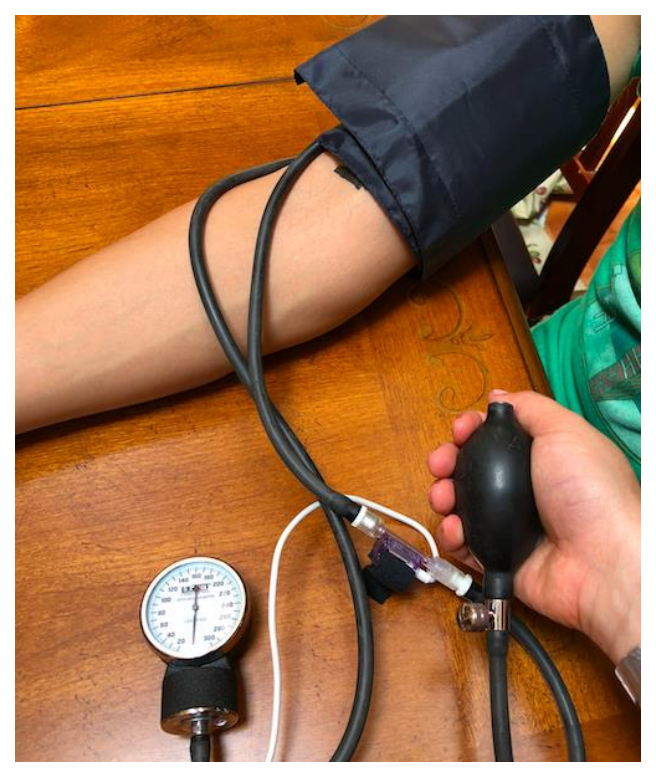

Figure 20 Investigator Pumps Pressure to $50 \mathrm{mmHg}$ Suprasystolic to Occlude Blood Flow

For the reactive hyperemia tests, the student was instructed again to keep feet flat on the ground, sit still, and relax during the test. The pump was pumped to $50 \mathrm{mmHg}$ suprasystolic and the investigator began recording the data through AcqKnowledge. A 3 or 5 minute timer was set and the pressure valve remained closed for this duration to hold pressure constant. When the specified time was complete, the pressure valve was released to slowly allow the cuff pressure to drop to the average MAP value of $100 \mathrm{mmHg}$, to which it was held constant for 30 seconds. After 30 seconds, the pressure valve was released, allowing the cuff to deflate, and data collection ended.

The student was instructed to return after a minimum of 30 minutes based on studies that show that 25 minutes is the minimum time for the body to return to normal physiological conditions for $90 \%$ of the population [32]. The arm cuff was placed within the markings identified on the student's arm, and the arm cuff flap was measured to ensure the same tightness was kept between tests $( \pm 0.5 \mathrm{~cm})$. The second reactive hyperemia test was performed using the same method as previously described but with the other duration of occlusion. The entire method was repeated for each of the 20 students over a 2 day period of testing. All students returned for their second reactive hyperemia test on the same day of the first test. 


\subsection{Software Methods}

AcqKnowledge 4 Software was used to analyze the oscillometric waveforms obtained from the Biopac unit. AcqKnowledge was connected to Biopac by adding a new module for the DA100C Biopac unit using the TSD120 - Sphygmomanometer transducer. The following data acquisition settings were input into the software to create a new graph template.

\section{Table 4 Data Acquisition Settings for New Graph Template}

\begin{tabular}{|c|c|}
\hline Sample rate & 200 samples/second \\
\hline Acquisition Length & 10 minutes \\
\hline
\end{tabular}

A graph template was used for each student before their data collection, so each student had identical setup and settings. The template included a Journal and Measurements option. The journal allows the user to record measurements, images, and raw data. Measurements was selected to set up the specific measurements that were taken during data analysis. For this test, the selected channel (SC) was designated to measure Peak-to-Peak (P-P). P-P is the height of the oscillation from the lowest peak to the highest peak.

\section{SC $\quad \hat{P}-\mathrm{P} \quad \hat{v}=28.228 \mathrm{mmHg}$}

Figure 21 Selected Channel Designated to Measure Peak-To-Peak (P-P)

\subsubsection{Baseline Test Analysis}

For each student, data collection began after the pressure was pumped to $50 \mathrm{mmHg}$ suprasystolic. For the baseline test, data was collected until cuff pressure reached approximately 0 mmHg. Shown in Figure 22 is an example of the baseline data. This file was saved with a unique code that kept the student anonymous. To obtain the arterial waveforms, a band pass filter with the parameters shown in Table 5 was implemented on the data. An example of the frequency response is shown in Figure 23. 


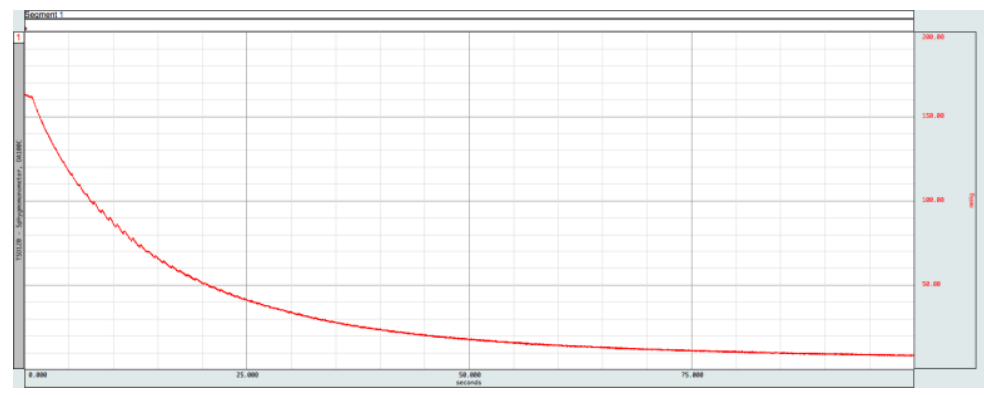

Figure 22 Example of Baseline Data Before Filtering Using Acqknowledge

Table 5 Band Pass Filter Parameters

\begin{tabular}{|c|c|}
\hline Source channel & $\mathrm{CH} 1$, TSD120 - Sphygmomanometer, DA1000C \\
\hline Low Frequency cutoff (fixed) & $0.5 \mathrm{~Hz}$ \\
\hline High Frequency cutoff (fixed) & $5 \mathrm{~Hz}$ \\
\hline Number of Coefficients & Optimize for sample rate and cutoff \\
\hline
\end{tabular}

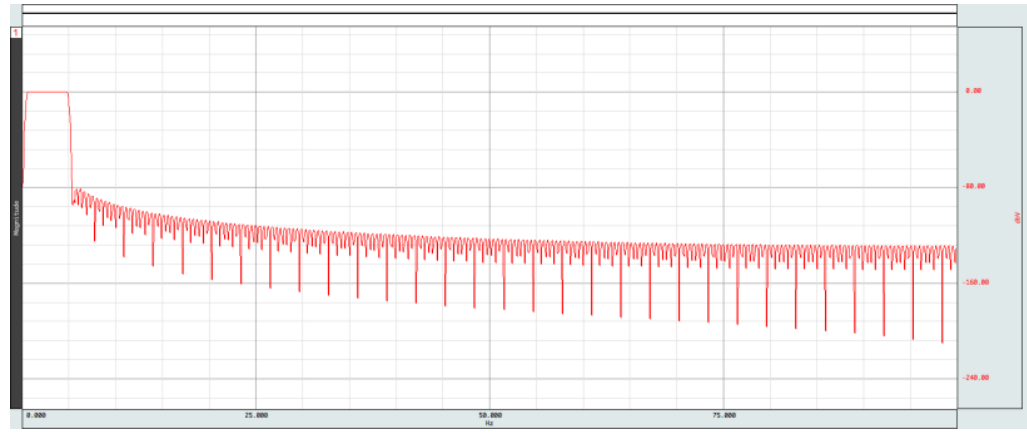

Figure 23 Frequency Response from Band Pass Filter on Baseline Data Using

\section{Acqknowledge}

The filtered response appeared in Channel 2. The shape of the filtered data reveals an increase in P-P oscillation height until a maximum peak was reached, and then a decrease in P-P oscillation height. This is the typical shape that is seen during blood pressure measurement tests. 


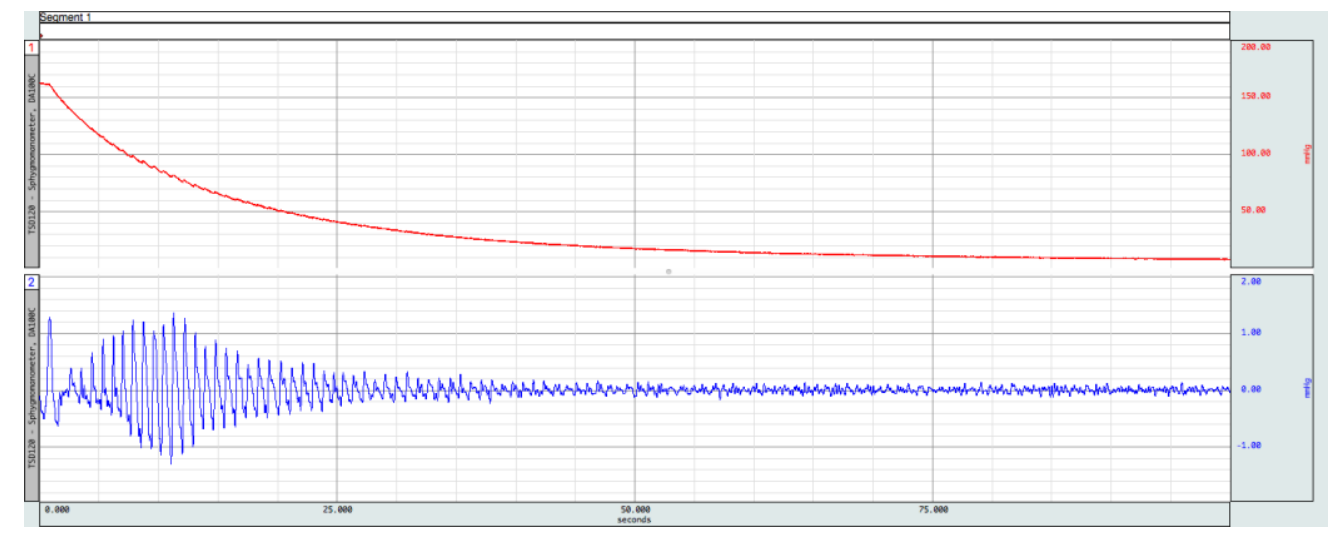

Figure 24 AcqKnowledge Baseline Graph. Original baseline data (top) and filtered baseline data (bottom) using AcqKnowledge.

The first waveform, which resembled the typical arterial waveform [28, 33], was selected, and the measurement was recorded to the journal. This process was repeated for each waveform that resembled an arterial waveform. The same process was repeated for each student's baseline tests.

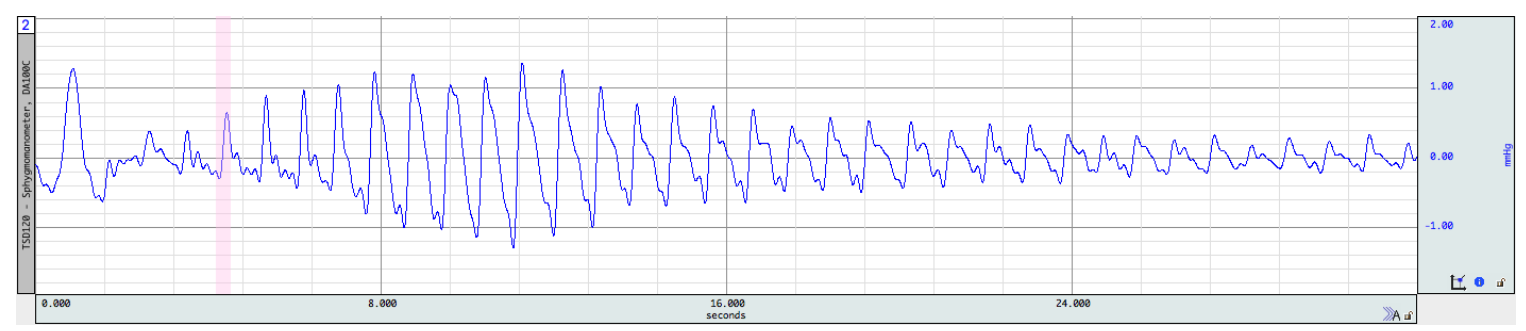

Figure 25 Selection of P-P Measurements of Baseline Data Using Acqknowledge

\subsubsection{Reactive Hyperemia Tests Analysis}

For each student, data collection began after the pressure was pumped to $50 \mathrm{mmHg}$ suprasystolic and continued through cuff pressure at $100 \mathrm{mmHg}$. Data collection ended after the 30 second time window where cuff pressure was held at $100 \mathrm{mmHg}$ following the 3 or 5 minutes of cuff occlusion at suprasystolic pressure. Figure 26 is an example of $3 \mathrm{~min}$ RH test data. The 3 min and 5 min RH test data acquisitions were very similar to each other. The only difference between these two RH tests was the duration of cuff occlusion, while only the 30 second time 
period post cuff occlusion where cuff pressure was held at $100 \mathrm{mmHg}$ was used for data analysis. Similarly, to the baseline test, the P-P heights were measured and recorded to the journal.

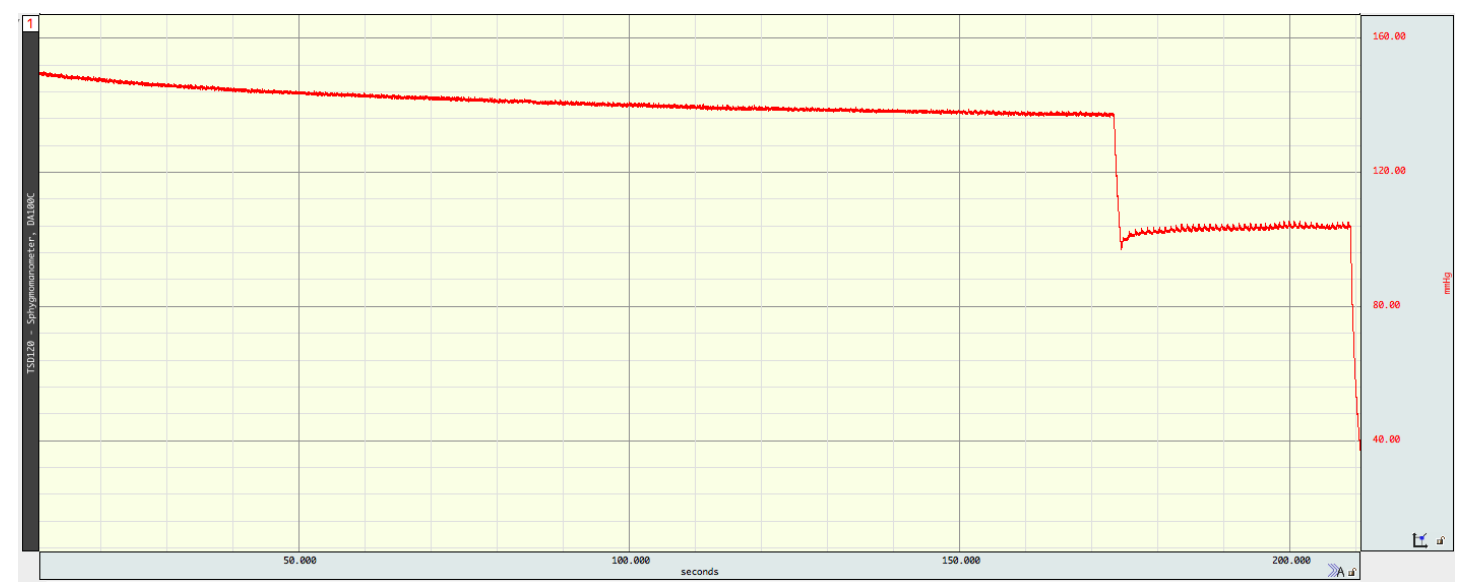

Figure 26 Original Data from a 3 Min Reactive Hyperemia Test Using Acqknowledge

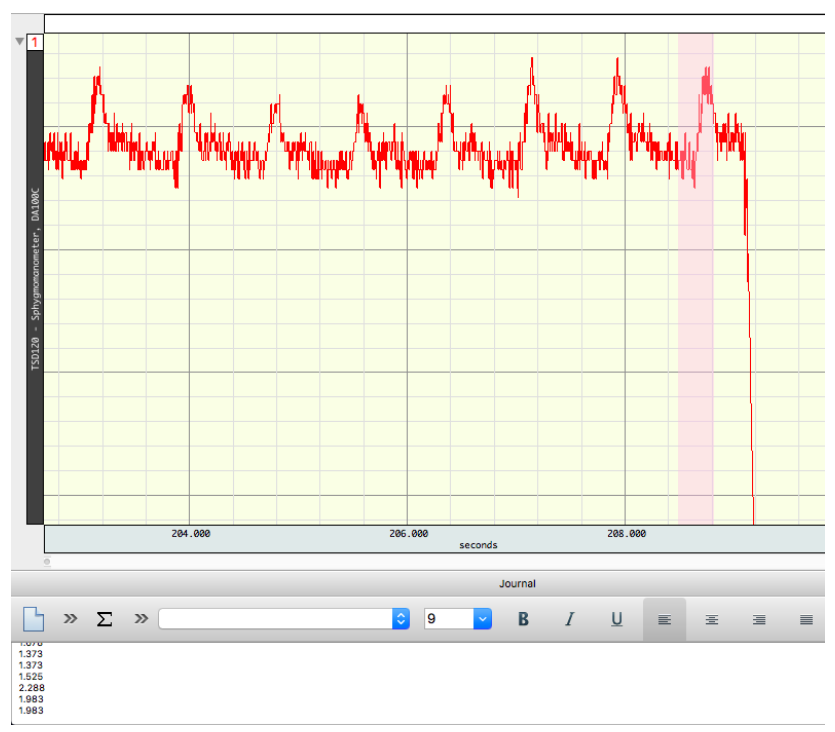

Figure 27 Selection of P-P Measurement for Reactive Hyperemia Data Using Acqknowledge

\subsection{Statistical Methods}

Peak-to-peak measurements were analyzed in JMP Pro 13 with a significance level of $\alpha=0.05$. The P-P data was averaged for each student, and an ANOVA analysis determined the overall significance between the three test means: baseline, $3 \mathrm{~min} \mathrm{RH}$, and $5 \mathrm{~min} \mathrm{RH}$. For a further understanding of the data, the P-P data for each individual student was put into ANOVA to determine the statistical significance between the three test means individually. 
Chapter 4

RESULTS

\subsection{Student Mean Results}

Twenty Cal Poly students (female $n=12$, male $n=8$ ), aged 22 years old with a standard deviation of 2.04 years, underwent a baseline test, $3 \mathrm{~min} \mathrm{RH}$, and $5 \mathrm{~min} \mathrm{RH}$ tests with sufficient rest in between. The P-P measurements for each student were averaged to obtain one value for each test and compared between all the students. For all tests, an alpha value of 0.05 was used to conclude any statistical significance. The results were summarized and shown below.

Table 6 Peak-to-Peak Data for the Overall Means of the Students for Each Test

\begin{tabular}{|c|c|c|c|}
\hline \multirow{2}{*}{} & \multicolumn{3}{|c|}{ Peak-to-Peak Data [mmHg] } \\
\cline { 2 - 4 } & $\mathbf{0}$ & $\mathbf{3}$ & $\mathbf{5}$ \\
\hline $\mathbf{N}$ & 20 & 20 & 20 \\
\hline Mean & 1.548 & 2.256 & 2.364 \\
\hline Std Dev & 0.506 & 0.441 & 0.529 \\
\hline
\end{tabular}

The Shapiro-Wilk Goodness-of-Fit Test tested the normality of the centered P-P data, which was generated using the residuals from the ANOVA analysis. The null hypothesis tested was that the data comes from a normal distribution. Evidence was found to conclude that the baseline test rejected normality, with a p-value of 0.0004 , while the 3 and $5 \mathrm{~min}$ RH tests failed to reject normality, with p-values of 0.057 and 0.253 , respectively. 

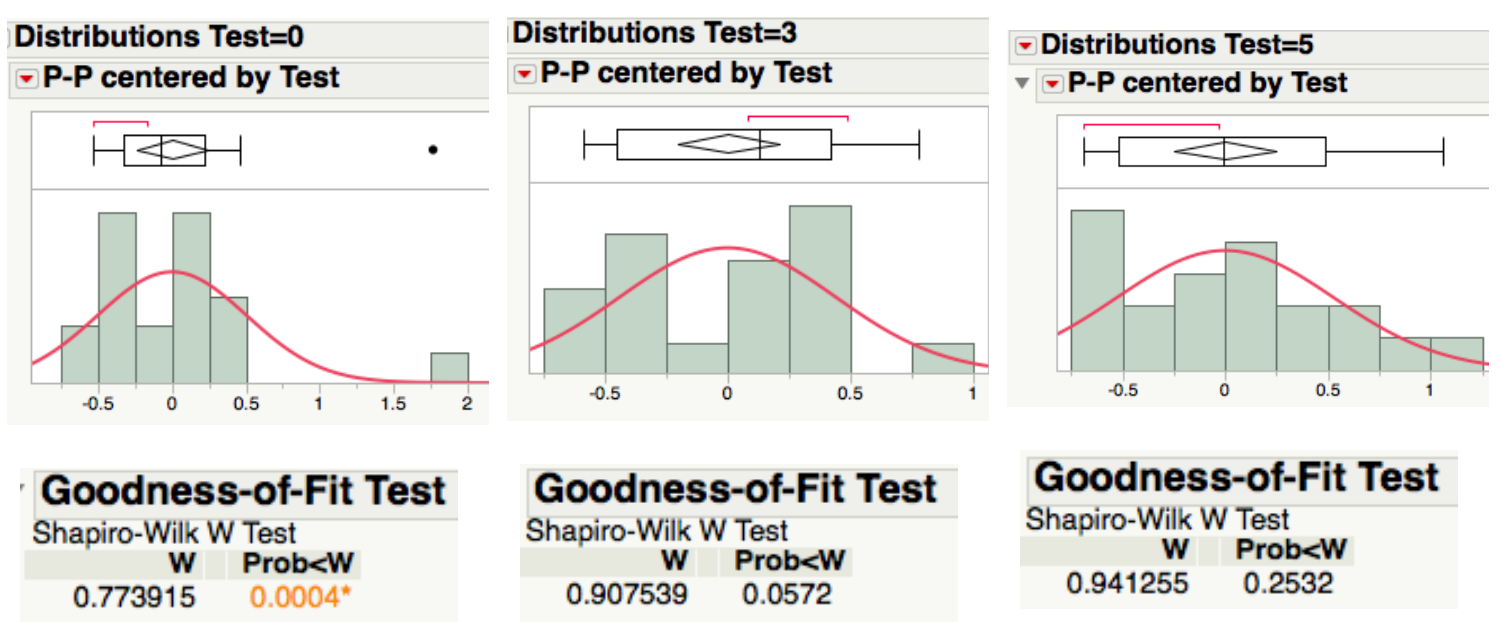

Figure 28 Goodness of Fit Tests. Shapiro-Wilk Goodness of Fit Tests for the overall means of the students for each test. The baseline test rejected normality with a p-value of 0.0004 . The 3 and 5 minute tests failed to reject normality with p-values of 0.0572 and 0.2532 . P-value must be less than 0.05 to be considered statistically significant.

The variance between tests was tested using an Equal Variance test. Levene's test was chosen to be most appropriate because it accounted for non-normal data. The null hypothesis tested was that the variances between the tests were equal. There was not enough evidence found to reject that the data has equal variance, with p-value of 0.607 . The data suggests that the three tests had similar variances, so the student means presented a similar spread of data across all the tests.

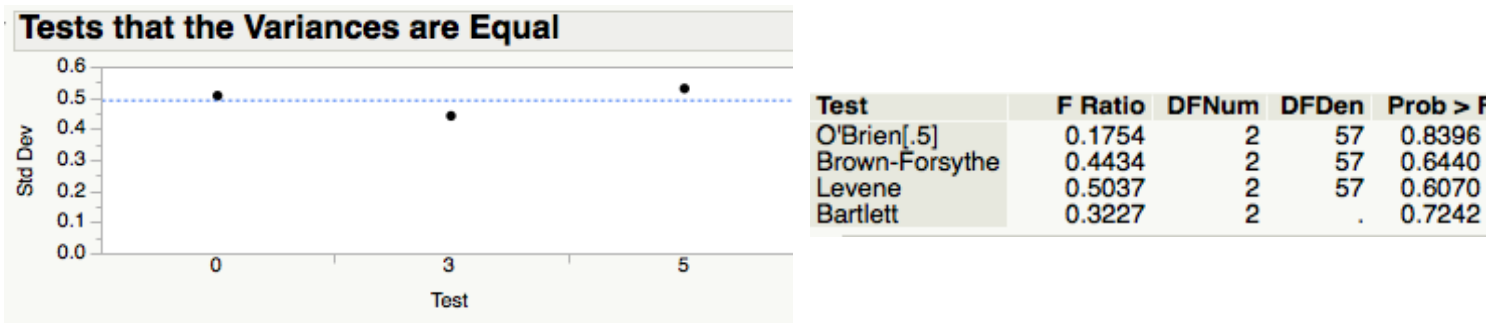

Figure 29 Equal Variance Tests. Levene's equal variance test shows evidence that the means of the students for each test failed to reject equal variance with a p-value of 0.607 . P-value must be less than 0.05 to be considered statistically significant. 
A one-way ANOVA analysis compared the means between the three tests. The baseline test had the lowest mean at $1.5 \mathrm{mmHg}$, while the 3 and 5 min RH tests had similar means at 2.26 $\mathrm{mmHg}$ and $2.36 \mathrm{mmHg}$, respectively. There is a high outlier in the baseline data. Further investigation into this student was done and explained in the Analysis.

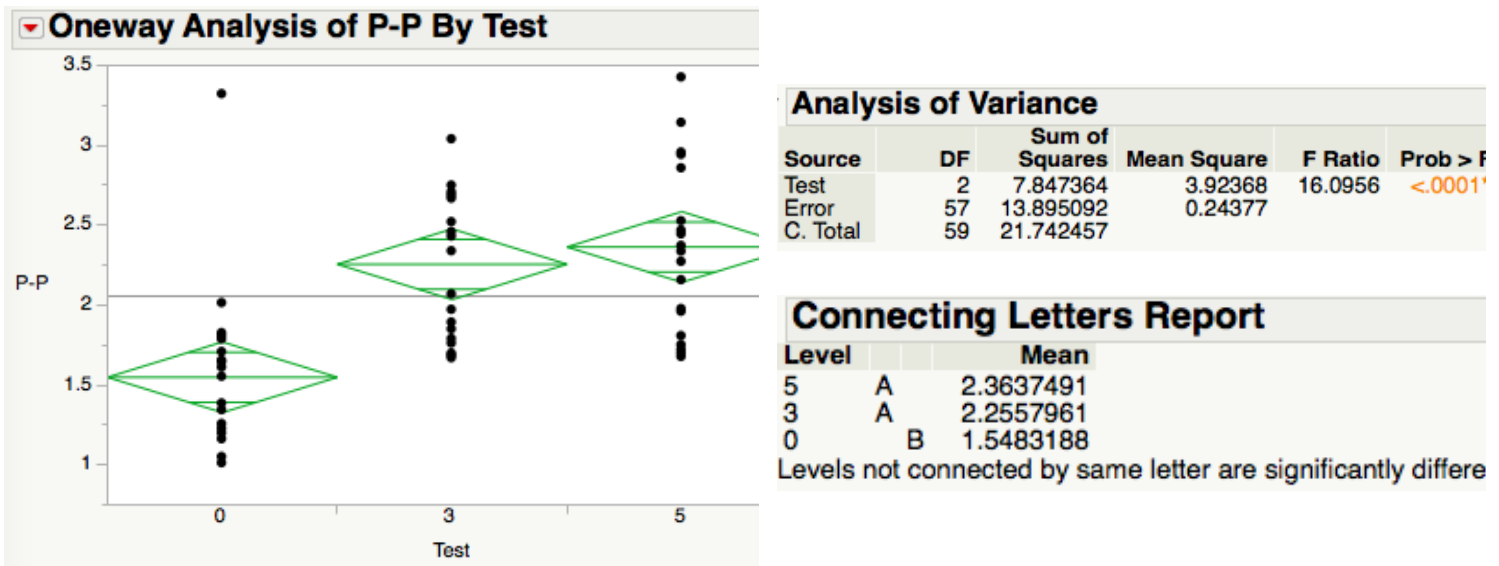

Figure 30 Overall ANOVA Results. ANOVA and Tukey Connecting Letters Report for the means of the students for each test show evidence that the baseline test is statistically lower than the 3 and 5 minute test means with a p-value less than 0.0001 . P-value must be less than 0.05 to be considered statistically significant.

The ANOVA showed a statistical difference for at least one test with a p-value less than 0.0001. Tukey's Connecting Letters Report revealed that the 3 and 5 min RH tests had similar means, and the baseline test had a significantly lower mean than the reactive hyperemia tests. Overall, the student mean data provided strong evidence that the mean P-P measurements from the 3 min RH test was significantly higher than the mean P-P measurements of baseline.

\subsection{Individual Results}

Although the previous analysis showed strong evidence of a significant difference between the $3 \mathrm{~min}$ RH test and baseline, it did not account for the variability within each student's data, and thus, must be used in conjunction with an analysis on each individual student. The student means were expected to show differences due to several factors that could create differences in 
the P-P oscillations including gender, age, diet, and stress. Due to this, each student was analyzed individually. For all tests, an alpha value of 0.05 was used to conclude any statistical significance.

To assess normality, the Shapiro-Wilk Goodness of Fit Test was performed on the data for each test of each student for a total of 60 normality tests. The null hypothesis tested was that the data comes from a normal distribution. Analysis of these tests show that $42 \%$ of the tests failed to reject the normality test with p-values greater than 0.05 , and $58 \%$ of the tests showed evidence which rejected the normality test, with p-values less than 0.05 .

Due to over half of the data showing non-normal distributions, Levene's test was used to test equal variances. The null hypothesis tested was that the variances between the tests were equal. There were 18 of 20 students who rejected equal variances between the tests. For all of these students, the 3 and 5 min RH tests showed significantly lower variance than the baseline test. In addition, the 3 and 5 min RH tests showed to have similar variation to each other for every student. There were 2 students who failed to reject the equal variance test and showed similar variance between all tests, with p-values of 0.376 and 0.440 .
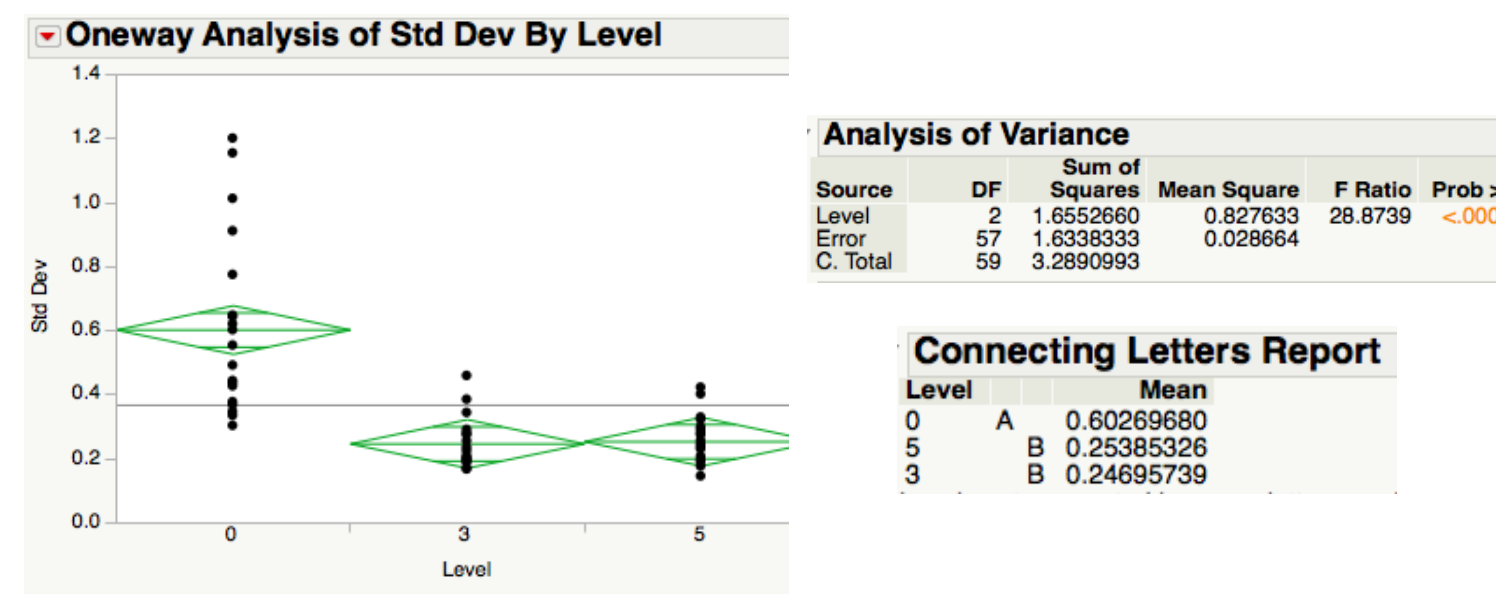

Figure 31 Standard Deviation ANOVA Results. ANOVA and Tukey Connecting Letters

Report of the standard deviation of the students for each test show evidence that the baseline test standard deviation is statistically higher than the 3 and 5 minute test standard deviations with a pvalue less than 0.0001 . P-value must be less than 0.05 to be considered statistically significant. 
The variance was further analyzed by doing a one-way ANOVA and Tukey Connecting Letters Report to compare the mean standard deviations of the three tests for each student. It can be seen in the graph that the baseline had a larger spread of standard deviation, while the 3 and 5 min RH tests had relatively consistent standard deviations between students. There was strong evidence with a p-value less than 0.0001 that the baseline test had a significantly higher mean standard deviation than 3 and 5 min RH tests. The baseline test had a mean standard deviation of 0.603, while the 3 and 5 min RH tests had mean standard deviations of 0.247 and 0.254 , respectively.

The 20 students were analyzed individually with a one-way ANOVA to compare the means of the three tests: baseline, $3 \mathrm{~min} \mathrm{RH}$, and $5 \mathrm{~min}$ RH. The focus of the remainder of the results and analysis will be between baseline and $3 \mathrm{~min}$ RH to determine if there was enough evidence to support that the mean P-P measurements from 3 min RH was significantly higher than the mean P-P measurements at baseline for each student. The results are summarized below.

Table 7 Individual Student Data for Peak-to-Peak Analysis

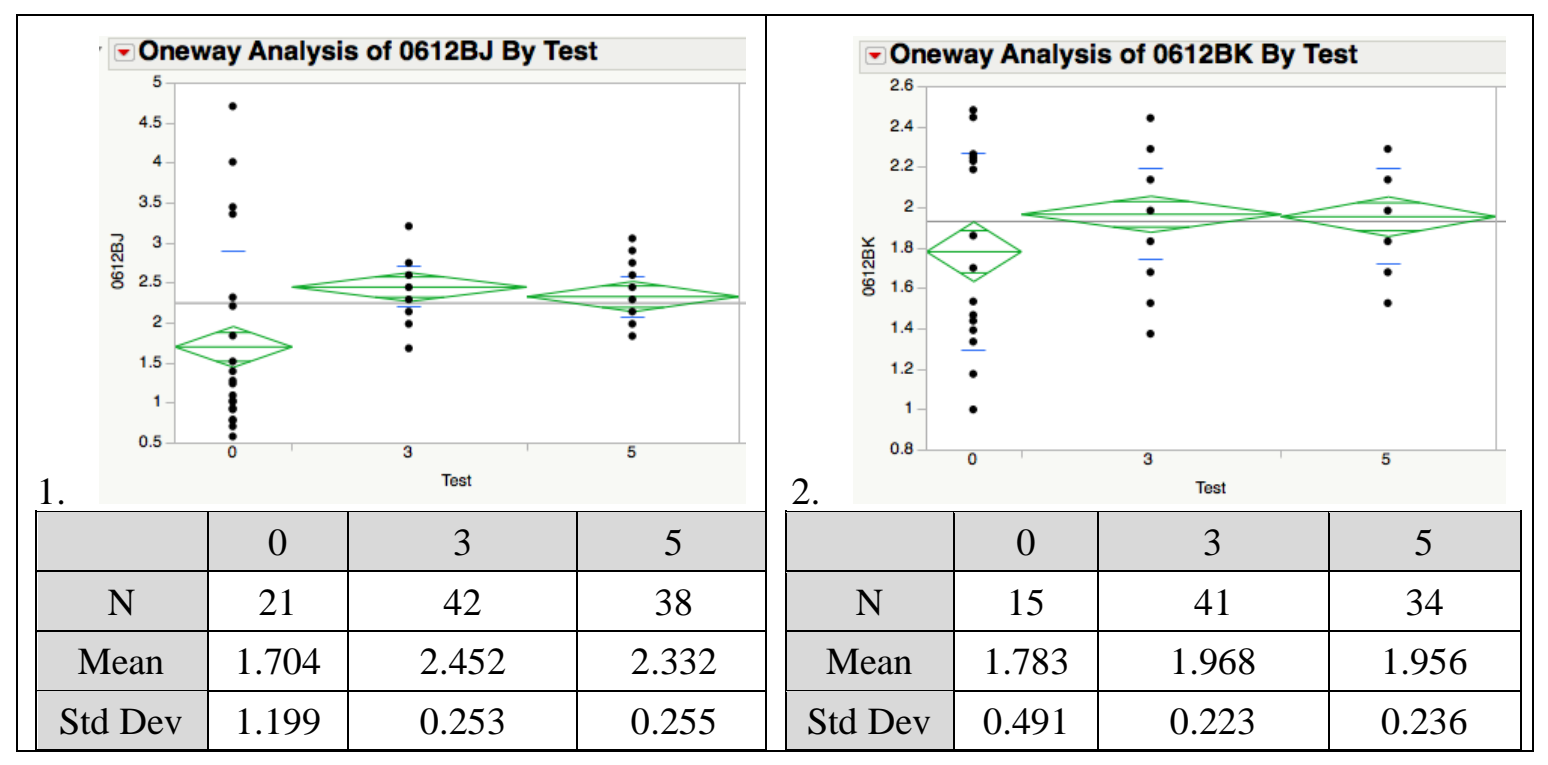




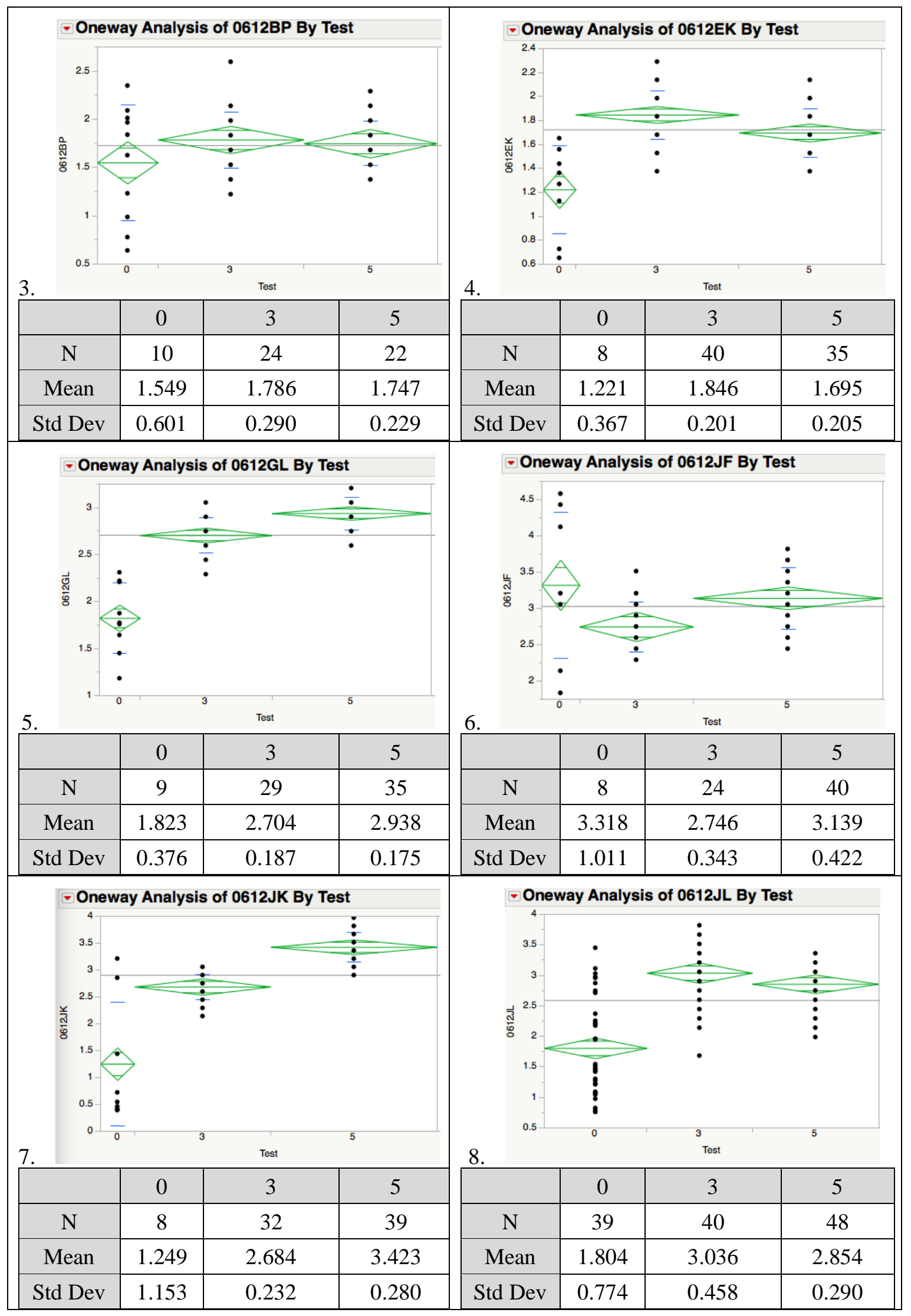




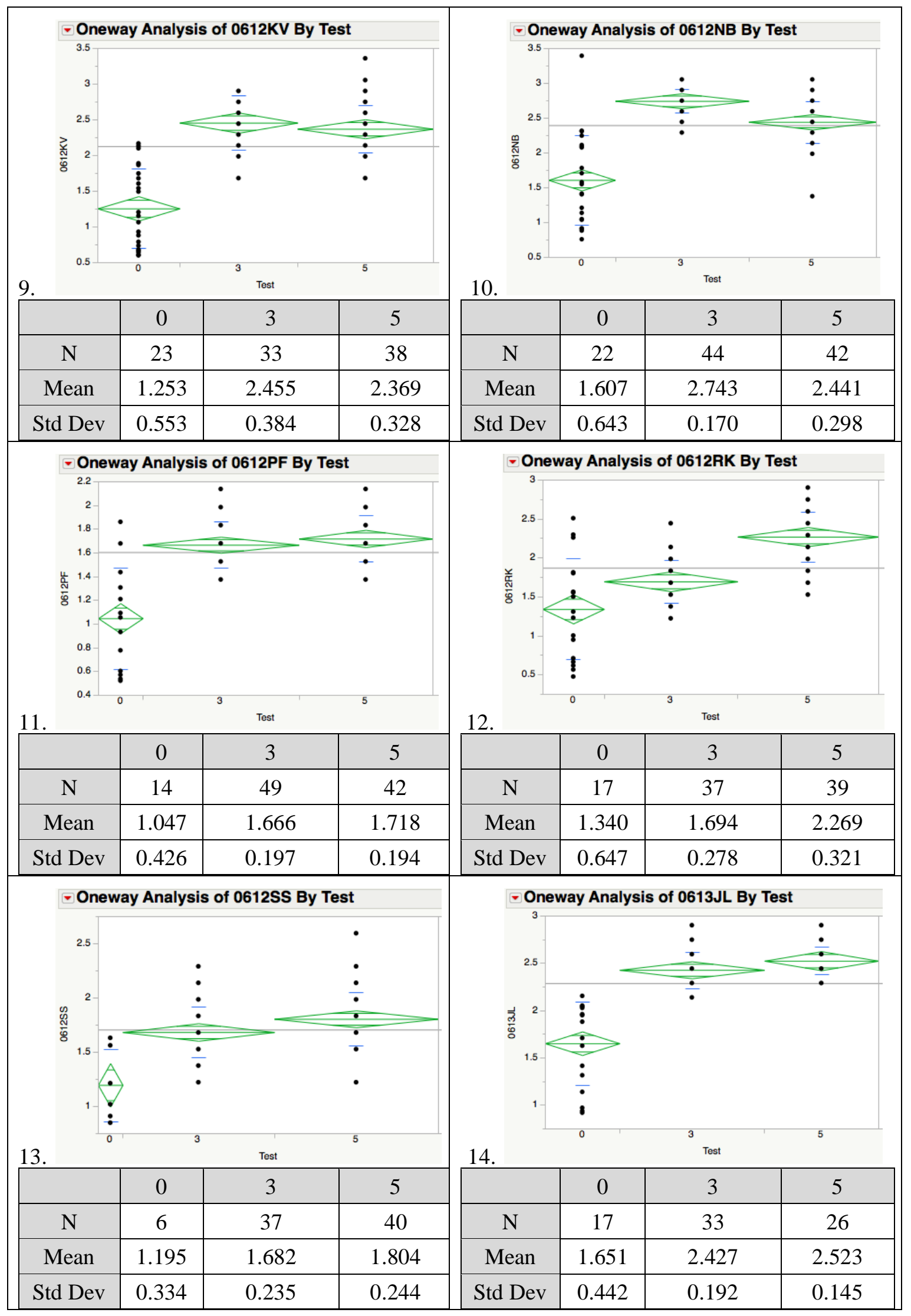




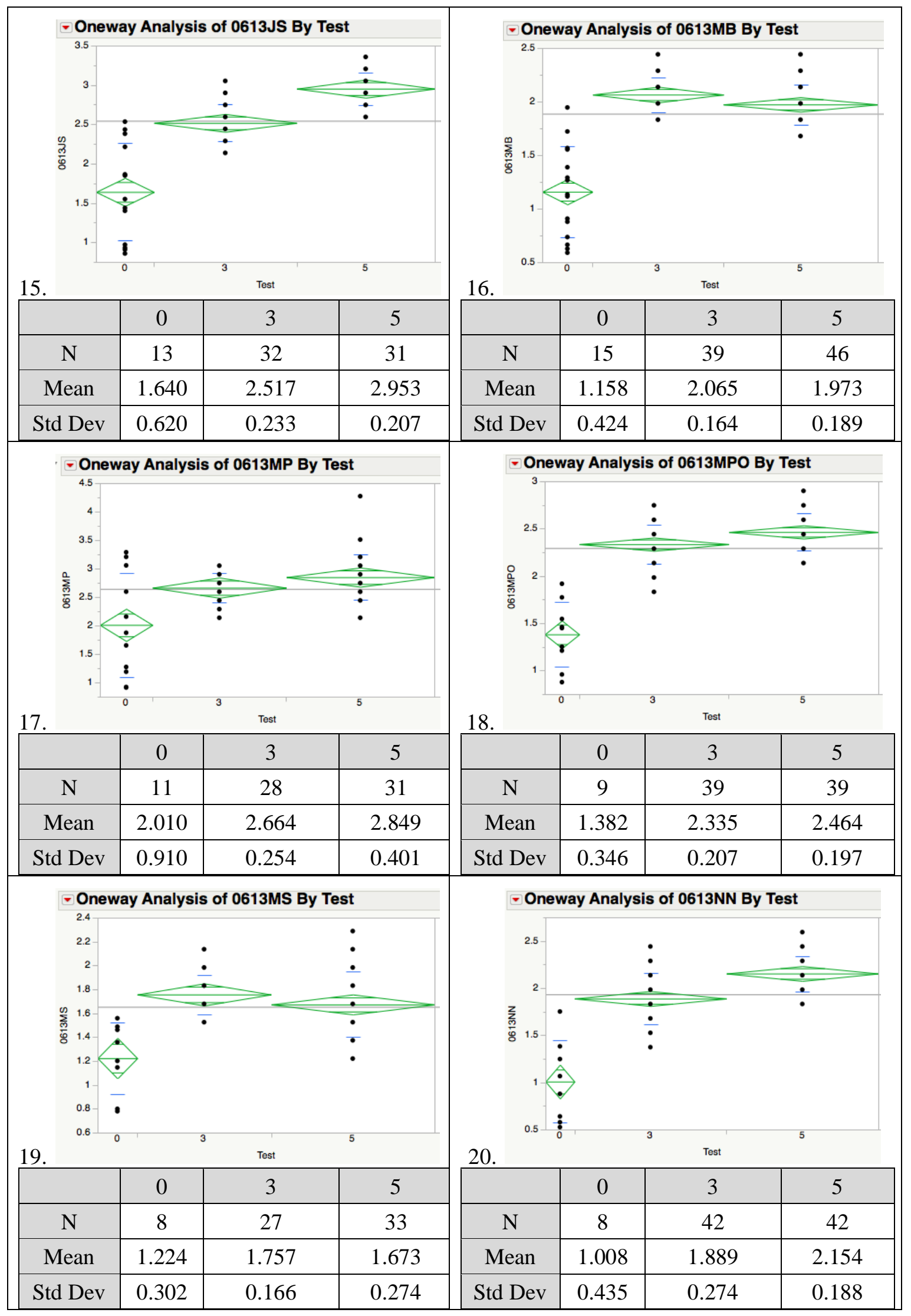


There was strong evidence for 18 out of 20 students with at least one test showing a significant difference for mean P-P measurements with all tests having p-values less than 0.0001 and one test with a p-value of 0.003 , which is less than 0.05 . Specifically, the goal was to show that 3 min RH had mean P-P measurements significantly higher than baseline. Seventeen of these 18 students had strong evidence that 3 min RH was associated with significantly higher mean P-P measurements than baseline with p-values less than 0.0001 for each student.

There was 1 student who had significantly lower mean P-P measurements for the $3 \mathrm{~min}$ RH test compared to baseline. The data showed that this student had several interruptions from motion artifact, resulting in data that may not be accurate. In addition, high outliers of the baseline test affected the baseline mean. There were also 2 out of 20 students who showed no significant differences between any of the tests. This was due to high standard deviations of the baseline test, which caused significant overlap into the other tests. These students had low mean P-P measurements for the 3 and 5 min RH tests and high standard deviation for all the tests. Overall from the individual student mean data, 17 of the 20 students showed strong evidence that the 3 minute test had significantly higher mean P-P measurements than baseline. 


\section{Chapter 5}

\section{DISCUSSION}

\subsection{Analysis}

The data was analyzed in two different ways to obtain valuable information from each analysis. The overall means for each student provided explicit evidence that the 3 min RH mean was statistically higher than the baseline mean. This analysis was done first to get an overall understanding of the data and to direct where further analysis was needed. However, due to a small sample size of 20 individuals, using 20 means does not provide high reliability in the data. The second analysis covered each student individually. This analysis provided a deeper analysis of the data and provided insight into the variance of each student. By measuring and analyzing each individual's oscillation peaks, the number of data points increased from 60 total data points to 1733 total data points. However, this analysis did not provide concrete evidence of whether the 3 min RH test was statistically significant from baseline due to varying results between students. There was no previously set acceptance criterion on how many students of the 20 had to show significant results in order to confirm the hypothesis. However, the best judgment was made based off the results. Fortunately, the two methods' results were in agreement with each other. The combination of the two analyses validated the final conclusion: Overall, the analyses revealed strong evidence that 3 min RH was statistically higher than baseline with a p-value less than 0.0001 .

There were a few outliers found in the data. The baseline test had one high outlier. It was found through the individual data that this outlier might have been due to motion artifact. The student had three high peaks greater than $4 \mathrm{mmHg}$. Further investigation of this student also revealed that this was the one student whom the $3 \mathrm{~min}$ RH test mean was statistically lower than the baseline mean. The reason for this is the high variance of the baseline test, the high outliers, and a low number of baseline data points. The peaks in which motion artifact was evident were 
not included in the data. This was decided based on the Channel 1 graph. If there were disruptions in the data, the respective peak was excluded from the study. For students with high amounts of motion artifact, the number of peaks was depleted. An example of an excluded peak is shown in Figure 32. Motion artifact caused enlarged peaks in the data. However, these peaks were not included in the final results.

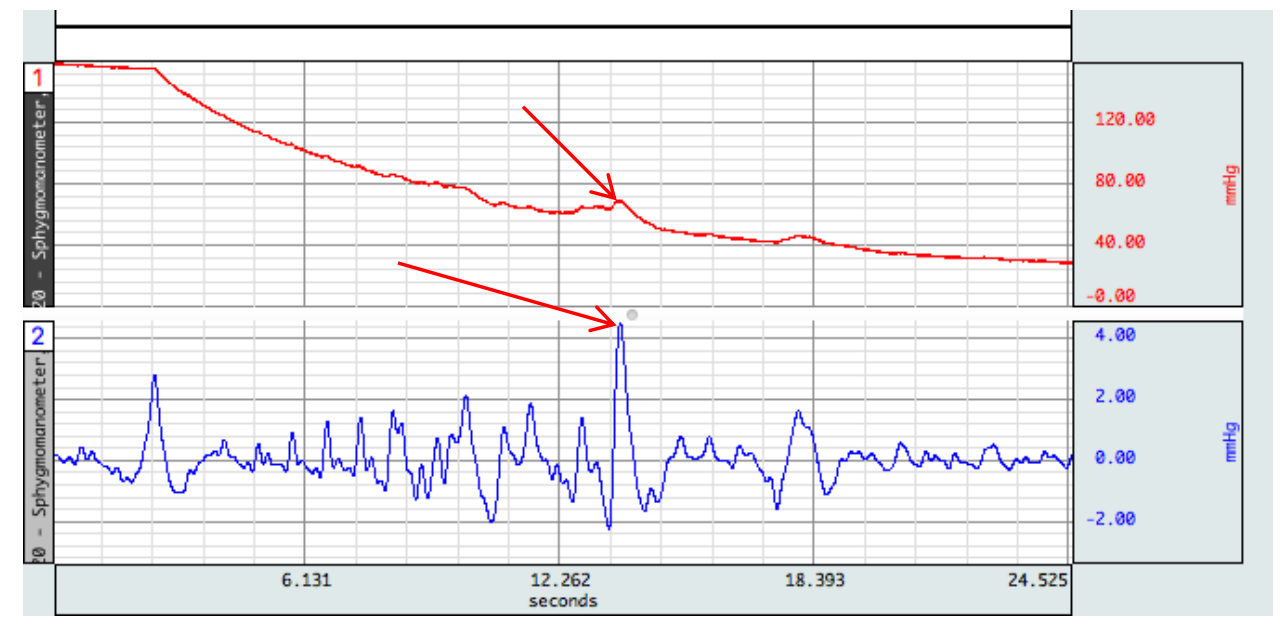

Figure 32 Example of Motion Artifact During Testing

The overall mean data failed to reject the equal variance test, meaning that the baseline, 3 min, and 5 min RH test means for the students were similar. This means that the students acted similarly between all the tests. Due to this, there is confidence that the method used was consistent between all the tests.

The individual data provided less concrete, but insightful evidence to support the significant difference between 3 min RH and baseline. It was found through the equal variance test that the baseline test had higher variation than the 3 and 5 min RH tests for every student. The artery showed more variation in compliance compared to the 3 and 5 min RH tests because the baseline test measured the mechanical function of the artery, which is sensitive to the sympathetic behavior of the subject during the test. The 3 and $5 \mathrm{~min}$ RH tests remained at a fairly consistent size for the 30 second time collection period, as shown by the low variance in peaks for these tests. This steady response is expected for healthy endothelium because the RH tests are not 
sensitive to the sympathetic behavior of the individual due to the structural integrity of the artery. The reactive hyperemia response is consistent within the 30 second window of data collection. As described in Corretti's study, the 5 minute FMD test resulted in significantly higher oscillations even after 20 minutes of data collection at MAP. The 3 and 5 min RH tests had similar variation because these oscillations arise from the structural components of the artery wall. The expected response from a healthy individual would be consistent peaks in the reactive hyperemia tests.

From Mary Corretti's study, where the 5 minute standard originated [11,13], by using FMD techniques, it was found that the 3 min RH test's standard deviation was very high and overlapped with baseline and the 5 min RH test, which disregarded it as significantly higher than baseline. Brachial artery ultrasound relies on the operator for the edge detection measurements, which could factor in human error to the variation. For this study using oscillometric techniques, the results showed a low standard deviation for $3 \mathrm{~min} \mathrm{RH}$, allowing $3 \mathrm{~min} \mathrm{RH}$ to display its significance from baseline. The method used in this study poses less risk for human error in the measurements because the AcqKnowledge software measures and records the peaks.

Two students showed that baseline, $3 \mathrm{~min} \mathrm{RH}$, and $5 \mathrm{~min}$ RH had no significant differences from each other. Further investigation into these two students showed that their baseline standard deviations were nearly double the standard deviation for the 3 and 5 minute tests, causing a large overlap. It did not appear that motion artifact caused the high deviation. These students had blood pressure on the lower side, especially the diastolic pressures. Holding the pressure at $100 \mathrm{mmHg}$ to represent MAP may have been too high for these students which could help explain why these students did not show significant differences in the RH tests. If the pressure was held too high, the oscillations would not have given as strong as a response that would occur at MAP because blood flow would not have been fully released.

The response of no significant differences between RH tests would be expected for diseased individuals. Since atherosclerosis causes plaque buildup and arteries to stiffen, arterial compliance would be low resulting in low P-P means for the RH tests. The standard deviation 
would be high due to the weakened damaged endothelium not being able to elicit a consistent response. To explain this response from healthy individuals, this could have been a natural response from the students, the arm cuff may have been loose, or it could be due to experimental error. It would have been desired to test these individuals again, but due to unavailability of the students, this was not an option.

From the results, the 3 and 5 min RH tests acted very similarly throughout the majority of the students. In addition to showing similarity, the tests also were found to be significantly higher than baseline for 17 out of 20 students. Five minutes of cuff occlusion using FMD is the current standard, but these results support the standard to be reduced to 3 minutes using oscillometric techniques to get more accurate results in a shorter testing period. General commentary from the students during and after testing were noted. There was a general consensus that the students preferred the $3 \mathrm{~min}$ RH test over the $5 \mathrm{~min}$ RH test due to slight discomfort felt during testing and the proximity of the 3 minute test in comparison to the 5 minute test. These reasons help to explain why reducing the cuff occlusion time is the ultimate goal to making the test more practical.

It was critical to keep as many parameters as possible constant for each student and between each test in order to keep cuff compliance constant and to make relative comparisons. Cuff tightness was kept constant by measuring the arm flap, and arm location was kept constant by marking on the arm where to position the cuff. The same operator administered all the testing and environment was controlled because all testing was performed in the same classroom with minimal distractions. Also, the age range in which the students were chosen from was a tight age range because all the recruited individuals were college students with an age range of $18-27$ (mean $=22$ years, standard deviation $=2.04$ years $)$. The goal was to include only healthy subjects in this study to decrease the possibility of high variability in the RH tests. Randomization of the order of the two RH tests was also important. For the second test, the individual knew what to expect, which could have resulted in less fidgeting, more calm nature, and less disturbances in 
data collection. Keeping as many parameters constant and randomizing the run order eliminated these factors from contributing to any discrepancies of the results.

One parameter that was difficult to control was motion artifact. Motion artifact was found in the AcqKnowledge graph results. Although instructed to remain still during the 30 second data collection period, it was present that students were displaying slight movements and fidgeting during testing. Motion artifact is a large factor to the discrepancies in the data because the cuff is very sensitive to movement.

It was important to have a consent form that was understandable to the individual, as well as clear exclusion criteria on who would not be allowed to participate in the test. Students with known cardiovascular risk factors were not allowed to participate in the test, including but not limited to: hypertension, metabolic syndrome, atherosclerosis, peripheral artery disease, heart disease, cancer, asthma, obesity, diabetes, etc. It was critical that all the participants were healthy in order to get significant results and avoid diseased arteries to cause discrepancies in the data.

\subsection{Limitations}

There were several limitations that presented themselves during this test. The small sample size was one limitation. Testing was performed during Final's Week of Spring Quarter 2018. Due to a restricted amount of time, it was more difficult to find a high number of willing students during this time of the school year.

A second limitation was that the operator was not a professionally trained medical operator, which is preferred for this test. However, the operator did have previous experience using blood pressure measurement devices and had an adequate amount of time to self-train on the software program. Since it was up to the operator to determine which arterial waveforms fit the typical arterial waveform curve, and which ones shouldn't be included in the measurements, subjective error may have been presented here in the determination of which peaks were included in the analysis. A small percentage of peaks for the baseline test had to be eliminated due to motion artifact, resulting in a lower number of peaks. When cuff pressure reached around $50 \mathrm{mmHg}$, the 
peaks decreased in size and appeared to lose the arterial waveform curve and therefore were not measured. These low-end peaks were not included in the results because the cuff becomes loose at low pressures and is unable to detect the arterial waveforms. The low number of peaks contributed to the high variation for the baseline test compared to the RH tests.

The AcqKnowledge program had a 0.001 resolution for measuring peaks. There were several duplicate measurement values for various peaks and it was believed this had an impact on the normality distribution being rejected for $58 \%$ of the tests. Although this resolution provided accurate data for the purposes of this study, a higher resolution would have allowed for a normal distribution of the data.

The last limitation was that the MAP was kept at $100 \mathrm{mmHg}$ for each student. This MAP was used as an average. However, the true MAP for each student may have been slightly different from $100 \mathrm{mmHg}$, which would have affected the P-P oscillations. 


\section{Chapter 6 \\ CONCLUSIONS}

The purpose of this test was to test whether the use of the oscillometric technique would lead to significant results from baseline for 3 minute reactive hyperemia versus the standard of 5 minute reactive hyperemia. Peak-to-peak oscillations were compared between the three tests: baseline, 3 minute reactive hyperemia, and 5 minute reactive hyperemia. Overall, there was strong evidence to support that the use of the oscillometric technique led to significant findings between the 3 minute reactive hyperemia test and baseline with p-values less that 0.05 . From these results, strong evidence was obtained to support the lowering of the standard cuff occlusion time from 5 minutes using FMD to 3 minutes using the oscillometric technique described in this study. 


\section{Chapter 7}

\section{FUTURE INNOVATIONS}

\subsection{Improvements to Study}

Several ideas and future improvements arose while performing this study. It would have been beneficial to further stress the importance to keep movements to a minimum. Although advised to remain still during testing, the investigator noticed small movements in the individuals. Minor movements caused peaks to be excluded from the study, so the importance of keeping completely still should be stressed in the future. An alternative would be a strap that connects to the table to aid in the individual to remain still. Also, further restrictions on the individual could be helpful for more accurate data. A suggestion would be to inflict dietary and exercise restrictions on the individuals for a set amount of time before testing or in between testing. For example, a restriction of no caffeine or intense exercise done 12 hours prior to testing would allow individuals to come in relaxed with a resting pulse rate, which would help in the consistency of the oscillation heights throughout all testing.

The investigator labeled each file with a specific code to link to which student, what test, and what the order of the tests were. Although anonymous to others, the investigator was aware of which peaks were from the 3 minute or 5 min RH test. For future improvements, it would be desired for the measurement taker to be blind to which test he or she is measuring so that there could be no possibilities of bias input into the results. However, for this test the AcqKnowledge program measured the peaks, so there was low risk of bias in these results.

Data collection for the 3 and 5 min RH tests began when the pressure was $50 \mathrm{mmHg}$ above the individual's systolic value, and continued for the duration of the 3 and 5 minutes in addition to the 30 second reactive hyperemia period. However, the data during the 3 and 5 minutes of cuff occlusion were not looked at during data analysis. For future studies, the data collection may begin after the 3 and 5 minutes, right before the pressure is reduced to $100 \mathrm{mmHg}$, or MAP. This 
would allow for only the necessary data to be included in the saved file. Also, instead of using an average MAP of $100 \mathrm{mmHg}$, future studies should use the MAP that is specific to each patient. This information can be obtained during the blood pressure or baseline test, and would only require a slight delay between the baseline test and the reactive hyperemia tests to obtain the specific MAP value.

Another future study would be to experiment with keeping other pressures constant. For instance, if pressure was held at diastolic pressure, the test results have the potential to show a more accurate reading for those with lower blood pressure values. The test may show lower cuff compliance and lower differences between diseased and healthy endothelium, but has the potential to have a stronger reactive hyperemia response due to increased blood flow. The advantages and disadvantages of holding pressure constant at other pressures would be a valuable future study.

Age and gender were recorded for each student, but further traits that could be helpful for future analyses would be height, weight, BMI, exercise routine, smoker status, and diet. This would be beneficial information to have for future studies because although all the subjects in this study were healthy individuals with no known cardiovascular risk factors, it would be valuable information to trend due to some people who may be unaware of their risk for cardiovascular disease. In 2013, it was found that $64 \%$ of women who died of coronary heart disease were asymptomatic [34]. The investigator may also be able to make the judgment from the patient's cardiovascular health based on the cardiovascular health metrics.

\subsection{Next Steps}

Although these results gave strong evidence that the $3 \mathrm{~min}$ RH test mean is statistically higher than the baseline mean, future studies would need to be done to further validate the claim to lower the standard from 5 minutes using FMD to 3 minutes using the oscillometric technique. Future studies would include expanding the sample size to allow for increased reliability and confidence in the results. In addition, the study should be done on the same individual more than once to gain 
repeatability in the results. For example, the same individual could repeat the test every 3 months for a year or more. Another necessary future study would be to include both individuals who are at risk of cardiovascular disease in the study as well as healthy individuals. Gathering the information on certain known risk factors to cardiovascular disease and their correlation with P-P measurements would allow for a better understanding into the traits and their effect on the test. Extensive testing must be done before this method can be used as a diagnosis tool, but including at risk individuals in future studies would allow for valuable information to determine if the test is sensitive enough to distinguish diseased arteries from healthy arteries.

\subsection{Benefits of Pushing this Test Forward}

There are several benefits to pushing this test forward and proceeding with the future tests as previously described. Eventually the goal for this test would be to use at routine hospital checkups for all adult patients: those who have known cardiovascular risk factors and those who do not. Since the test is noninvasive, there would be no complications to administering this test at routine checkups. Due to its similarity to routine blood pressure measurement tests, the test could be taken right after blood pressure is taken, and would only require 3 additional minutes to get potentially critical life-saving information.

The hospitals would have professionally trained operators to analyze the data and return results to the patient within hours or even minutes of testing. This test would be able to determine the presence of early indicators of cardiovascular disease at the earliest stage before harmful effects occur to the patient. At this point, the doctor would be able to recommend to the patient certain lifestyle changes that could prevent the disease from progressing before it even got started. The doctor could also provide medication for the individual if necessary, and the treatment has the potential to be more effective due to the early treatment in relation to the progression of the disease.

By reducing the duration of the test, the patient's stay in the hospital gets reduced, which would also reduce hospital costs. The benefits of this test are unmatched because it provides 
people with a tool to determine if they are at risk for cardiovascular disease, before it is too late when treatment may not be an option. This test has the potential to have a global impact and save patient's lives around this world in which cardiovascular disease is the leading cause of death. The future to saving patients' lives relies on early diagnosis, so this test would be a significant step in this direction because it allows for a quick noninvasive method for early detection of cardiovascular diseases. 


\section{REFERENCES}

1. Benjamin EJ, Blaha MJ, Chiuve SE, Cushman M, Das SR, Deo R, de Ferranti SD, Floyd J, Fornage M, Gillespie C, Isasi CR, Jimenez MC, Jordan LC, Judd SE, Lackland D, Lichtman JH, Lisabeth L, Liu S, Longenecker CT, Mackey RH, Matsushita K, Mozaffarian D, Mussolino ME, Nasir K, Neumar RW, Palaniappan L, Pandey DK, Thiagarajan RR, Reeves MJ, Ritchey M, Rodriguez CJ, Roth GA, Rosamond WD, Sasson C, Towfighi A, Tsao CW, Turner MB, Virani SS, Voeks JH, Willey JZ, Wilkins JT, Wu JHY, Alger HM, Wong SS, Muntner P; on behalf of the American Heart Association Statistics Committee and Stroke Statistics Subcommittee. Heart disease and stroke statistics - 2017 update: a report from the American Heart Association

2. Murphy S, Xu J, Kochanek K, Curtin S, Arias E. (2017). Deaths: Final Data for 2015. National Vital Statistics Reports, 66. National Center for Health Statistics.

3. Types of Cardiovascular Disease. New York State Department of Health. 2012. <https://www.health.ny.gov/diseases/cardiovascular/heart_disease/types_of_cv.htm>

4. What is Atherosclerosis. National Heart, Lung, and Blood Institute. <https://www.nhlbi.nih.gov/health-topics/atherosclerosis>

5. Heart disease overview. Mayo Clinic.

$<$ https://www.mayoclinic.org/diseases-conditions/heart-disease/symptoms-causes/syc$\underline{20353118>}$

6. Lloyd-Jones DM, Hong Y, Labarthe D, Mozaffarian D, Appel LJ, Van Horn L, Greenlung K, Daniels S, Nichol G, Tomaselli G, Arnett D, Fonarow G, Ho P, Lauer M, Masoudi F, Robertson R, Roger V, Schwamm L, Sorlie P, Yancy C, Rosamond W. (2010) Defining and Setting National Goals for Cardiovascular Health Promotion and Disease Reduction. Circulation 121:4, 568-613.

7. Whitt M. (1999) Noninvasive Determination of Peripheral Arterial Lumen Area, Rutgers University/University of Medicine and Dentistry of New Jersey.

8. Raitakari OT, Celermajer DS. (2000) Flow-mediated dilatation. British Journal of Clinical Pharmacology, 50(5), 397-404.

9. $\quad$ N/A. Measuring Blood Pressure. Centers for Disease Control and Prevention.

10. Babbs CF. (2015) The origin of Korotkoff sounds and the accuracy of auscultatory blood pressure measurements. Journal of the American Society of Hypertension, 9:12, 935-950.

11. Corretti MC, Plotnick GD, Vogel RA. (1995). Technical aspects of evaluating brachial artery vasodilation using high-frequency ultrasound. American Journal of Physiology, 268, H1397-1404.

12. Laminar Blood Flow Seen in a Brachial Artery Ultrasound. $\langle$ https://www.youtube.com/watch? $=$ NfNL0 JmdoY $>$

13. Corretti MC, Anderson TJ, Benjamin EJ, Celermajer D, Charbonneau F, Creager MA, Deanfield J, Drexler H, Gerhard-Herman M, Herrington D, Vallance P, Vita J, Vogel R. (2002). Guidelines for the Ultrasound Assessment of Endothelial-Dependent FlowMediated Vasodilation of the Brachial Artery. Journal of the American College of Cardiology, 39. 
14. Adams MR, Robinson J, Sorensen KE, Deanfield JE, Celermajer DS. (1996) Normal ranges for brachial artery flow-mediated dilatation: A non-invasive ultrasound test of arterial endothelial function. Journal of Vascular Investigation, 2(3), 146-150.

15. Blood Vessel Structure and Function. Lumen Learning. $<$ https://courses.lumenlearning.com/boundless-ap/chapter/blood-vessel-structure-andfunction/>

16. Alonso D, Radomski M. (2003). The Nitric Oxide-Endothelin-1 Connection. Heart Failure Reviews, 8, 107-115.

17. Liao JK. (2013). Linking endothelial dysfunction with endothelial cell activation. Journal of Clinical Investigation, 123, 540-541.

18. Davies PF, Remuzzi A, Gordon EJ, Dewey CF, Gimbrone MA. (1986) Turbulent fluid shear stress induces vascular endothelial cell turnover in vitro. Proceedings of the National Academy of Sciences of the United States of America, 83(7), 2114-2117.

19. Klabunde RE. (2007) Metabolic Mechanisms of Vasodilation. Cardiovascular Physiology Concepts.

20. MacIntyre NR. (2014). Tissue hypoxia: implications for the respiratory clinician. Respiratory Care, 59, 1591-1596.

21. Klabunde RE. (2007) Reactive Hyperemia. Cardiovascular Physiology Concepts.

22. Von Mises, R. (1914). Der kritische aussendruck zylindrischer rohre. Ver. Deut. Ing. Z. 58: $750-755$.

23. Drzewiecki G, Hood R, Apple H. (1994). Theory of the Oscillometric Maximum and the Systolic and Diastolic Detection Ratios. Annals of Biomedical Engineering, 22, 88-96.

24. Noordergraaf, A. (1978). Circulatory system dynamics. New York: Academic Press.

25. Bank AJ, Kaiser DR. (1998) Smooth Muscle Relaxation. Hypertension, 32, 356-359.

26. Bank, AJ, Wang H, Holte JE, Mullen K, Shammas R, Kubo SH. (1997) Contribution of Collagen, Elastin, and Smooth Muscle to In Vivo Human Brachial Artery Wall Stress and Elastic Modulus. Circulation, 94, 3263-3270.

27. Geddes LA, Voelz M, Combs C, Reiner D, and Babbs CF. (1982). Characterization of the Oscillometric Method for Measuring Indirect Blood Pressure. Weldon School of Biomedical Engineering Faculty Publications. Paper 66.

28. Du Y, Wang L, Li S, Zhi G, Li D, Zhang C. (2015). Influential factors for pressure pulse waveform in healthy young adults. Bio-medical materials and engineering, 26, S497S505.

29. Drzewiecki G, Bansal V, Karam E, Hood R, Apple H. (1993). Mechanics of the Occlusive Arm Cuff and Its Application as a Volume Sensor. Transactions on Biomedical Engineering, 40.

30. Liu J, Hahn J, Mukkamala R. (2013) Error Mechanisms of the Oscillometric Fixed-Ratio Blood Pressure Measurement Method. Annals of Biomedical Engineering, 41, 587-597.

31. BIOPAC Systems Inc.: MP160 Starter Systems. <https://www.biopac.com/product-category/research/systems/mp150-starter-systems/> 
32. Mahe G, Comets E, Nouni A, Paillard F, Dourmap C, Faucheur A, Jaquinandi V. (2017) A minimal resting time of $25 \mathrm{~min}$ is needed before measuring stabilized blood pressure in subjects addressed for vascular investigations. Scientific Reports, 7:12893.

33. Moxham IM. (2003) Understanding Arterial Pressure Waveforms. Southern African Journal of Anaesthesia and Analgesia, 9:1, 40-42.

34. Go AS, Mozaffarian D, Roger VL, Benjamin EJ, Berry JD, Borden WB, Bravata DM, Dai S, Ford ES, Fox CS, Franco S, Fullerton HJ, Gillespie C, Hailpern SM, Heit JA, Howard VJ, Huffman MD, Kissela BM, Kittner SJ, Lackland DT, Lichtman JH, Lisabeth LD, Magid D, Marcus GM, Marelli A, Matchar DB, McGuire DK, Mohler ER, Moy CS, Mussolino ME, Nichol G, Paynter NP, Schreiner PJ, Sorlie PD, Stein J, Turan TN, Virani SS, Wong ND, Woo D, Turner MB; on behalf of the American Heart Association Statistics Committee and Stroke Statistics Subcommittee. (2013) Heart disease and stroke statistics - 2013 update: a report from the American Heart Association. Circulation, 127:e6-e245. 
Appendix A: AcqKnowledge Data

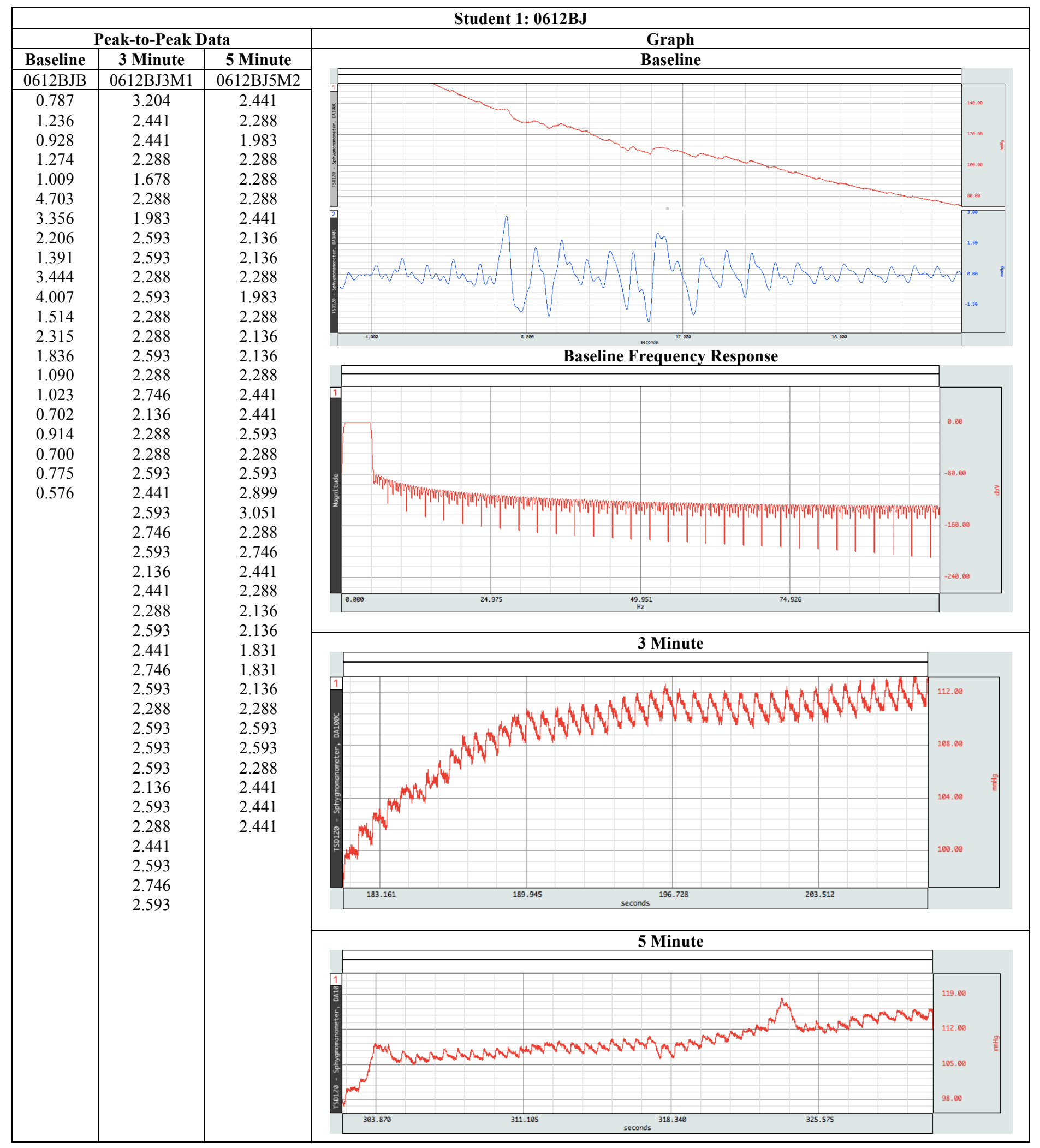


Appendix A: AcqKnowledge Data

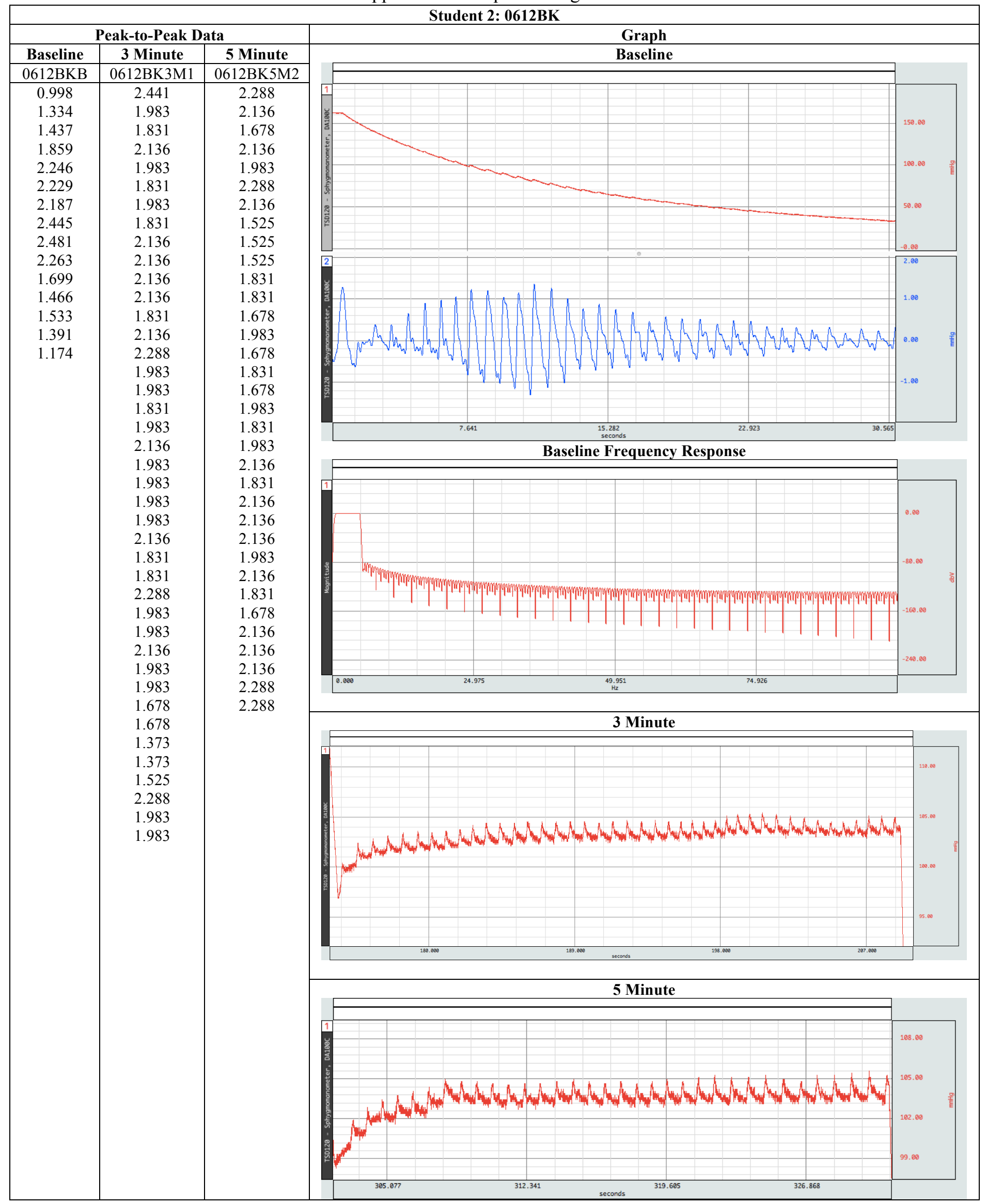


Appendix A: AcqKnowledge Data

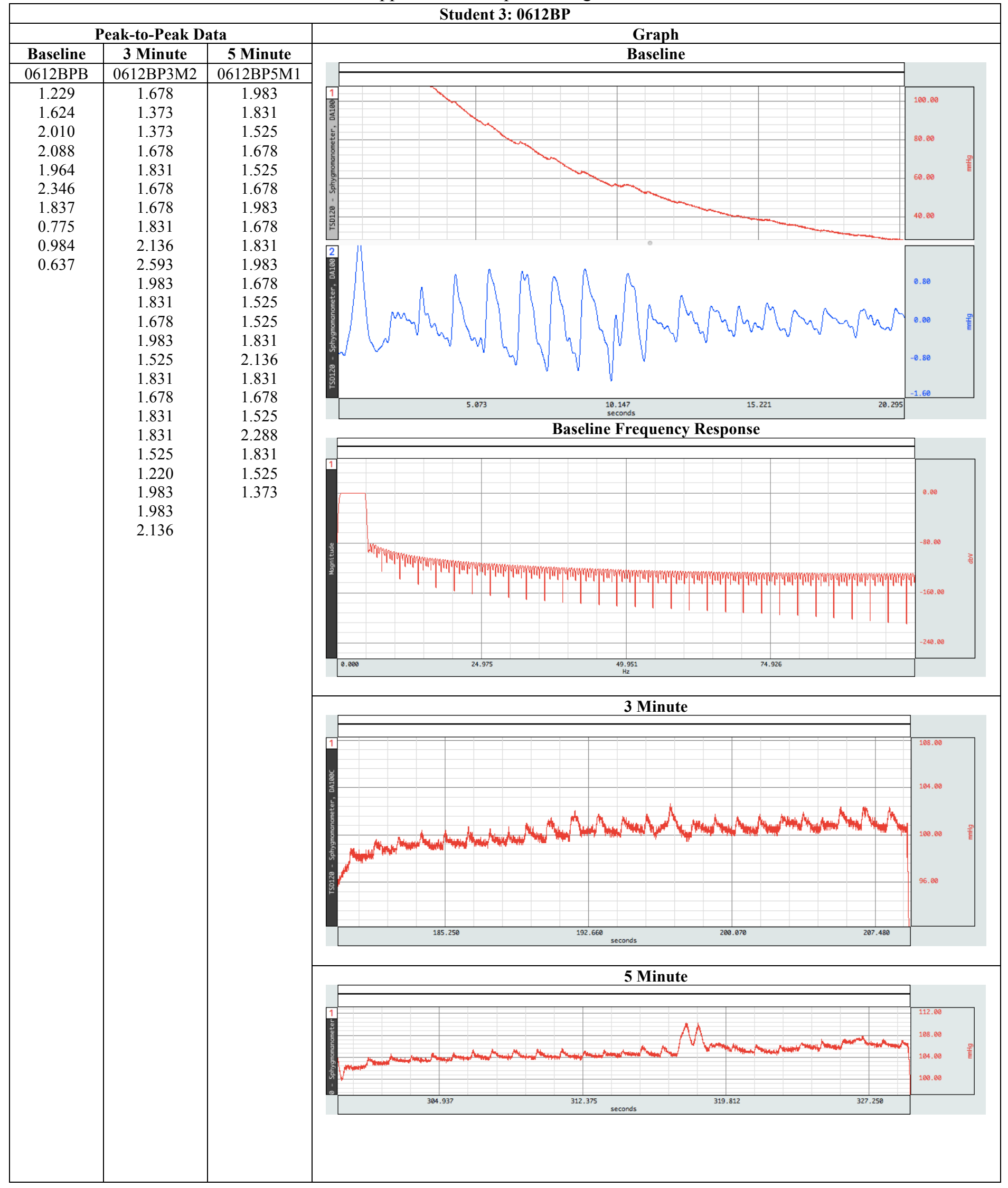


Appendix A: AcqKnowledge Data

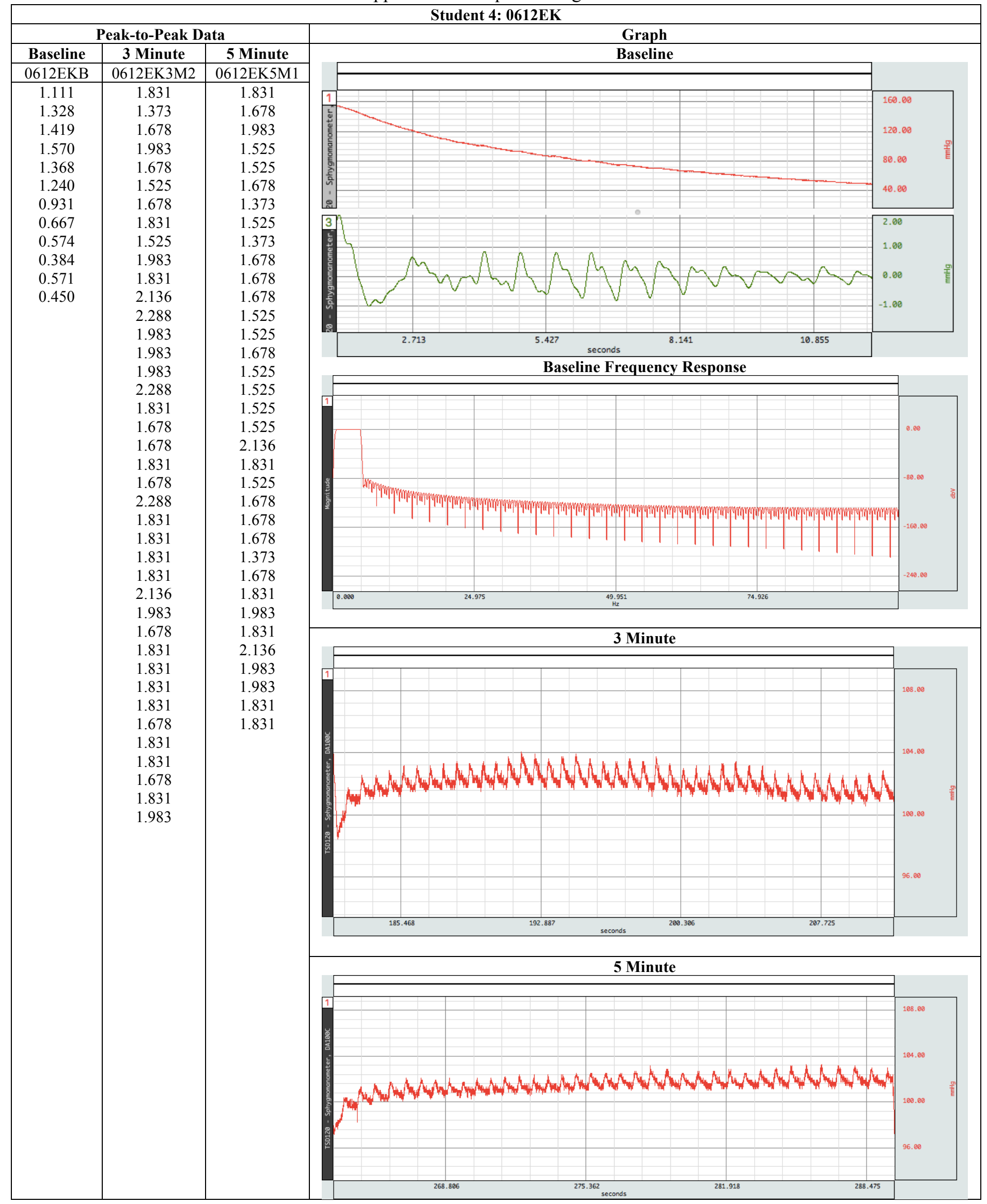


Appendix A: AcqKnowledge Data

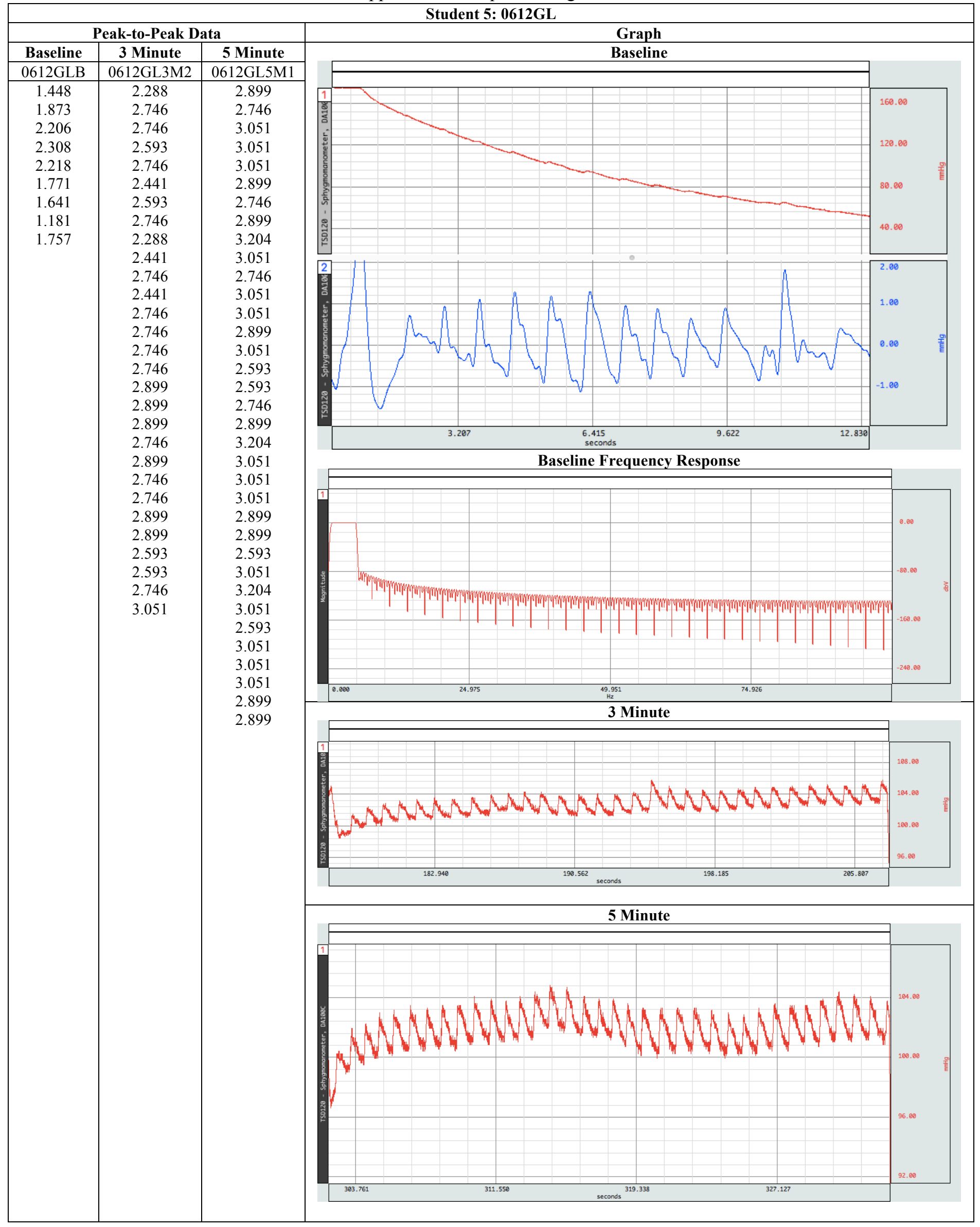


Appendix A: AcqKnowledge Data

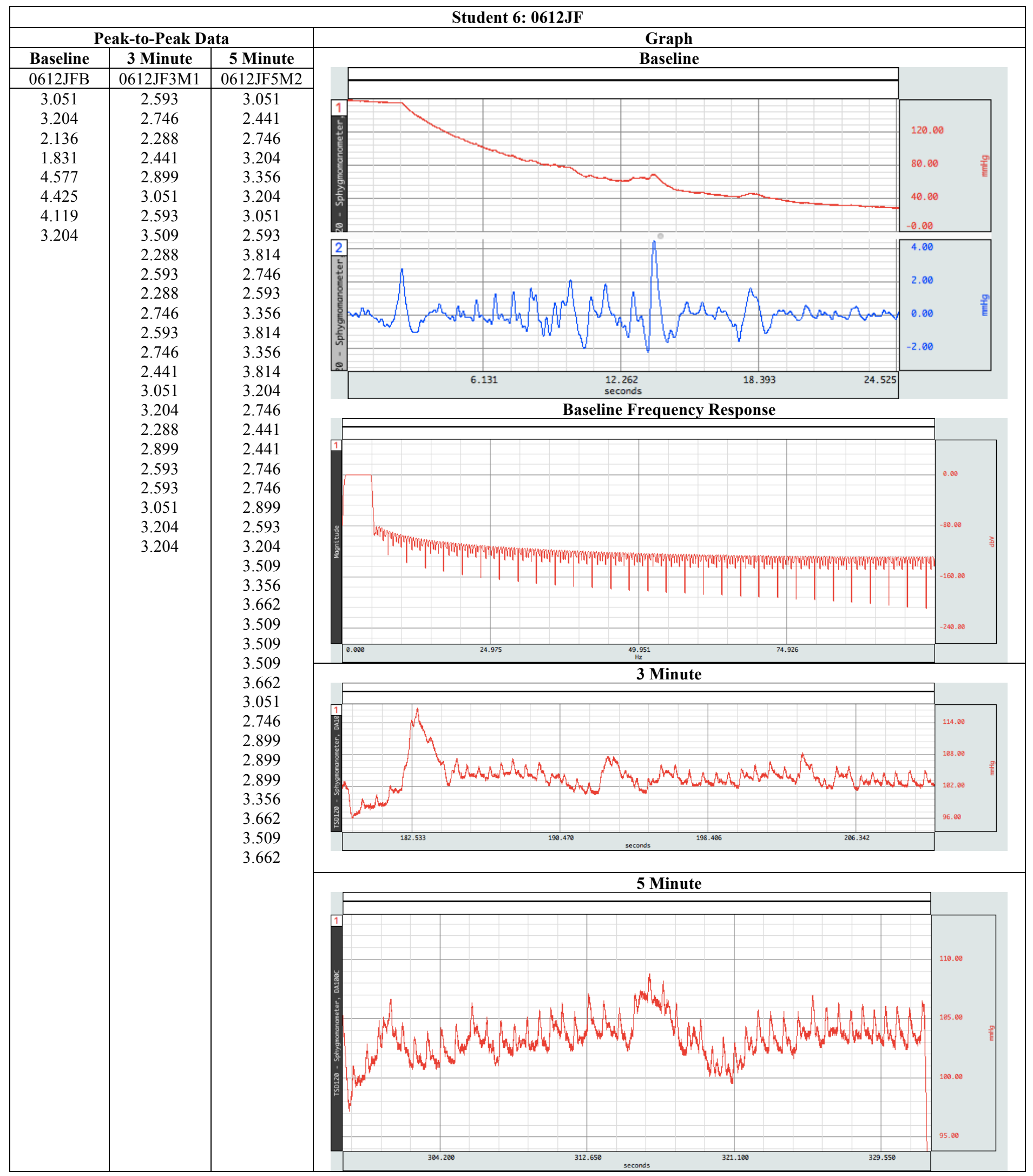


Appendix A: AcqKnowledge Data

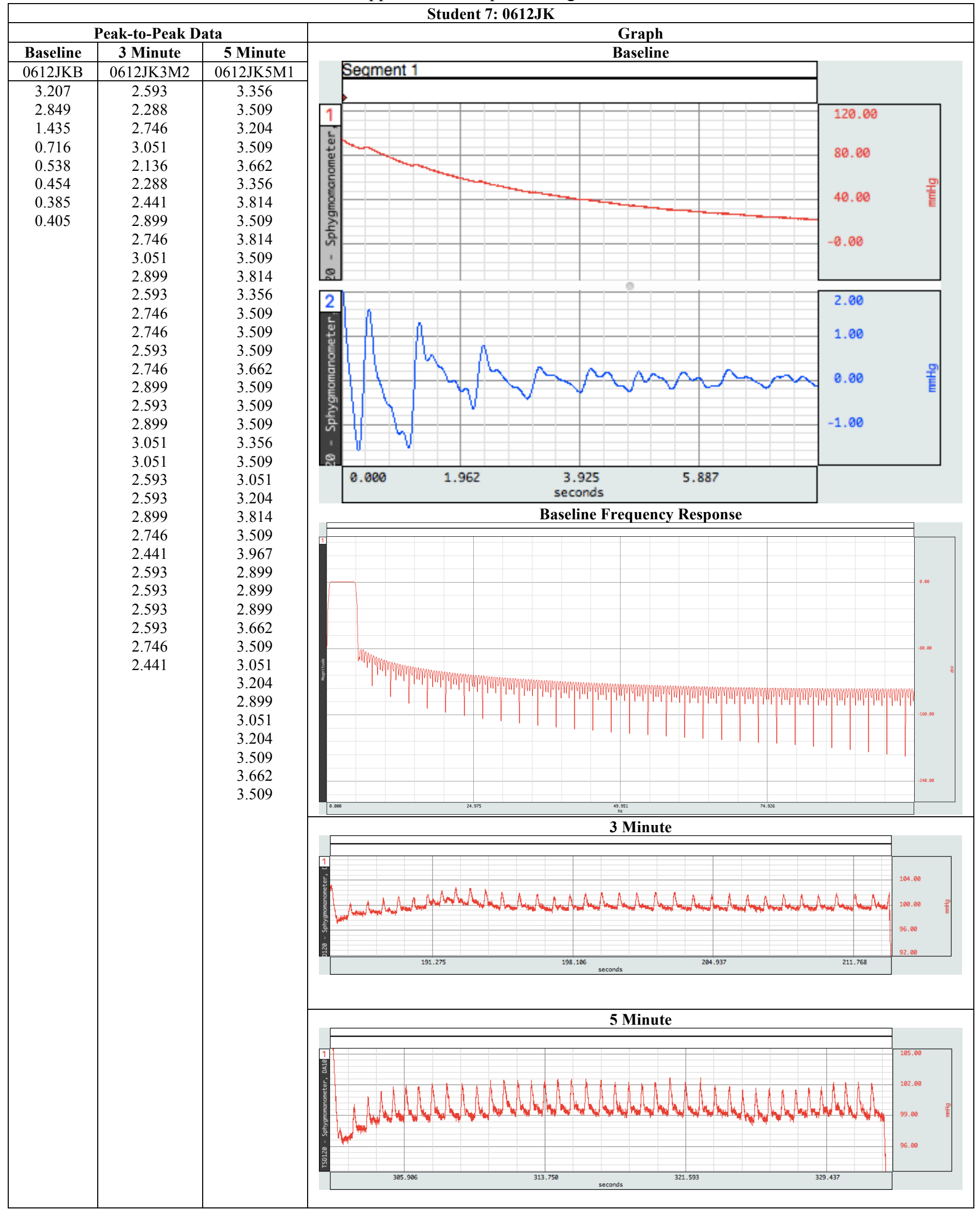


Appendix A: AcqKnowledge Data

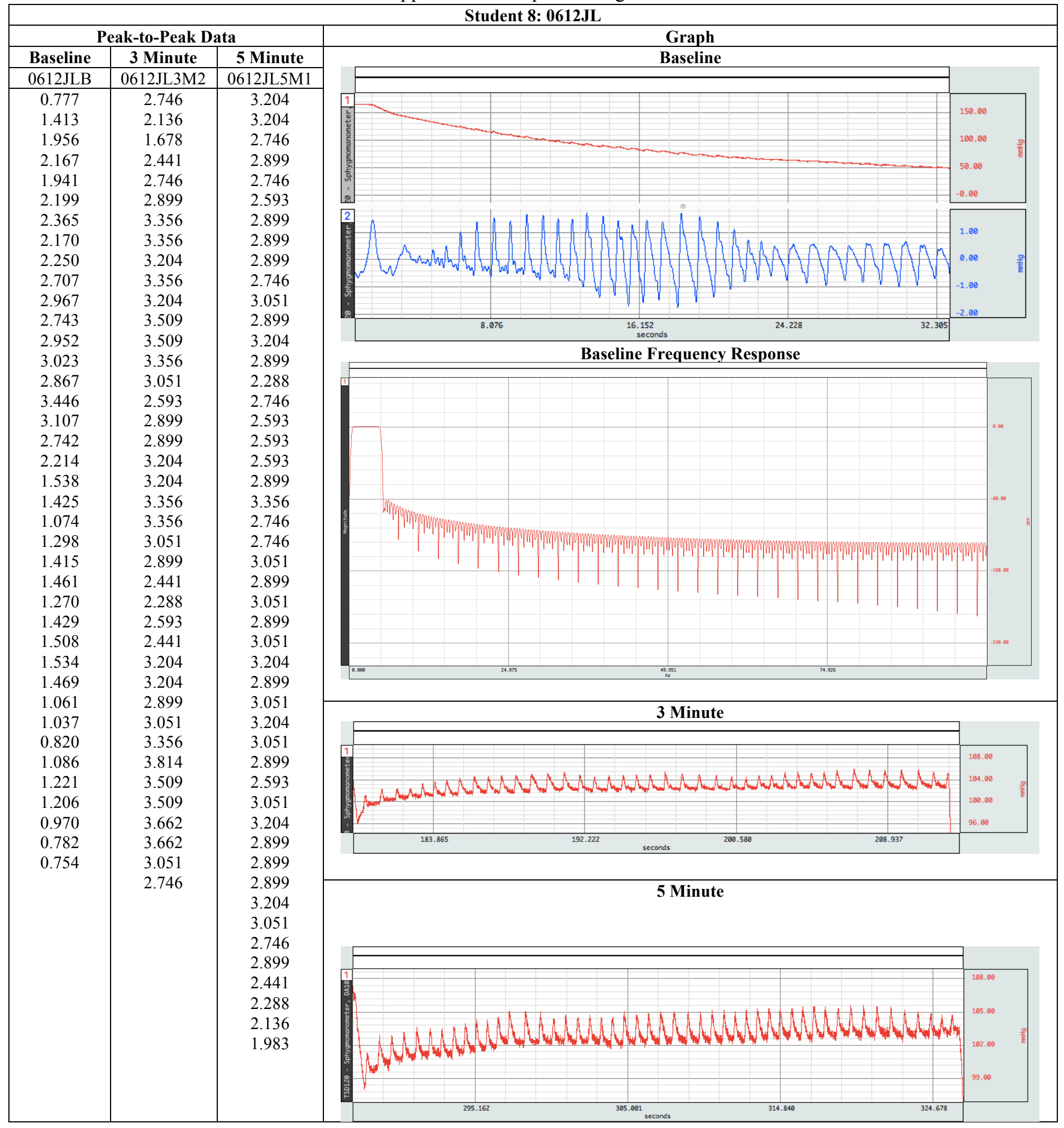


Appendix A: AcqKnowledge Data

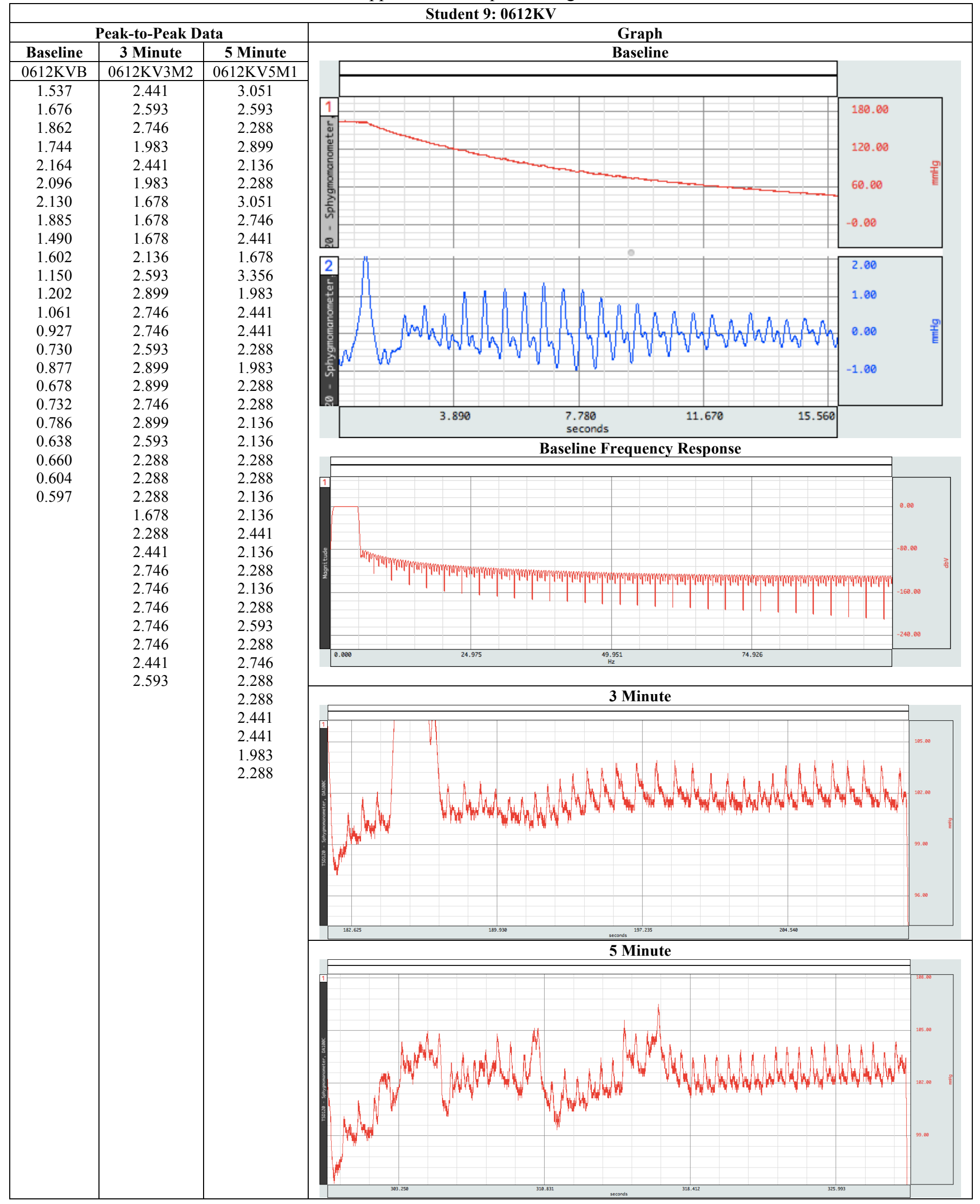


Appendix A: AcqKnowledge Data

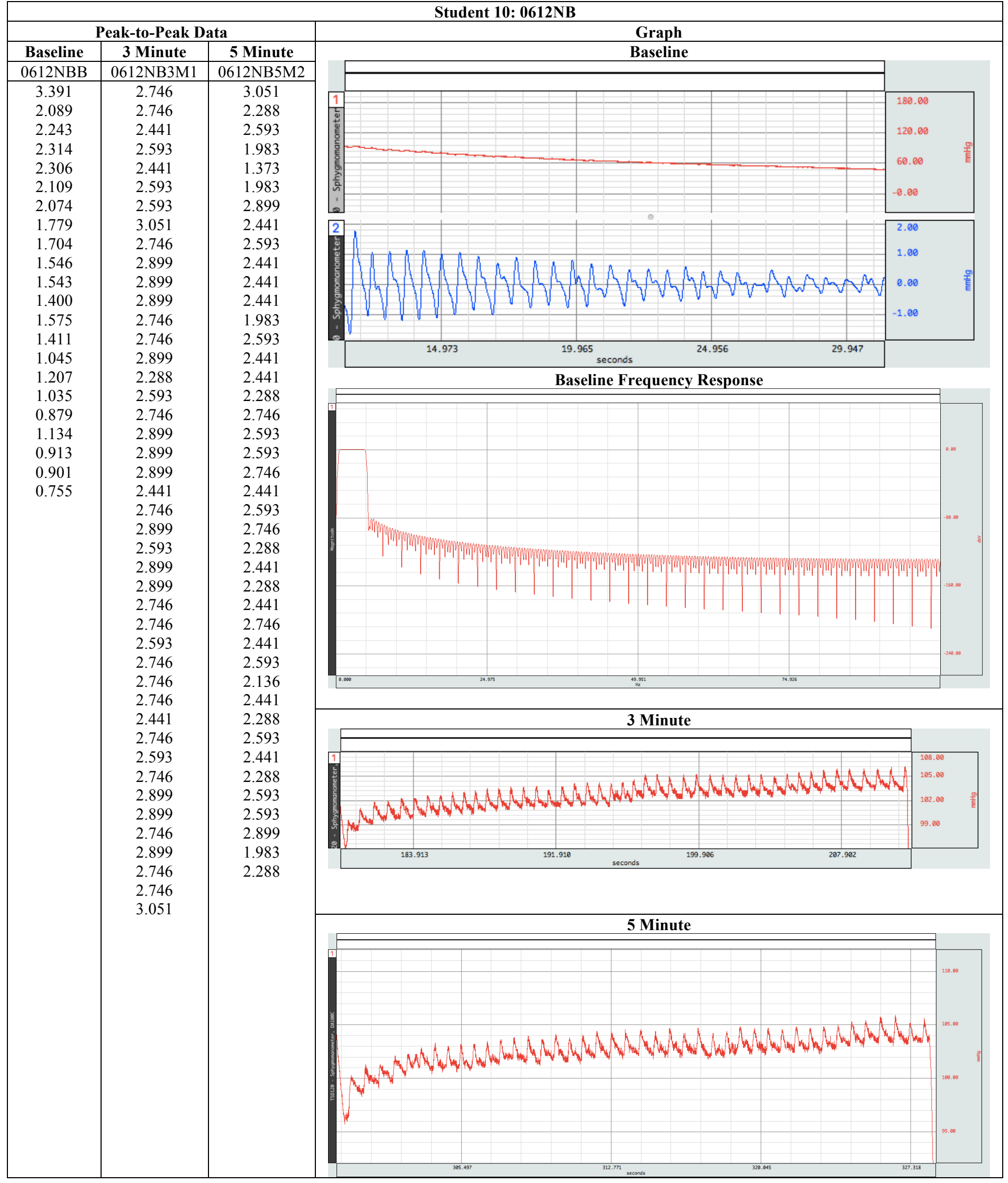


Appendix A: AcqKnowledge Data

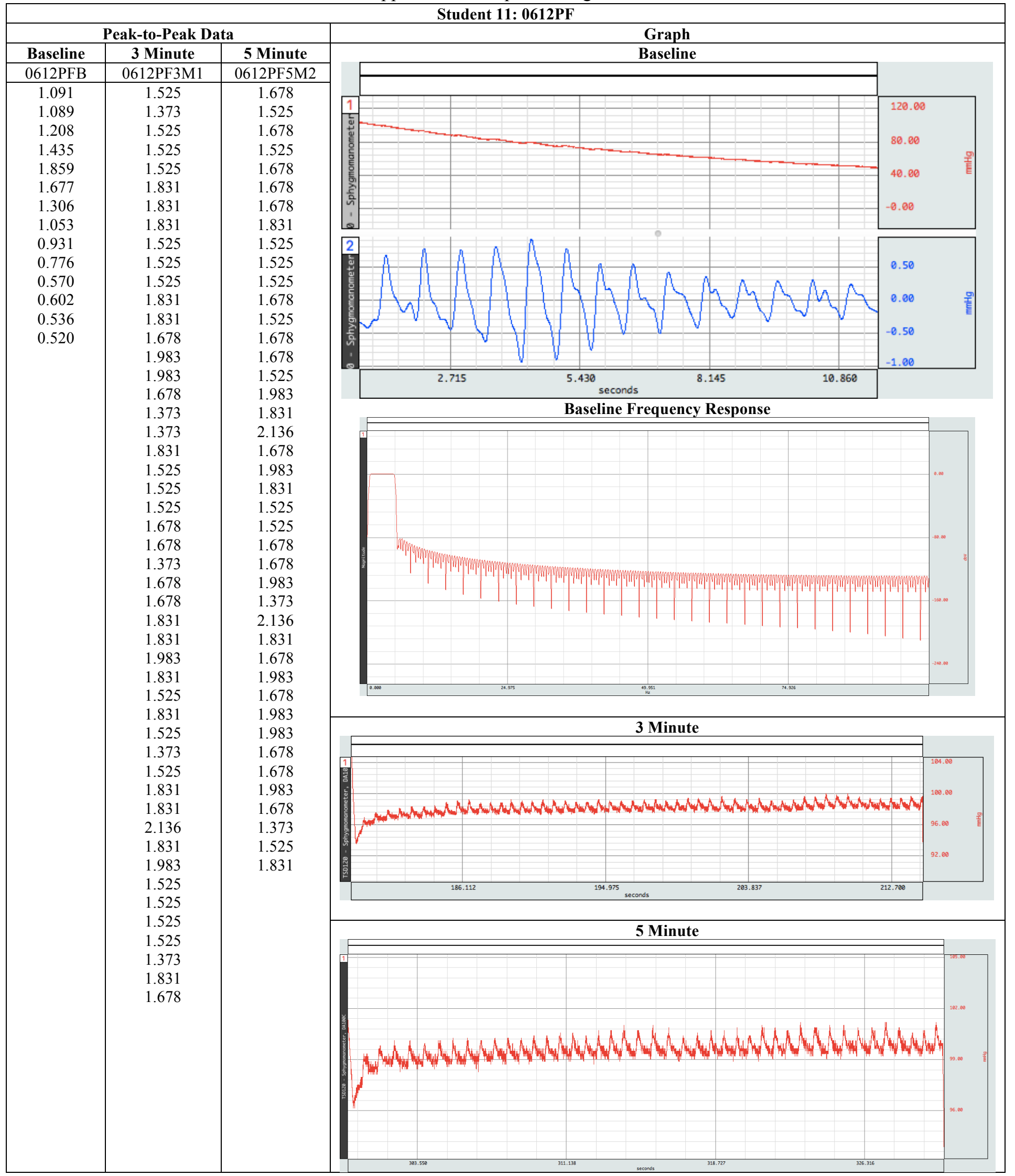


Appendix A: AcqKnowledge Data

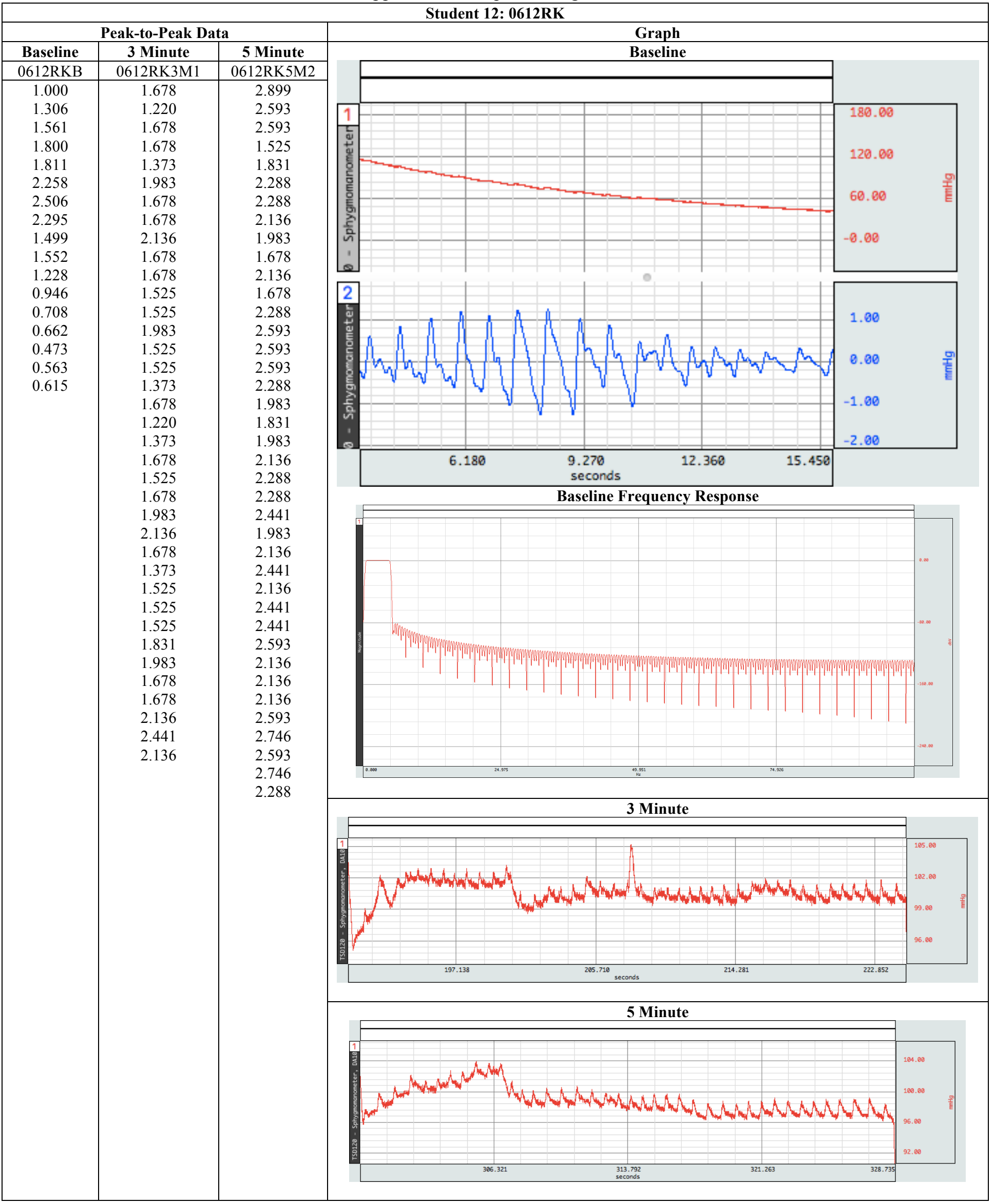


Appendix A: AcqKnowledge Data

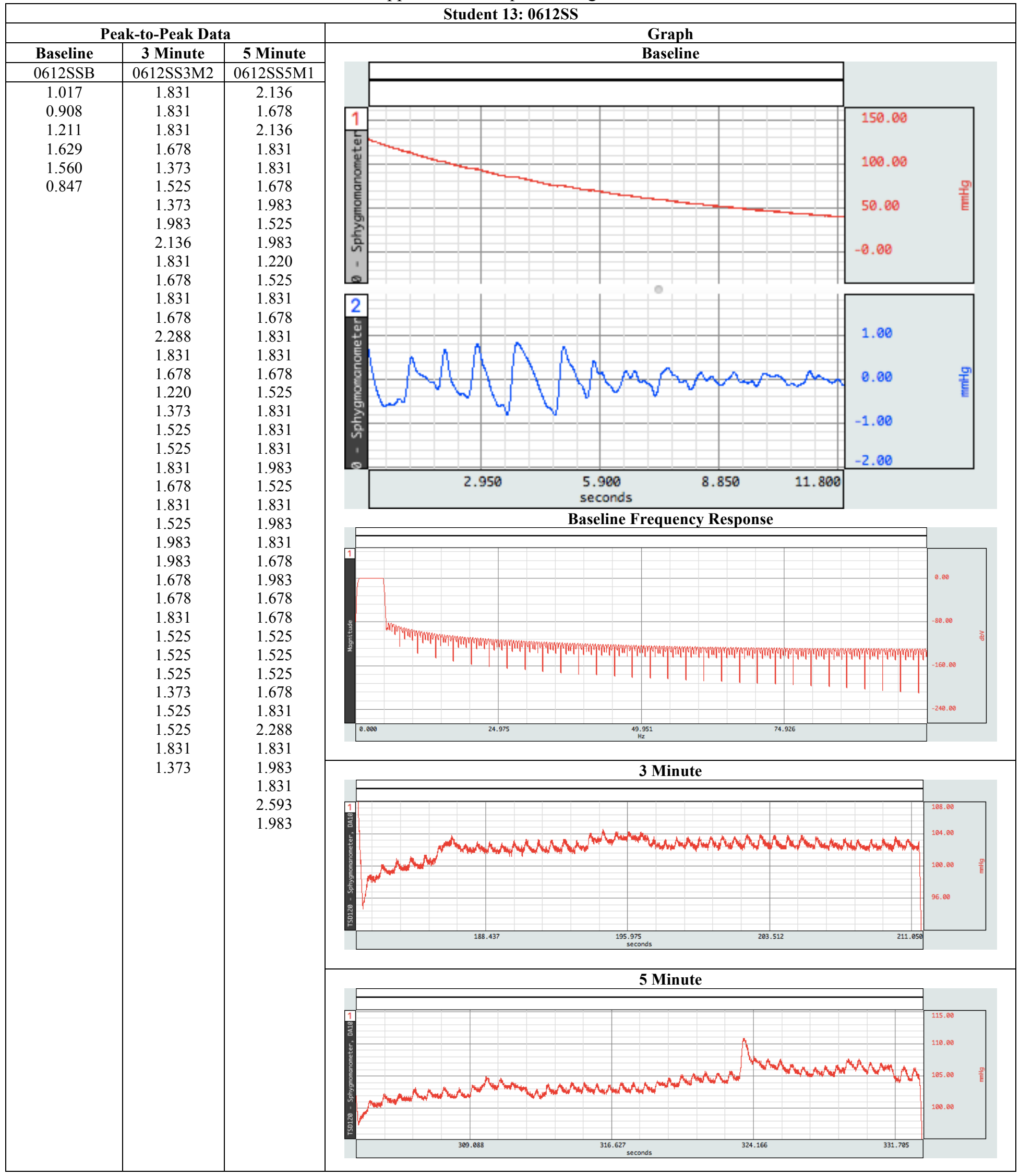


Appendix A: AcqKnowledge Data

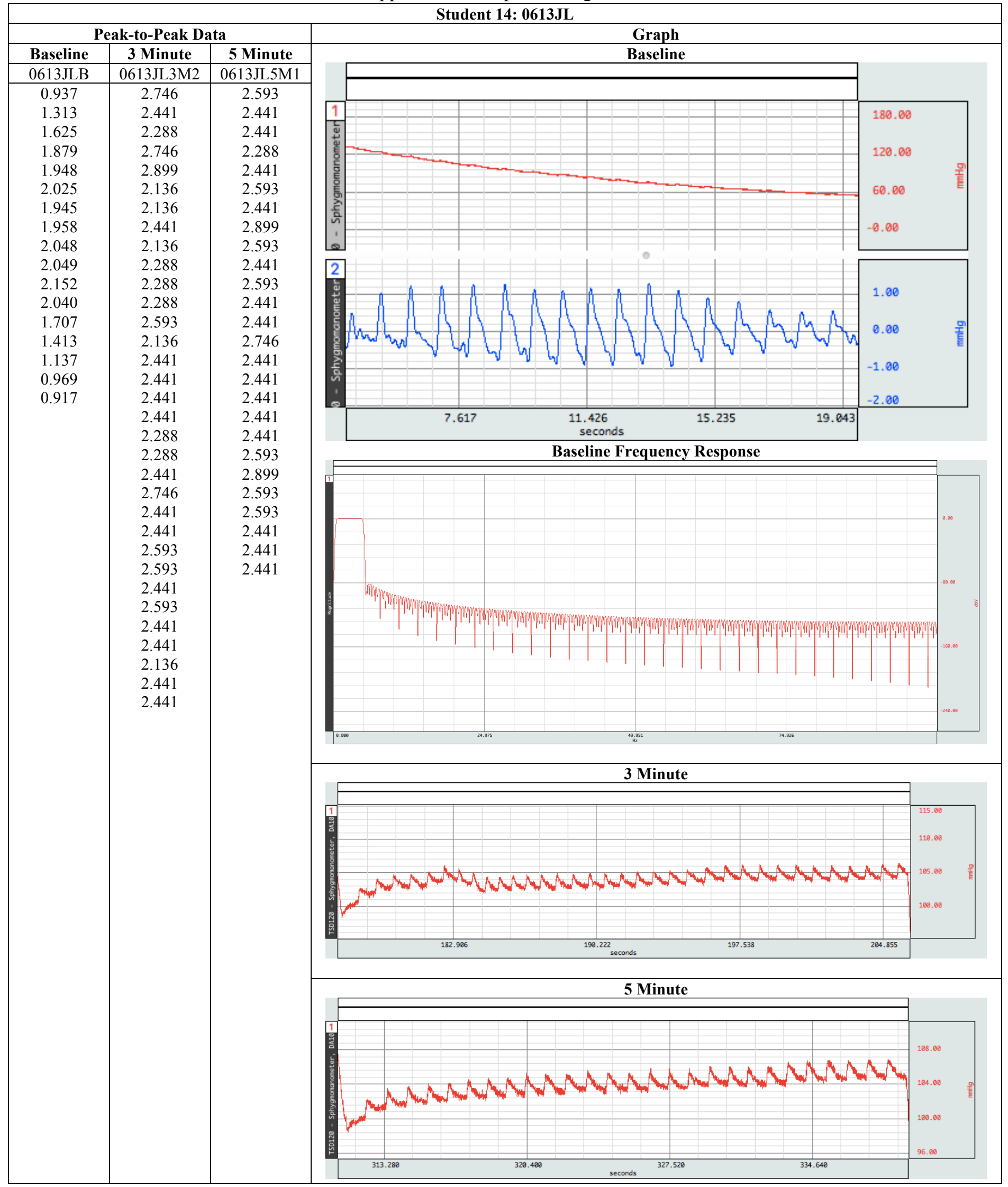


Appendix A: AcqKnowledge Data

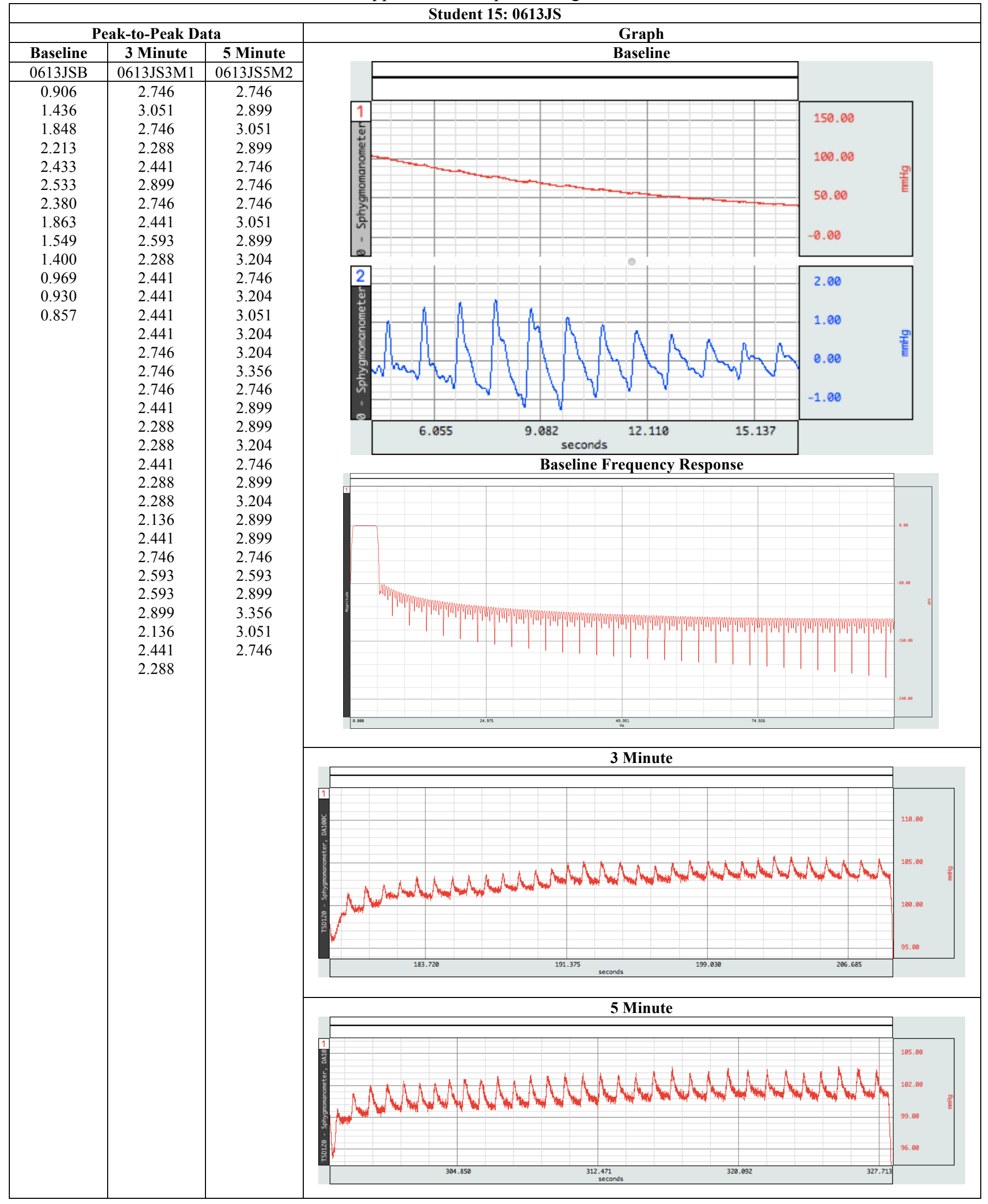


Appendix A: AcqKnowledge Data

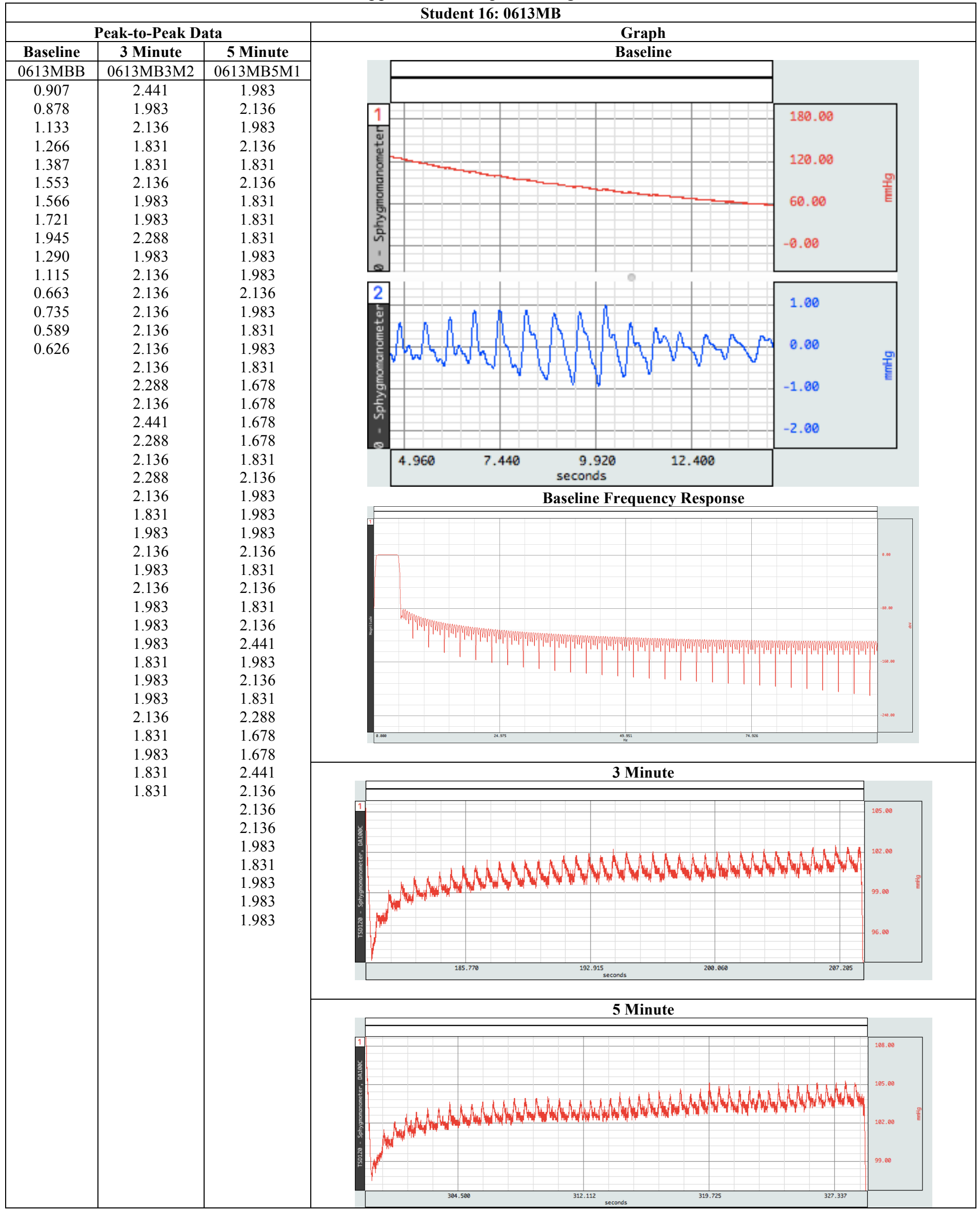


Appendix A: AcqKnowledge Data

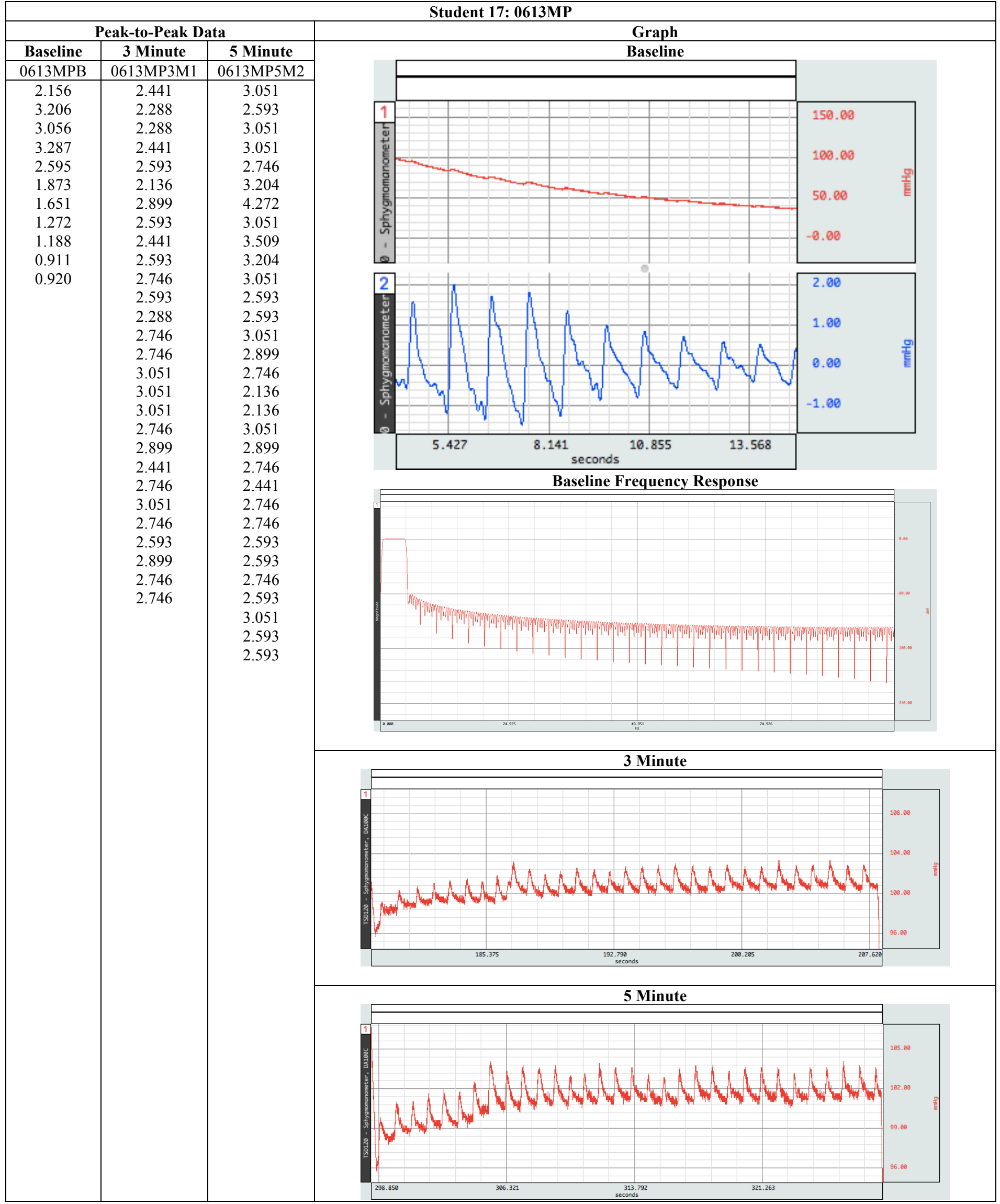


Appendix A: AcqKnowledge Data

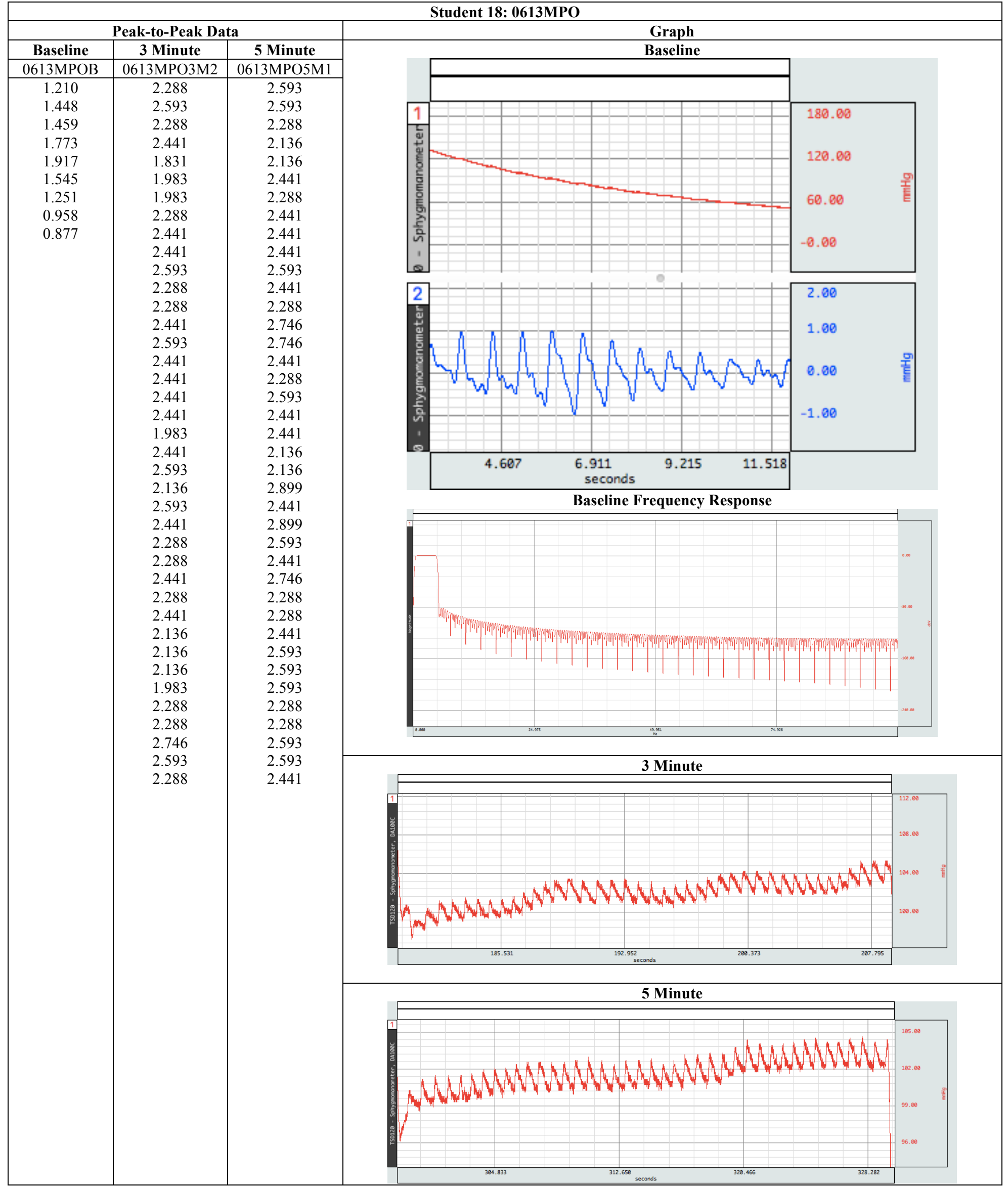


Appendix A: AcqKnowledge Data

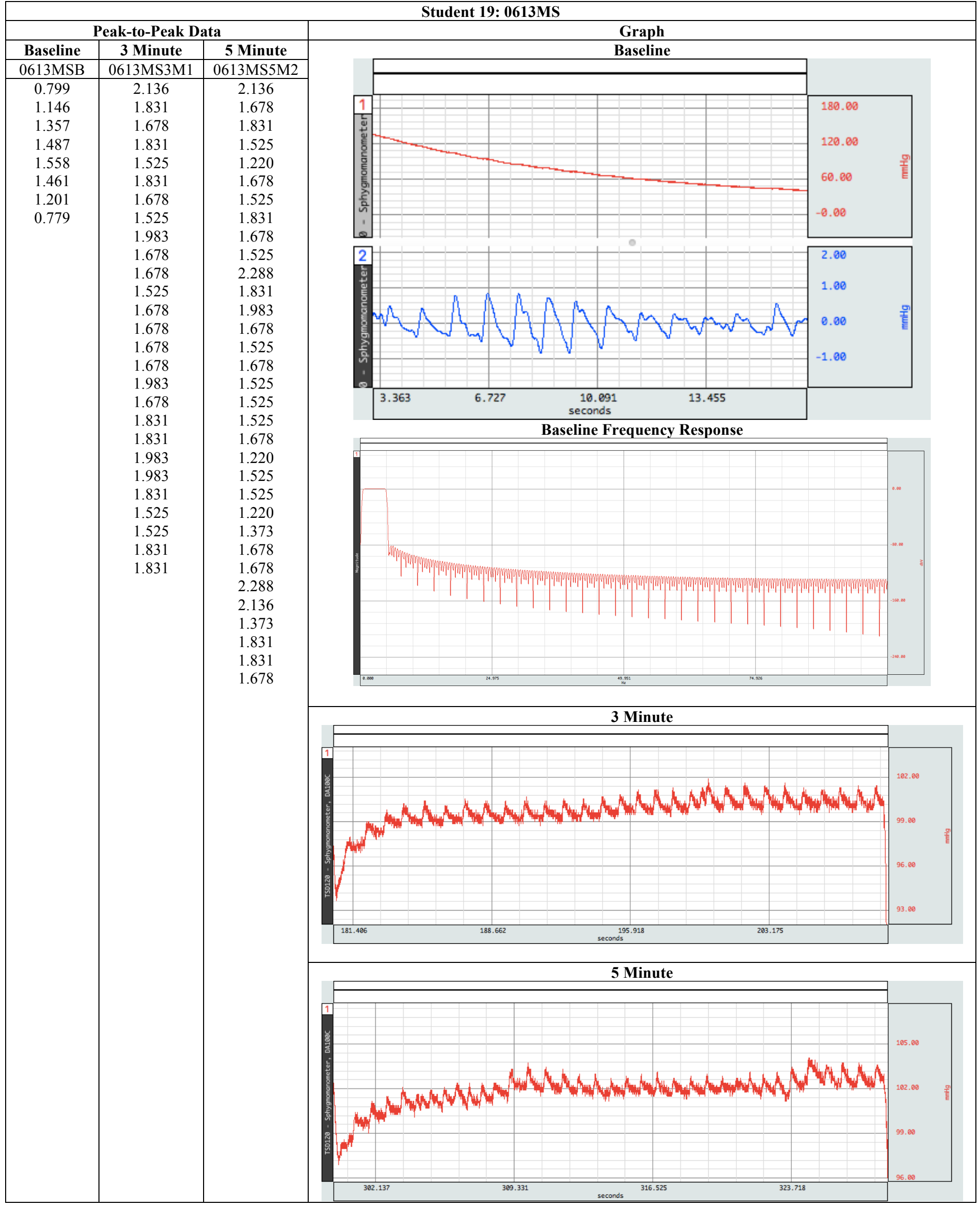


Appendix A: AcqKnowledge Data

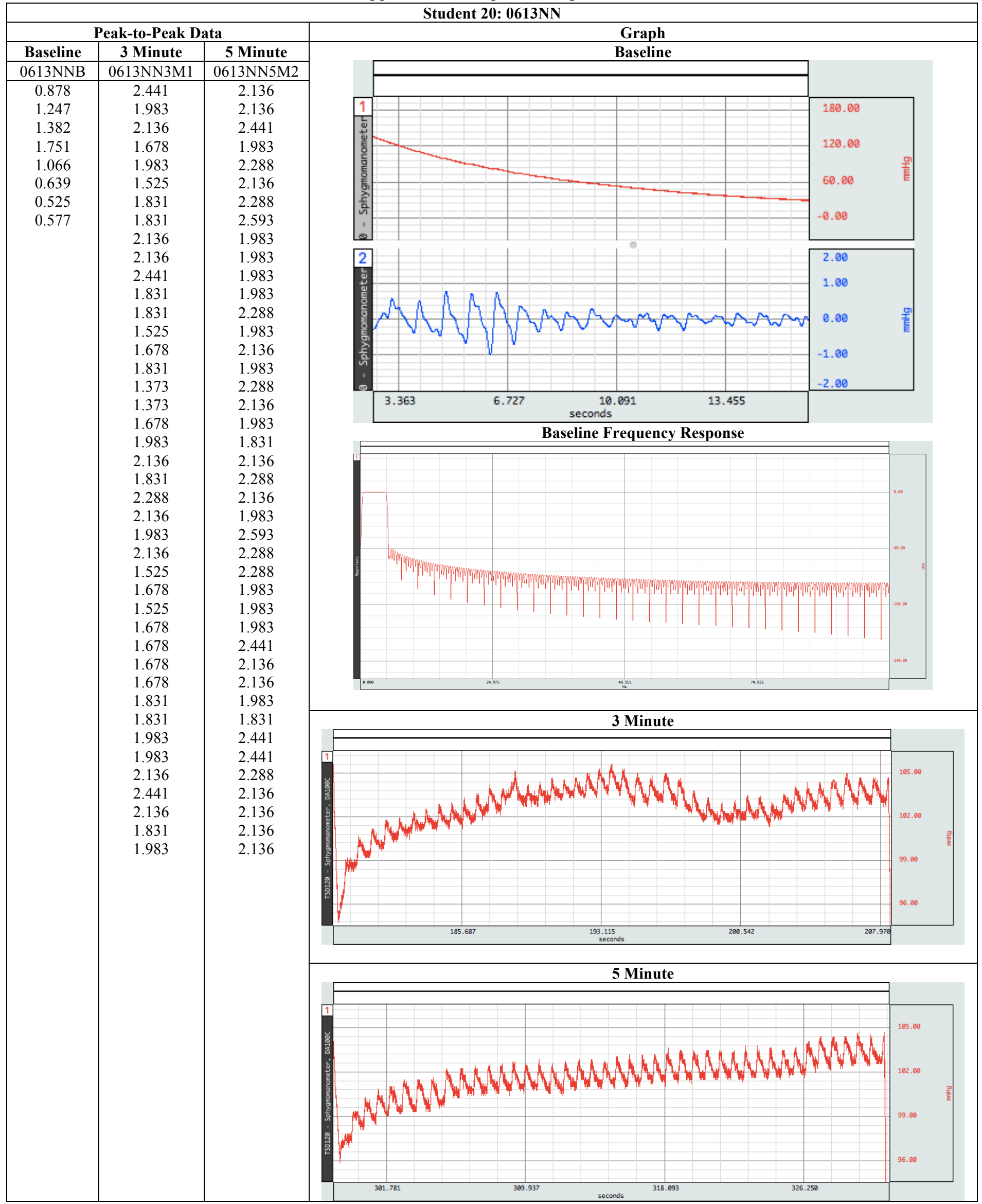


Overall Means Data

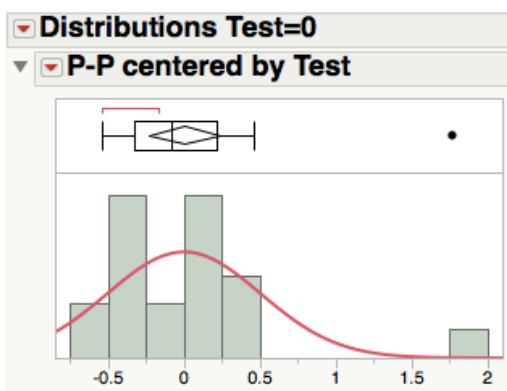

- Distributions Test=3
V-P centered by Test

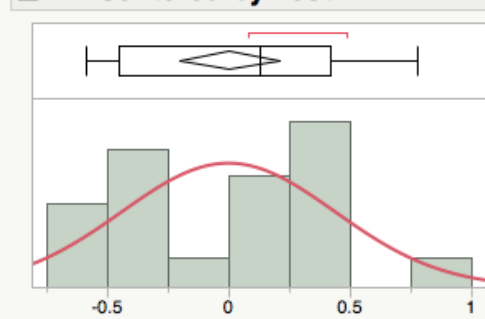

Normal $(0,0.50625)$

$\checkmark$ Fitted Normal

- Parameter Estimates

v Goodness-of-Fit Test Shapiro-Wilk W Test

W Prob $<W$

$0.773915 \quad 0.0004^{*}$
Normal(4e-16,0.44141)

v Fitted Normal

- Parameter Estimates

v Goodness-of-Fit Test

Shapiro-Wilk W Test

$\begin{array}{rc}\text { W } & \text { Prob }<W \\ 0.907539 & 0.0572\end{array}$
- Distributions Test $=5$

$\checkmark$ P-P centered by Test

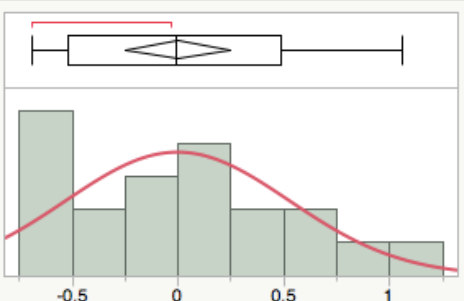

Normal(1.2e-16,0.52933)

v Fitted Normal

- Parameter Estimates

v Goodness-of-Fit Test

Shapiro-Wilk W Test

$\begin{array}{rr}0.941255 & 0.2532\end{array}$

\section{Tests that the Variances are Equal}

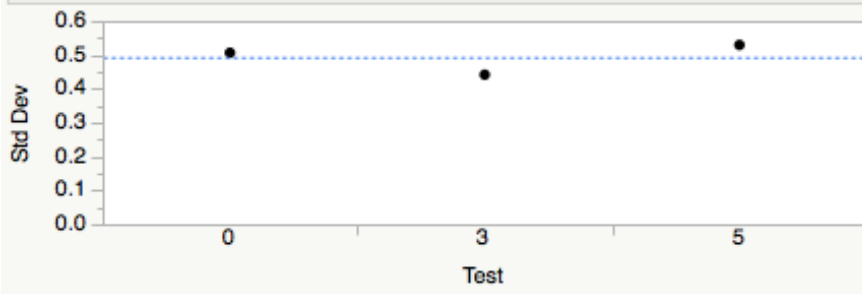

Test

O'Brien[.5]

Brown-Forsythe

Levene

Bartlett
F Ratio

0.1754

0.4434

0.5037

0.3227
DFNum DFDen Prob $>$ F

$\begin{array}{lll}2 & 57 & 0.8396\end{array}$

$\begin{array}{lll}2 & 57 & 0.8396 \\ 2 & 57 & 0.6440\end{array}$

$2 \quad 57-0.6070$
- Oneway Analysis of P-P By Test

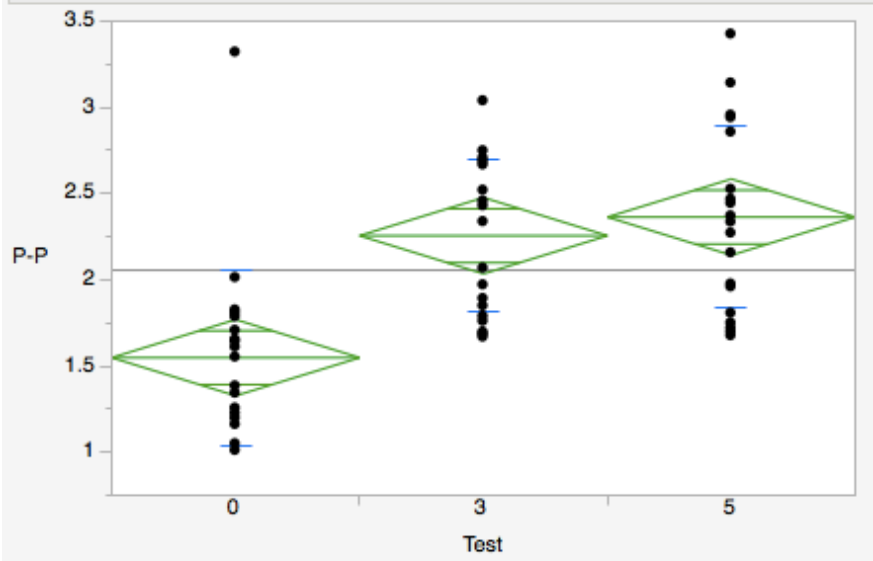

Analysis of Variance

\begin{tabular}{|l|r|r|r|r|r|}
\hline Source & DF & $\begin{array}{r}\text { Squares } \\
\text { Squares }\end{array}$ & Mean Square & F Ratio & Prob > F \\
\hline Test & 2 & 7.847364 & 3.92368 & 16.0956 & $<.0001$ * \\
Error & 57 & 13.895092 & 0.24377 & & \\
C. Total & 59 & 21.742457 & & & \\
\hline
\end{tabular}

\section{' Connecting Letters Report} Level

5
3
0
A $\quad 2.3637491$
A $\quad 2.2557961$
B 1.5483188 
Student 1: 0612BJ

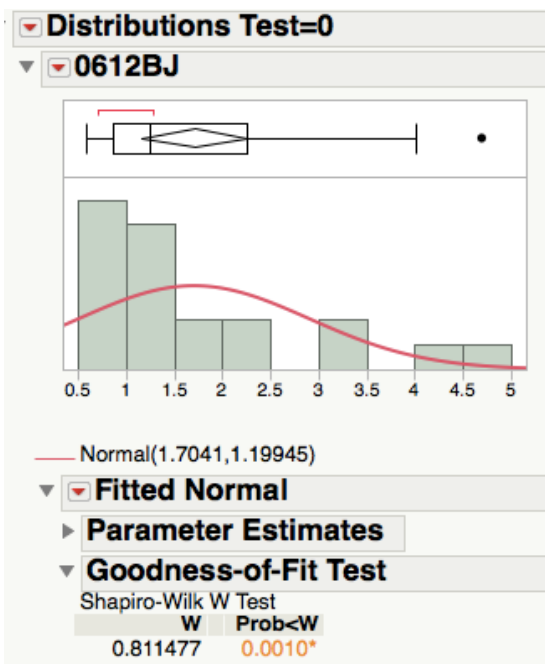

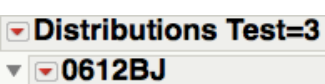

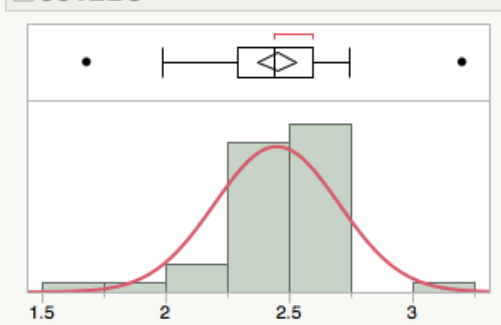

_ Normal (2.45157,0.25301)

v Fitted Normal

- Parameter Estimates

$\checkmark$ Goodness-of-Fit Test

Shapiro-Wilk W Test

$\begin{array}{rr}\text { W } & \text { Prob<W } \\ 0.913341 & 0.0037^{*}\end{array}$

\section{- Distributions Test=5 \\ $\checkmark$ 0612BJ}

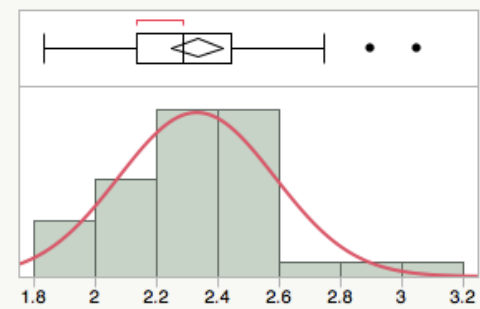

_ Normal(2.33242,0.25549)

$\checkmark$ Fitted Normal

- Parameter Estimates

$\checkmark$ Goodness-of-Fit Test

Shapiro-Wilk W Test

W Prob<W

\section{Tests that the Variances are Equal}

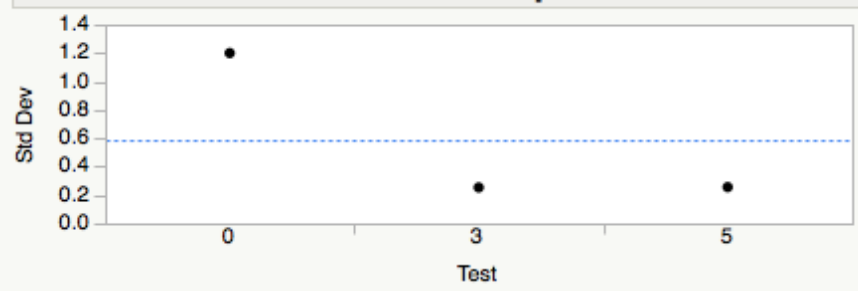

Test

O'Brien[.5]

Brown-Forsythe Levene Bartlett
F Ratio

14.1089

16.2936

38.5060

50.2933
DFNum DFDen Prob $>$ F

$\begin{array}{rrr}2 & 98 & <.0001^{*} \\ 2 & 98 & <.0001^{*} \\ 2 & 98 & <.0001^{*} \\ 2 & . & <.0001^{*}\end{array}$

- Oneway Analysis of 0612BJ By Test

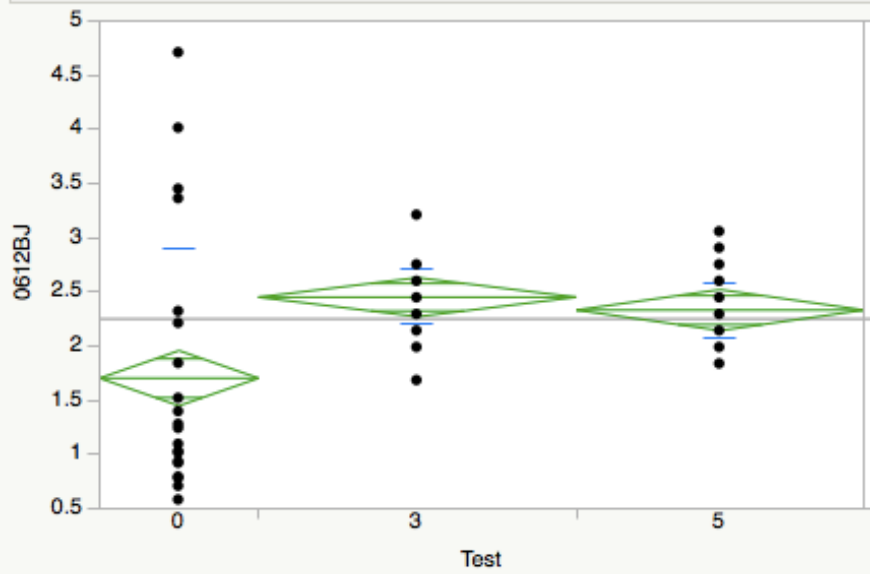

\begin{tabular}{|l|r|r|r|r|r|}
\hline \multicolumn{6}{|l}{ Analysis of Variance } \\
Sum of \\
Source & DF & $\begin{array}{r}\text { Squares } \\
\text { Sean Square }\end{array}$ & F Ratio & Prob > F \\
Test & 2 & 8.222721 & 4.11136 & 11.9158 & $<.0001^{*}$ \\
Error & 98 & 33.813409 & 0.34503 & & \\
C. Total & 100 & 42.036130 & & &
\end{tabular}

Connecting Letters Report Level Mean

3

5

0

2.4515714

2.3324211

B 1.7040952 
Student 2: 0612BK
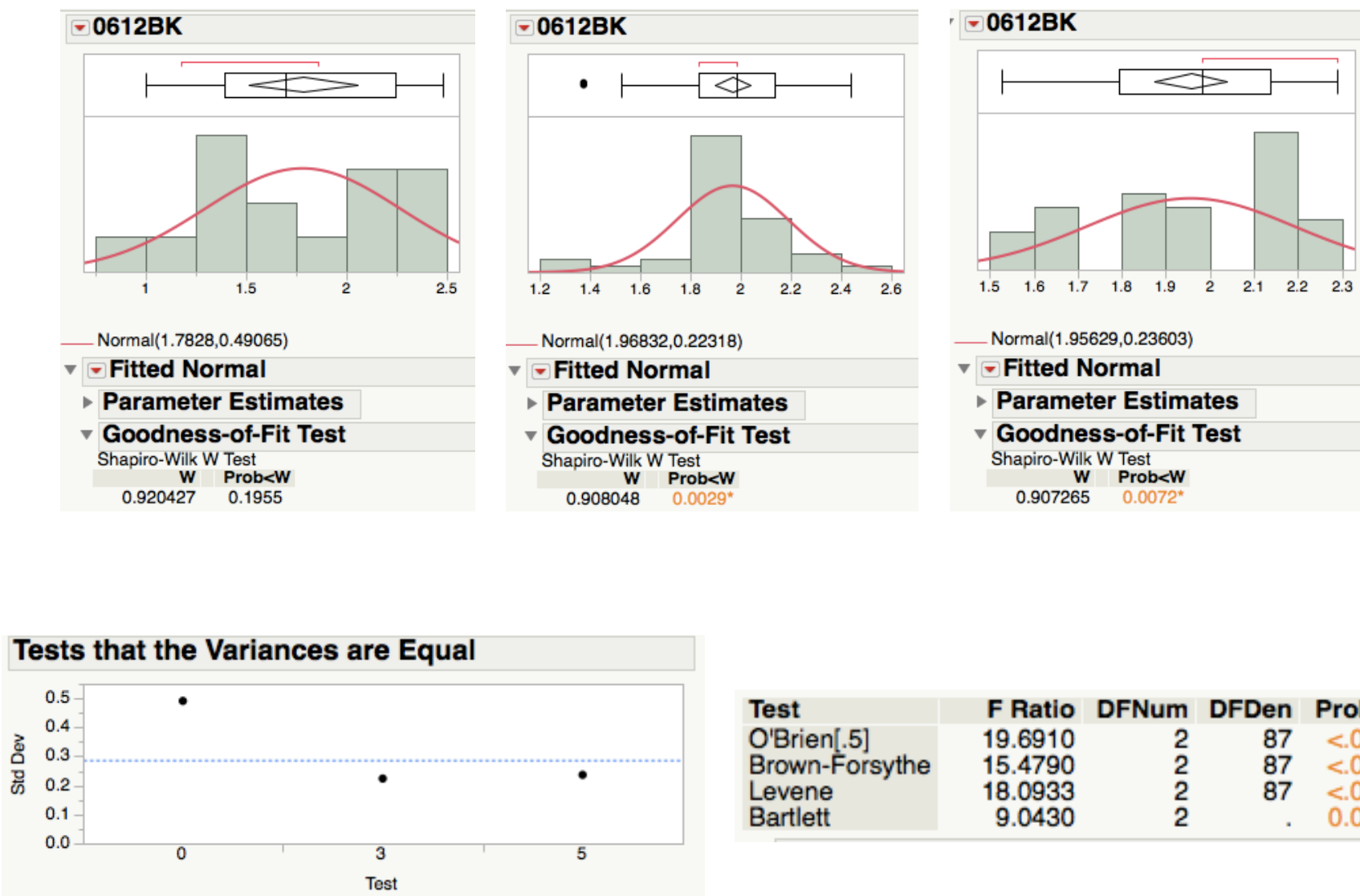

Test

O'Brien[.5]

Brown-Forsythe Levene Bartlett
F Ratio

19.6910

15.4790

18.0933

9.0430
DFNum DFDen Prob $>$ F

$287<0001$

$287<0001$ *

$2 \quad 87<.0001$

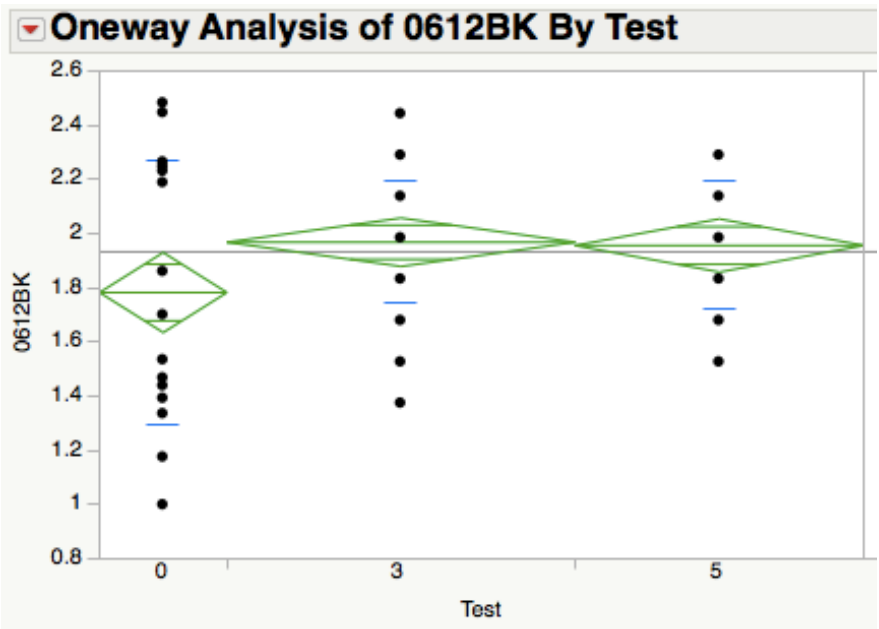

- Analysis of Variance

\begin{tabular}{l|rr|rr|c|}
\hline Source & DF & $\begin{array}{r}\text { Squm of } \\
\text { Squares }\end{array}$ & Mean Square & F Ratio & Prob > F \\
Test & 2 & 0.4079868 & 0.203993 & 2.4646 & 0.0910 \\
Error & 87 & 7.2010703 & 0.082771 & & \\
C. Total & 89 & 7.6090571 & & &
\end{tabular}

\section{Connecting Letters Report Level} 3

5

A $\quad 1.9683171$

A 1.9562941

A 1.7828000 
Student 3: 0612BP
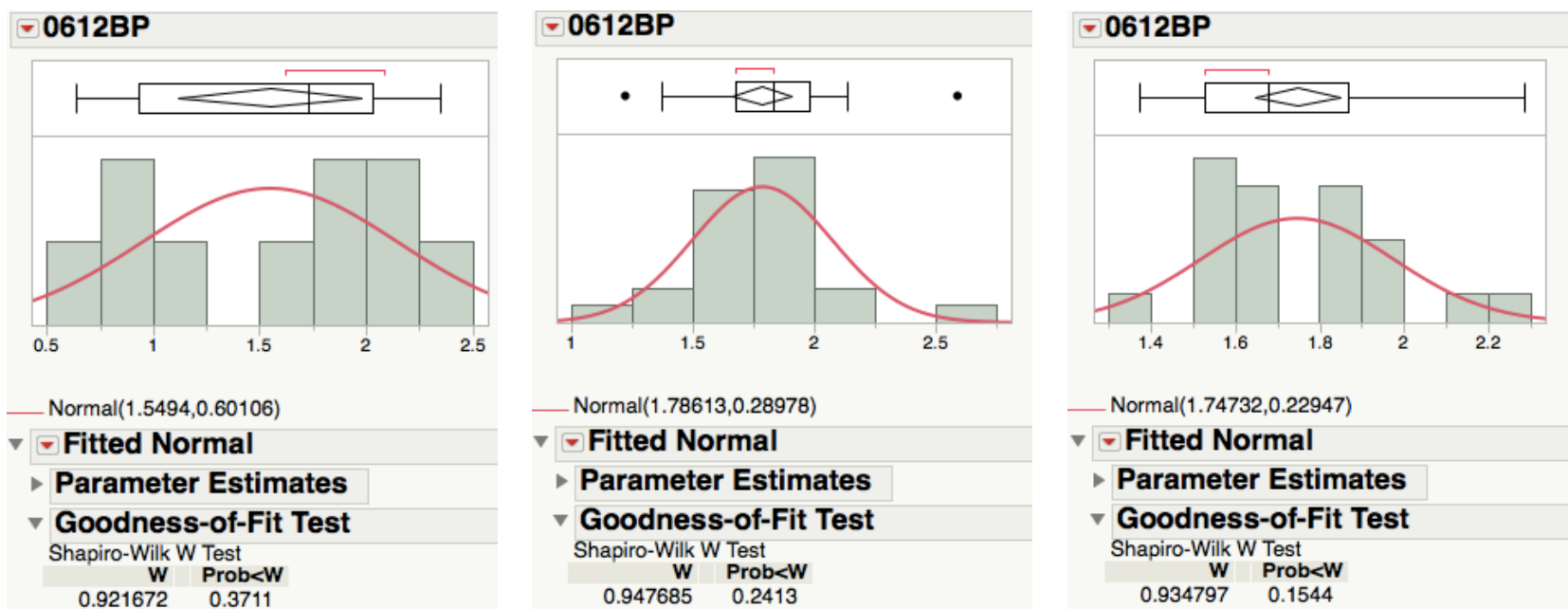

_ Normal(1.74732,0.22947)

v Fitted Normal

Parameter Estimates

Goodness-of-Fit Test

Shapiro-Wilk W Test

W
0.934797 $\quad 0.1544$

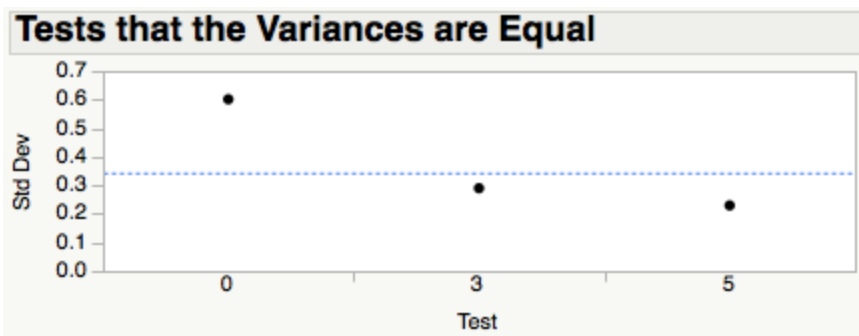

Test

O'Brien[.5]

Brown-Forsythe

Levene

Bartlett

$\begin{array}{rrrr}\text { F Ratio } & \text { DFNum } & \text { DFDen } & \text { Prob }>\text { F } \\ 11.8406 & 2 & 53 & <.0001^{*} \\ 8.1375 & 2 & 53 & 0.0008^{*} \\ 12.1701 & 2 & 53 & <.0001^{*} \\ 7.2737 & 2 & . & 0.0007^{*}\end{array}$

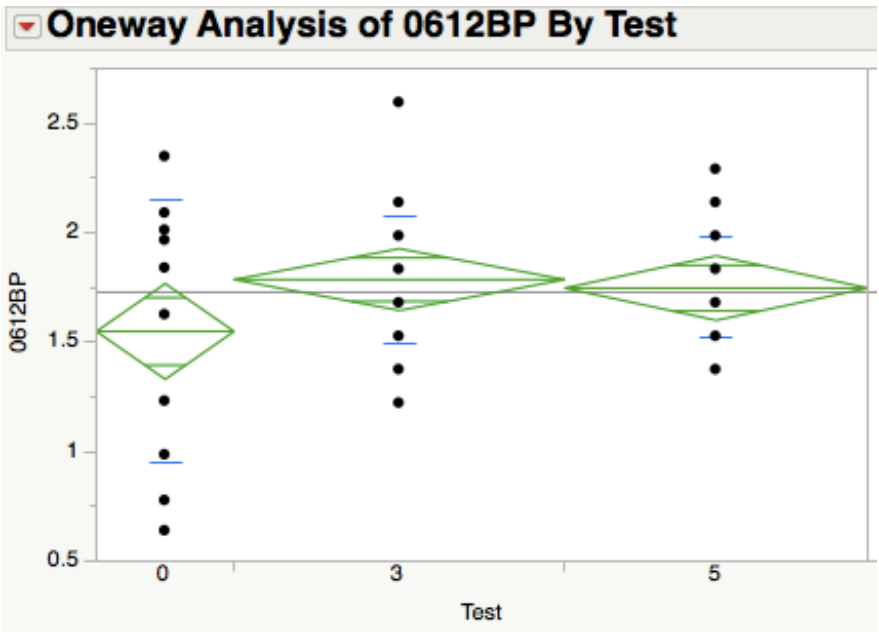

- Analysis of Variance

\begin{tabular}{|l|r|r|r|r|r|}
\hline Source & DF & $\begin{array}{r}\text { Sum of } \\
\text { Squares }\end{array}$ & Mean Square & F Ratio & Prob > F \\
\hline Test & 2 & 0.4082536 & 0.204127 & 1.7204 & 0.1888 \\
Error & 53 & 6.2885958 & 0.118653 & & \\
C. Total & 55 & 6.6968494 & & & \\
\hline-- & - & - & & &
\end{tabular}

\section{Connecting Letters Report} Level Mean

3 A 1.7861250

5 A 1.7473182

O A 1.5494000 
Student 4: 0612EK
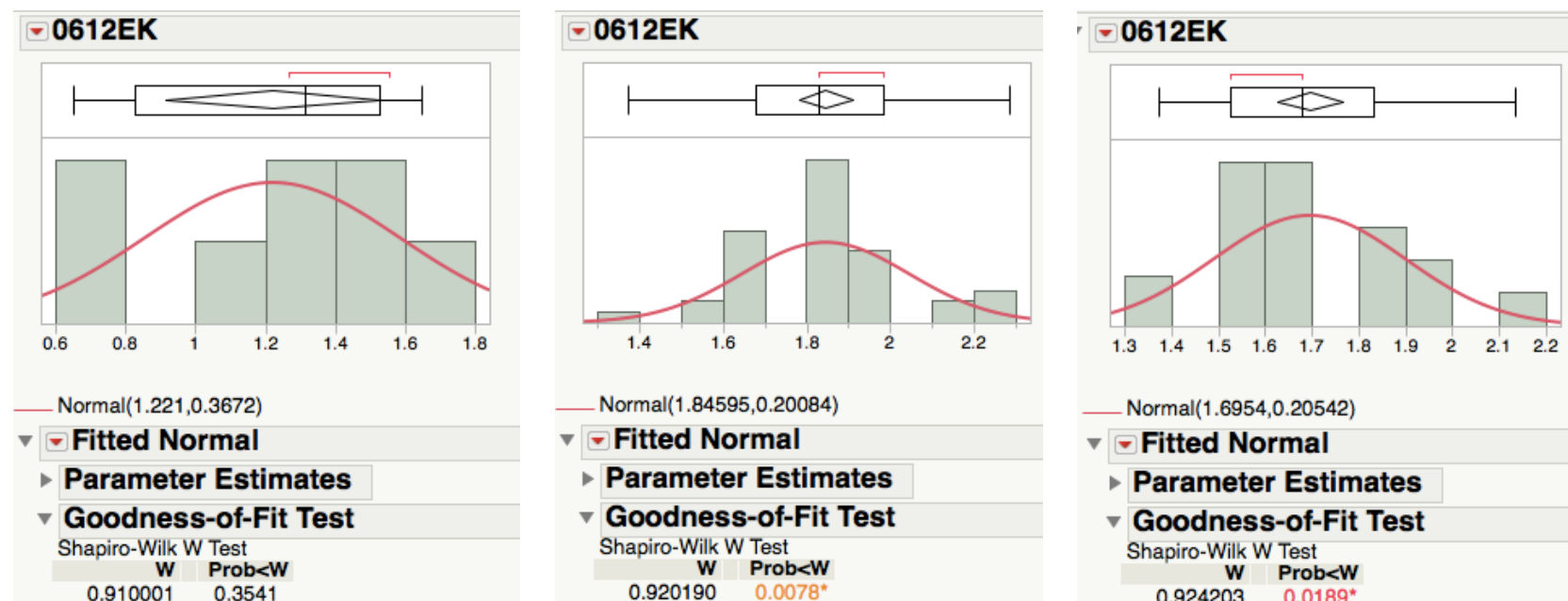

_ Normal(1.6954,0.20542)

$\checkmark$ Fitted Normal

- Parameter Estimates

$\checkmark$ Goodness-of-Fit Test Shapiro-Wilk W Test $\begin{array}{rr}\text { W } & \text { Prob }<\text { W } \\ 0.924203 & 0.0189^{*}\end{array}$

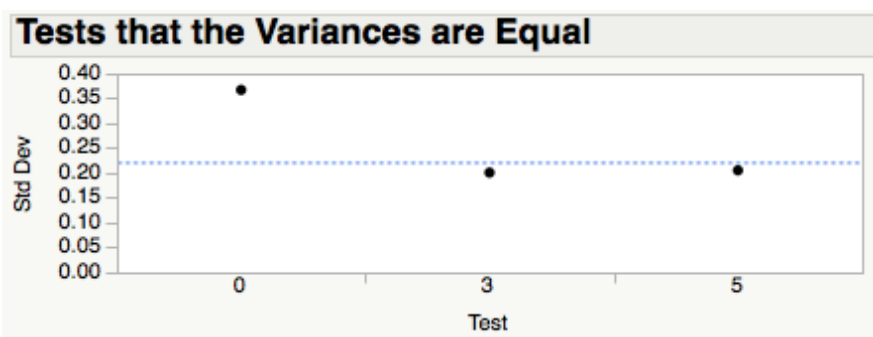

Test

O'Brien[.5]

Brown-Forsythe Levene

Bartlett

$\begin{array}{rrrr}\text { F Ratio } & \text { DFNum } & \text { DFDen } & \text { Prob }>\text { F } \\ 6.1294 & 2 & 80 & 0.0033^{*} \\ 2.9843 & 2 & 80 & 0.0562 \\ 3.7916 & 2 & 80 & 0.0267^{*} \\ 3.0210 & 2 & & 0.0488^{*}\end{array}$

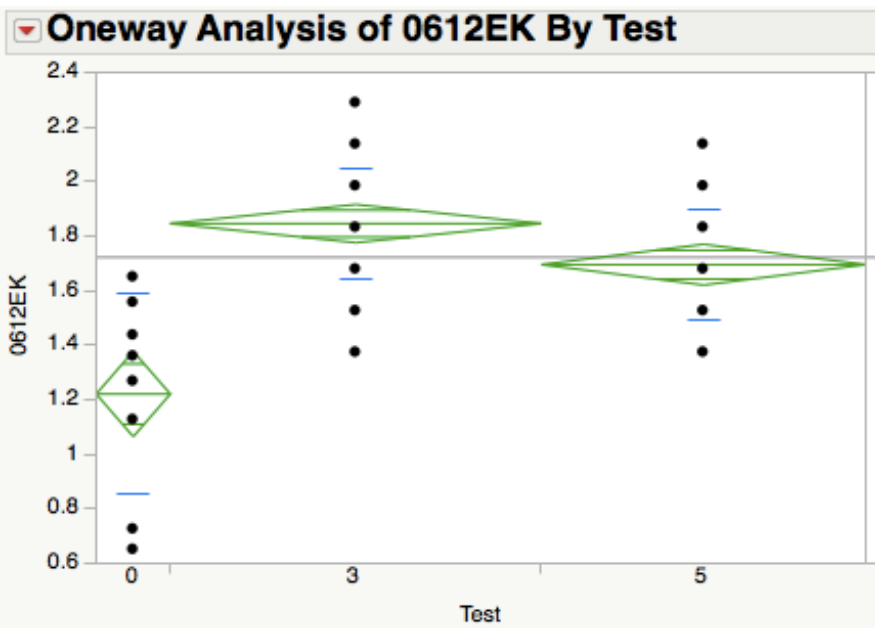

- Analysis of Variance

\begin{tabular}{|l|r|r|r|r|r|}
\hline Source & DF & $\begin{array}{r}\text { Sum of } \\
\text { Squares }\end{array}$ & Mean Square & F Ratio & Prob > F \\
\hline Test & 2 & 2.6473124 & 1.32366 & 26.7972 & $<.0001$ * \\
Error & 80 & 3.9516283 & 0.04940 & & \\
C. Total & 82 & 6.5989407 & & &
\end{tabular}

\section{Connecting Letters Report} Level 3

5

0
A

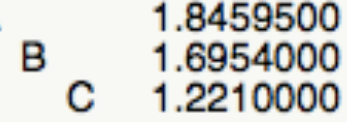


Student 5: 0612GL
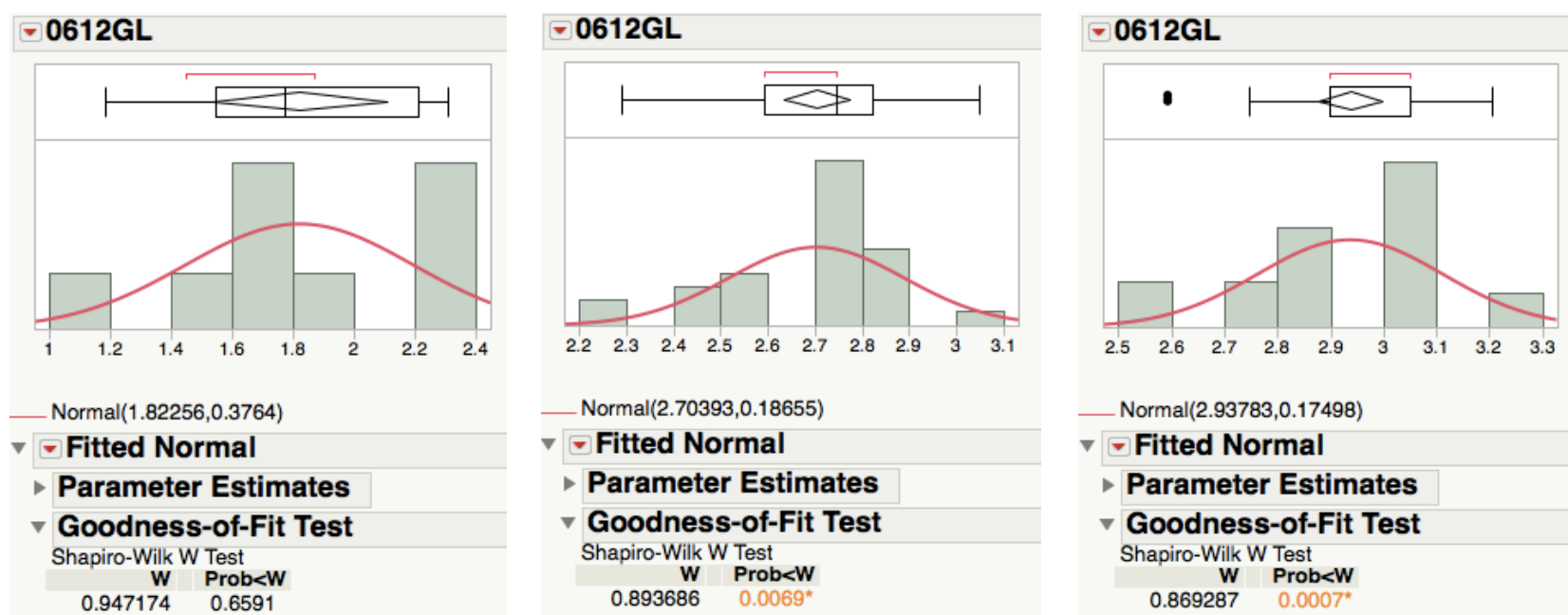

— Normal(2.70393,0.18655)

- Fitted Normal

- Parameter Estimates

$\checkmark$ Goodness-of-Fit Test

Shapiro-Wilk W Test $\begin{array}{rr}\text { W } & \text { Prob }<\mathbf{W} \\ 0.893686 & 0.0069^{*}\end{array}$

\section{— Normal(2.93783,0.17498) \\ v Fitted Normal \\ - Parameter Estimates \\ $\checkmark$ Goodness-of-Fit Test \\ Shapiro-Wilk W Test \\ $\begin{array}{rr}\mathbf{w} & \text { Prob }<\mathbf{W} \\ 0.869287 & 0.0007^{*}\end{array}$}

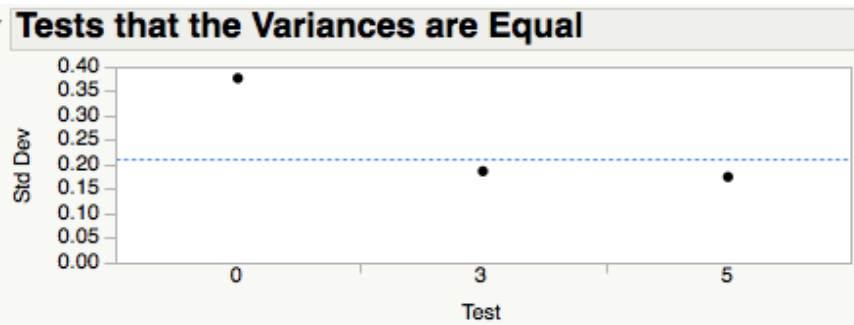

Test

O'Brien[.5]

Brown-Forsythe

Levene

Bartlett

$\begin{array}{rrrr}\text { F Ratio } & \text { DFNum } & \text { DFDen } & \text { Prob }>\text { F } \\ 9.6432 & 2 & 70 & 0.0002^{*} \\ 3.6598 & 2 & 70 & 0.0308^{*} \\ 5.7236 & 2 & 70 & 0.0050^{*} \\ 5.3863 & 2 & . & 0.0046^{*}\end{array}$

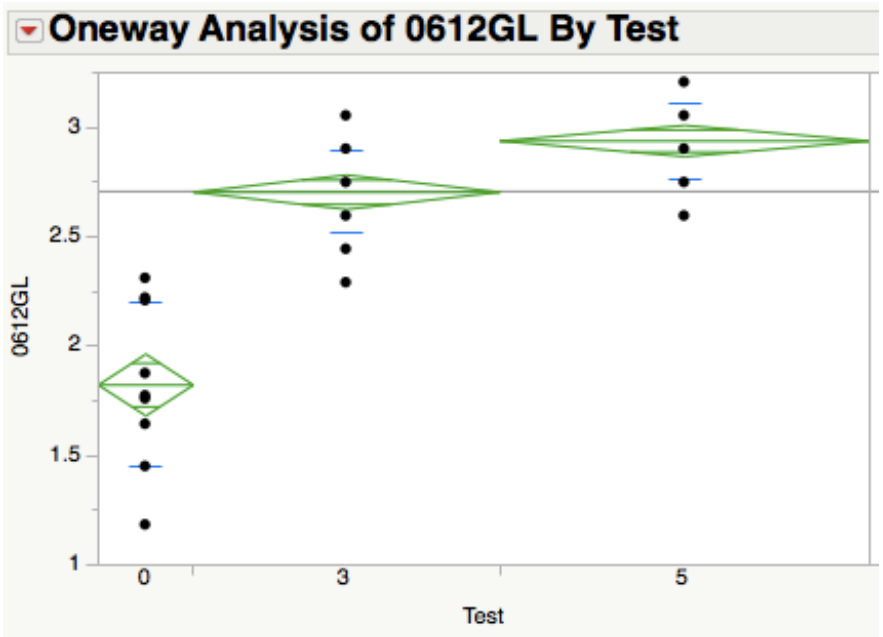

- Analysis of Variance

\begin{tabular}{|l|r|r|r|r|r|}
\hline Source & DF & $\begin{array}{r}\text { Sum of } \\
\text { Squares }\end{array}$ & Mean Square & F Ratio & Prob $>$ F \\
Test & 2 & 8.905303 & 4.45265 & 98.9839 & $<.00011^{*}$ \\
Error & 70 & 3.148851 & 0.04498 & & \\
C. Total & 72 & 12.054154 & & &
\end{tabular}

\section{Connecting Letters Report} Level

A

Mean

5

3

0

B

2.9378286

2.7039310

C $\quad 1.8225556$ 
Student 6: 0612JF
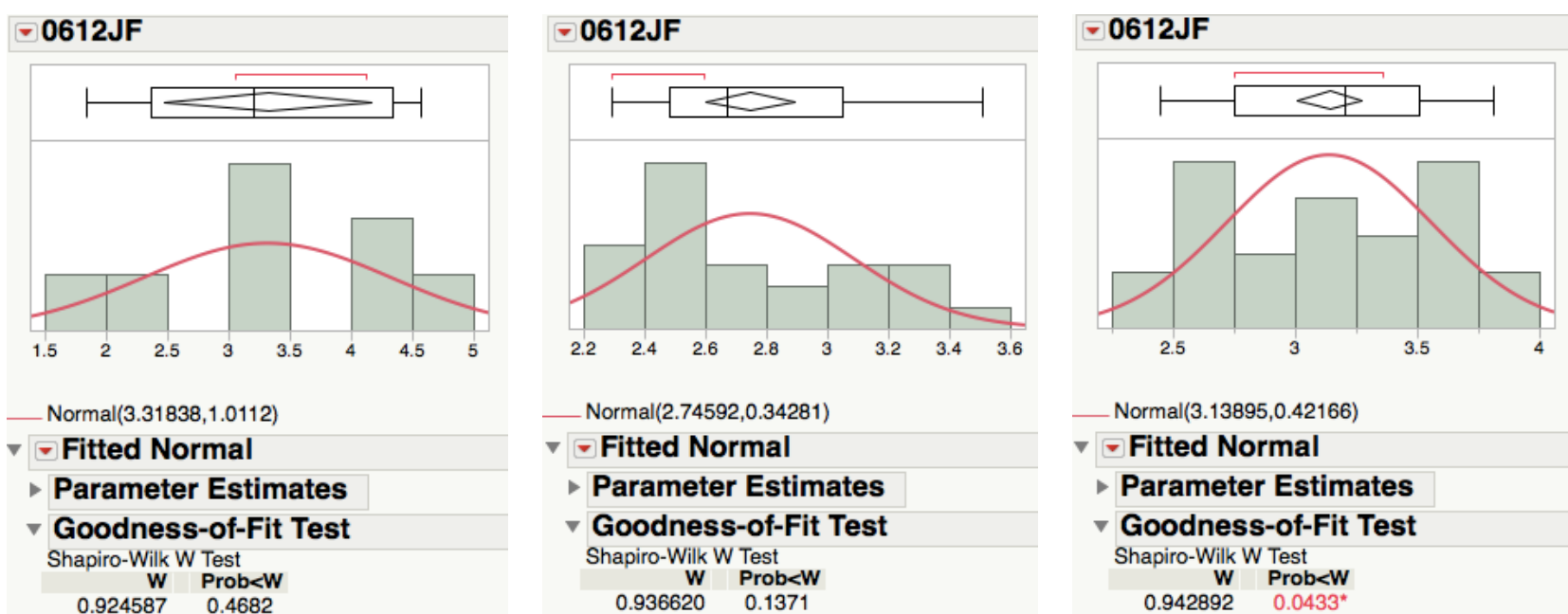
_ $\operatorname{Normal}(3.13895,0.42166)$
- Fitted Normal
- Parameter Estimates
v Goodness-of-Fit Test
Shapiro-Wilk W Test
$0.942892 \quad 0.0433$

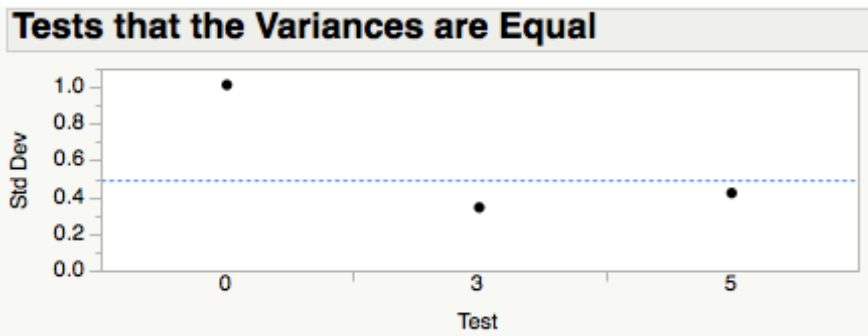

Test

O'Brien[.5]

Brown-Forsythe

Levene

Bartlett
F Ratio 20.8392

9.0753

12.1319

9.1722
DFNum DFDen Prob $>$ F

$269<0001$ "

$2690.0003^{*}$

$269<0001^{*}$
- Oneway Analysis of 0612JF By Test

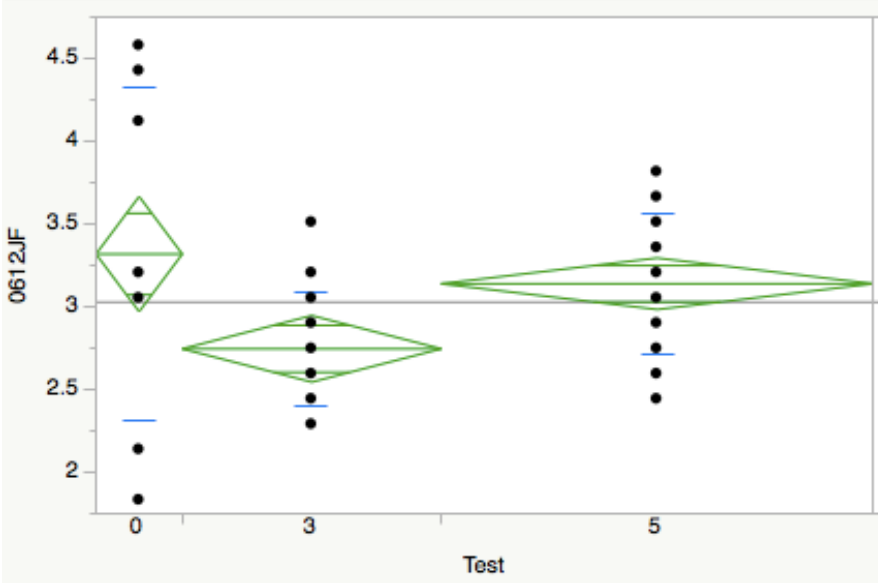

- Analysis of Variance

\begin{tabular}{|c|c|c|c|c|c|}
\hline Source & DF & $\begin{array}{l}\text { Sum of } \\
\text { Squares }\end{array}$ & Mean Square & F Ratio & Prob $>$ F \\
\hline $\begin{array}{l}\text { Test } \\
\text { Error } \\
\text { C. Total }\end{array}$ & $\begin{array}{r}2 \\
69 \\
71\end{array}$ & $\begin{array}{r}3.076640 \\
16.794740 \\
19.871380\end{array}$ & $\begin{array}{l}1.53832 \\
0.24340\end{array}$ & 6.3201 & $0.0030^{*}$ \\
\hline
\end{tabular}

\section{- Connecting Letters Report} Level

0

5

3
A 3.3183

3.3183750

A

(3.1389500

B 2.7459167 
Student 7: 0612JK
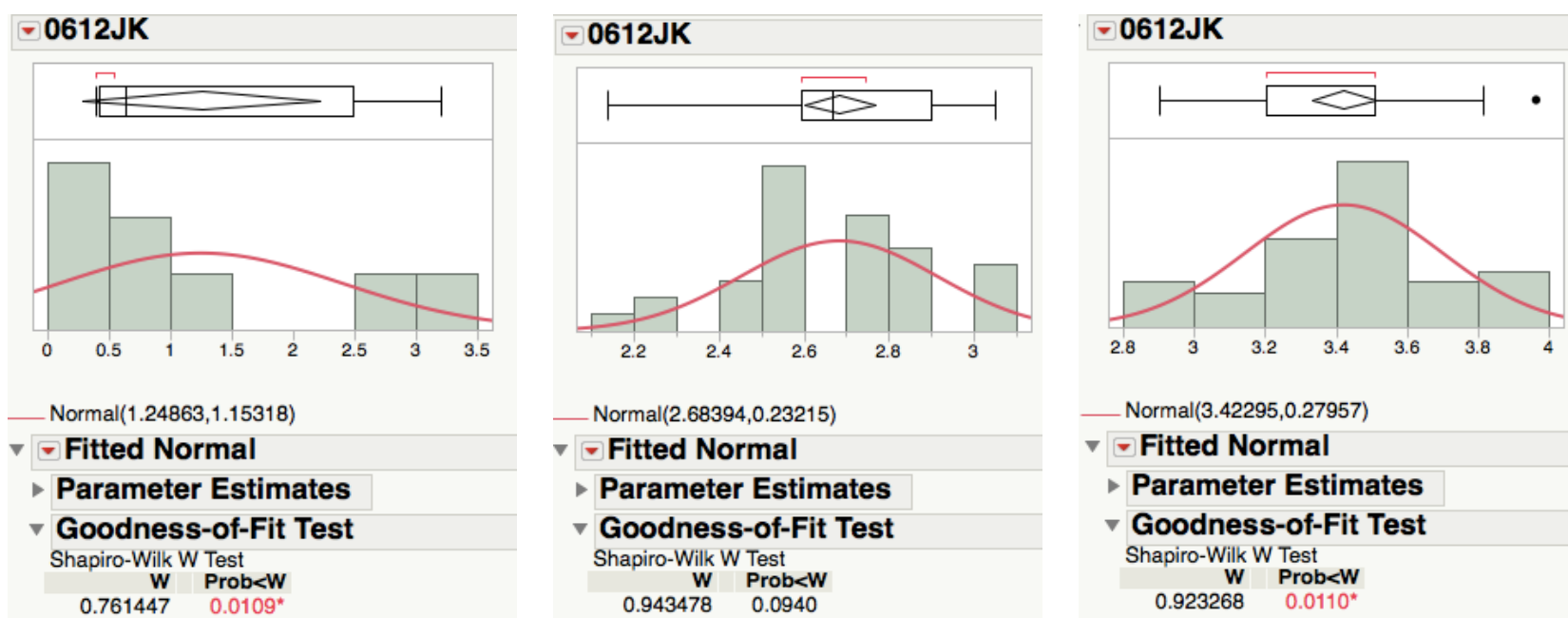

_ Normal(3.42295,0.27957)

- Fitted Normal

- Parameter Estimates

$\checkmark$ Goodness-of-Fit Test

Shapiro-Wilk W Test $\begin{array}{rr}\text { W } & \text { Prob }<W \\ 0.923268 & 0.0110^{*}\end{array}$

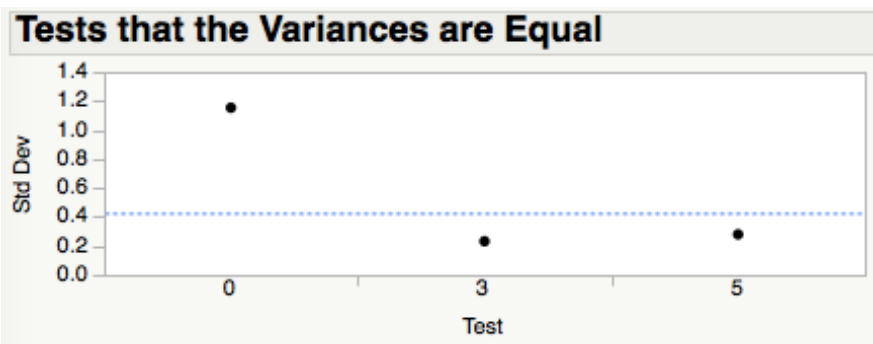

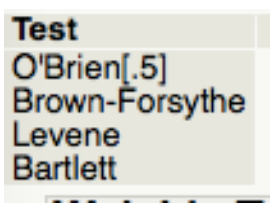

22.6100
10.6867

10.6867

27.4235
DFNum DFDen Prob $>$ F

$\begin{array}{lll}2 & 76 & <.0001^{*} \\ 2 & 76 & <.0001^{*} \\ 2 & 76 & <.0001^{*} \\ 2 & . & <.0001^{*}\end{array}$

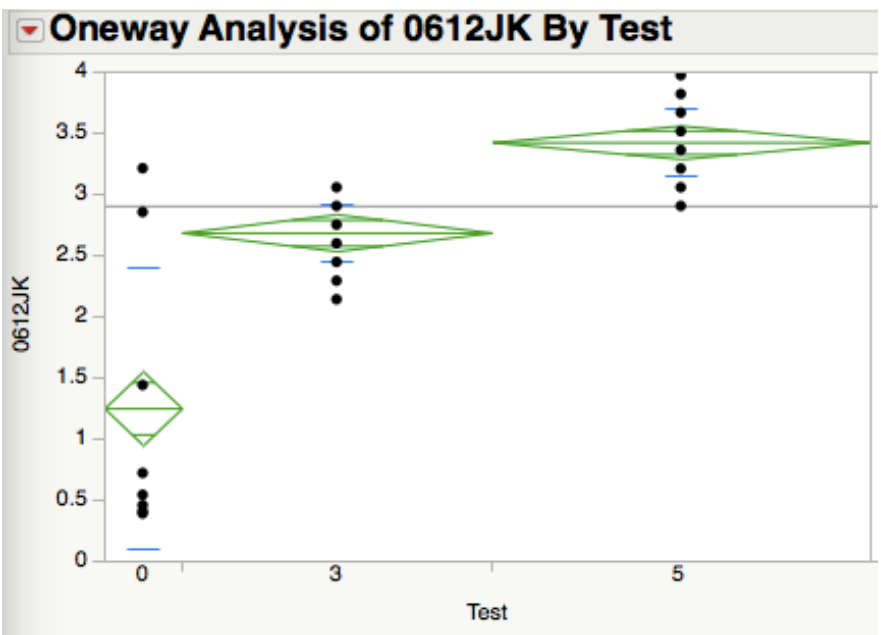

\begin{tabular}{|l|r|r|r|r|r|}
\multicolumn{6}{|l|}{ Analysis of Variance } \\
Sum of & & & \\
\hline Source & DF & $\begin{array}{r}\text { Squares } \\
\text { Mean Square }\end{array}$ & F Ratio & Prob > F \\
\hline Test & 2 & 33.974788 & 16.9874 & 92.5501 & $<.0001$ * \\
Error & 76 & 13.949648 & 0.1835 & & \\
C. Total & 78 & 47.924435 & & & \\
\hline
\end{tabular}

Connecting Letters Report

Level

5 A

3

0

\section{Mean}

A

3.4229487

B $\quad 2.6839375$

C 1.2486250 
Student 8: 0612JL
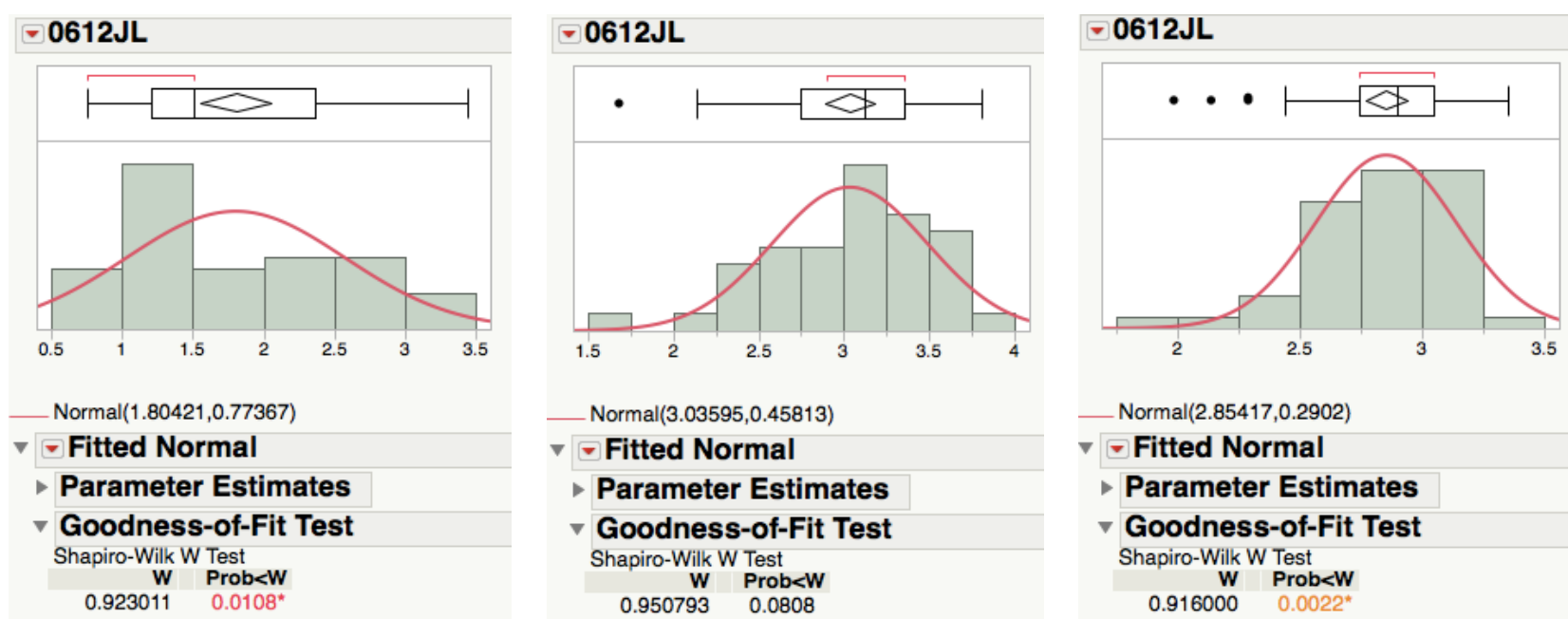

_ Normal(3.03595,0.45813)

$\checkmark$ Fitted Normal

- Parameter Estimates

voodness-of-Fit Test

Shapiro-Wilk W Test

$\begin{array}{rc}\text { W } & \text { Prob }<\text { W } \\ 0.950793 & 0.0808\end{array}$

Normal(2.85417,0.2902)

$\checkmark$ Fitted Normal

- Parameter Estimates

$\checkmark$ Goodness-of-Fit Test

Shapiro-Wilk W Test

$0.916000 \quad 0.0022^{*}$

\section{Tests that the Variances are Equal}

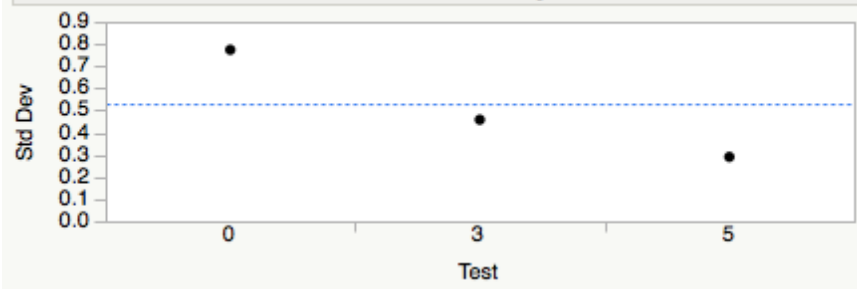

Test

O'Brien[.5]

Brown-Forsythe

Levene

Bartlett
F Ratio

19.0902

16.3001

29.4576

19.5081
DFNum DFDen Prob $>$ F

$2124<.0001$

$2124<0001 *$

$2124<.0001^{*}$
- Oneway Analysis of 0612JL By Test

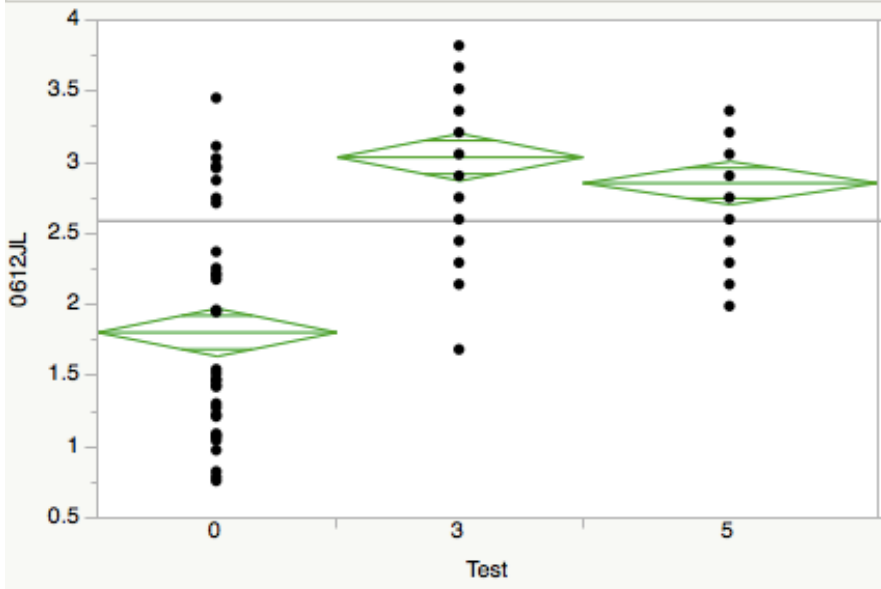

Analysis of Variance

\begin{tabular}{|l|r|r|r|r|r|}
\hline Source & DF & $\begin{array}{r}\text { Sum of } \\
\text { Squares }\end{array}$ & Mean Square & F Ratio & Prob $>$ F \\
\hline Test & 2 & 35.385830 & 17.6929 & 62.8834 & $<.00011^{*}$ \\
Error & 124 & 34.888725 & 0.2814 & & \\
C. Total & 126 & 70.274555 & & & \\
\hline-- & - & - & - & &
\end{tabular}

\section{Connecting Letters Report} Level
A
3.0359500
A $\quad 2.8541667$
B 1.8042051

5 
Student 9: 0612KV
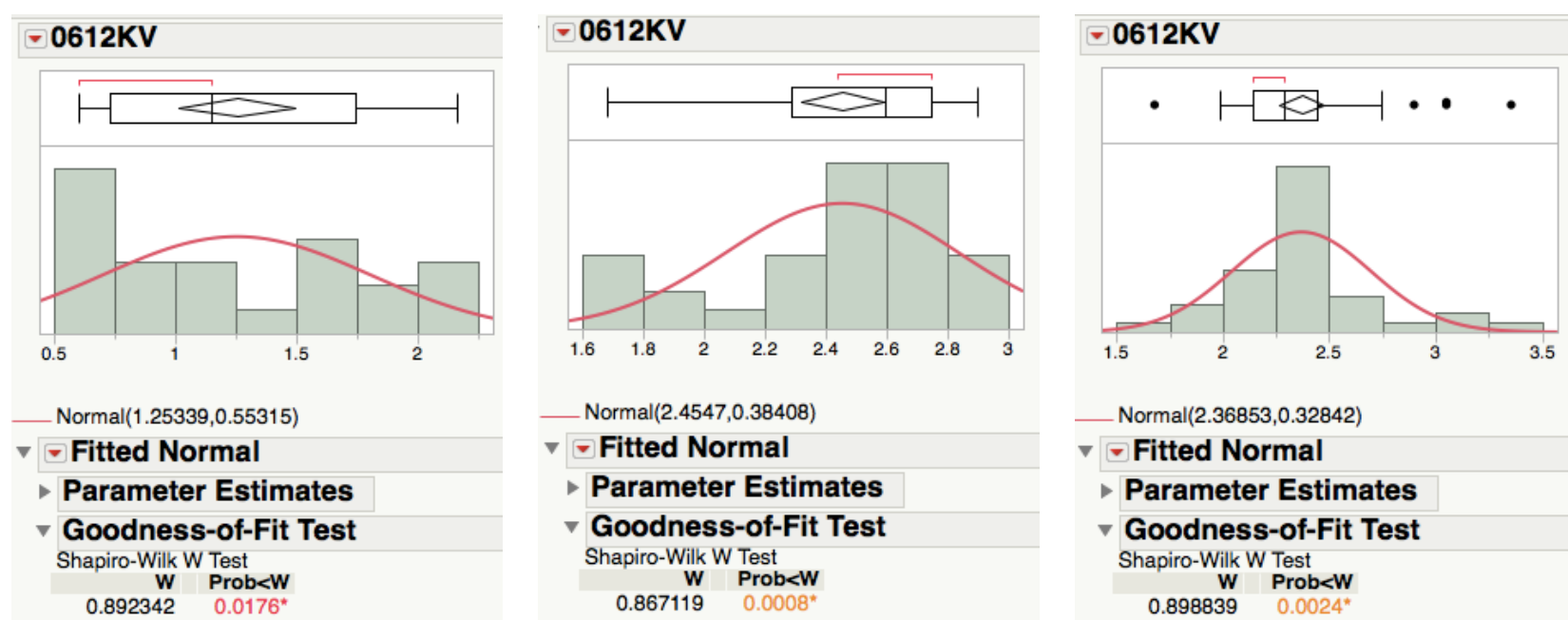

_ Normal(2.36853,0.32842)

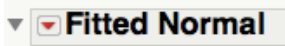

- Parameter Estimates

v Goodness-of-Fit Test

Shapiro-Wilk W Test

$\begin{array}{rr}\text { W } & \text { Prob }<\text { W } \\ 0.898839 & 0.0024^{*}\end{array}$

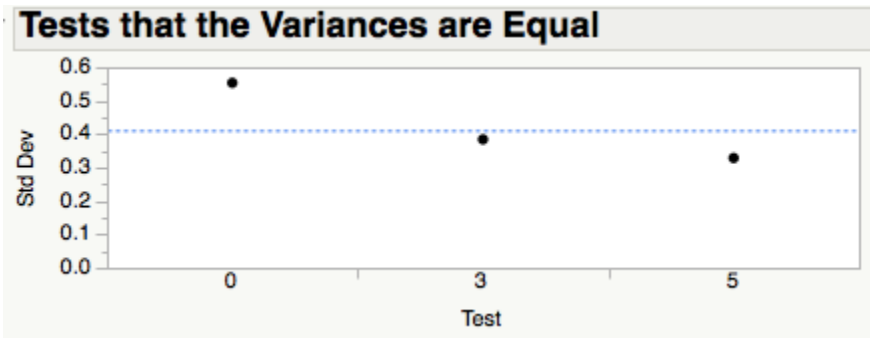

\begin{tabular}{l|rrrr|}
\hline Test & F Ratio & DFNum & DFDen & Prob > F \\
\hline O'Brien[.5] & 6.5092 & 2 & 91 & $0.0023^{*}$ \\
Brown-Forsythe & 7.1101 & 2 & 91 & $0.0014^{*}$ \\
\hline Levene & 9.2530 & 2 & 91 & $0.0002^{*}$ \\
Bartlett & 4.0788 & 2 &. & $0.0169^{*}$ \\
\hline
\end{tabular}

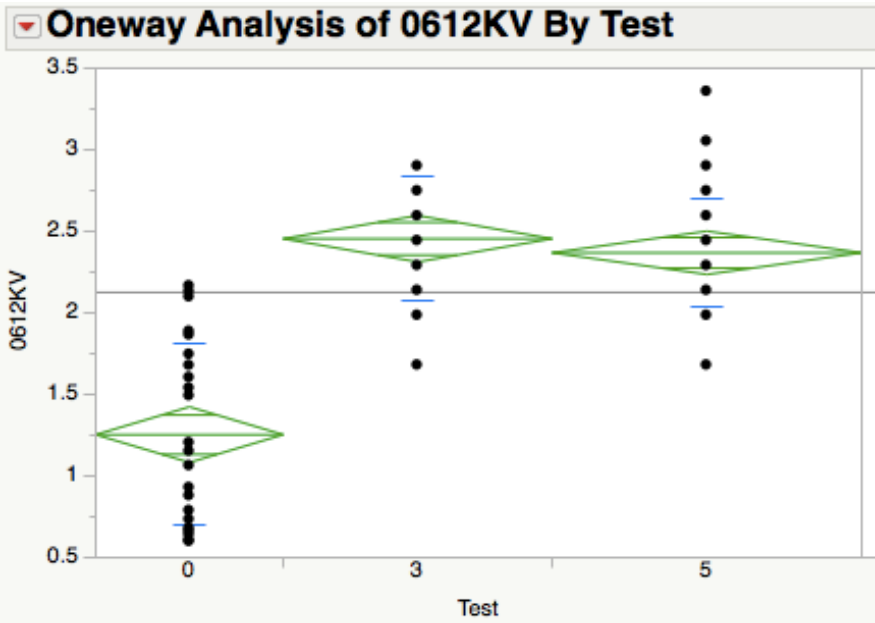

\begin{tabular}{|c|c|c|c|c|c|}
\hline \multicolumn{6}{|c|}{ Analysis of Variance } \\
\hline ource & DF & $\begin{array}{r}\text { Sum of } \\
\text { Squares }\end{array}$ & Mean Square & F Ratio & Prob $>$ F \\
\hline $\begin{array}{l}\text { Test } \\
\text { Error } \\
\text { C. Total }\end{array}$ & $\begin{array}{r}2 \\
91 \\
93\end{array}$ & $\begin{array}{l}23.313755 \\
15.442740 \\
38.756494\end{array}$ & $\begin{array}{r}11.6569 \\
0.1697\end{array}$ & 68.6909 & $<.0001^{*}$ \\
\hline
\end{tabular}

\section{r Connecting Letters Report Level}

$\begin{array}{llll}3 & & \text { A } & 2.4546970 \\ 5 & & \text { A } & 2.3685263 \\ 0 & & & \text { B } \\ 1.2533913\end{array}$


Student 10: 0612NB
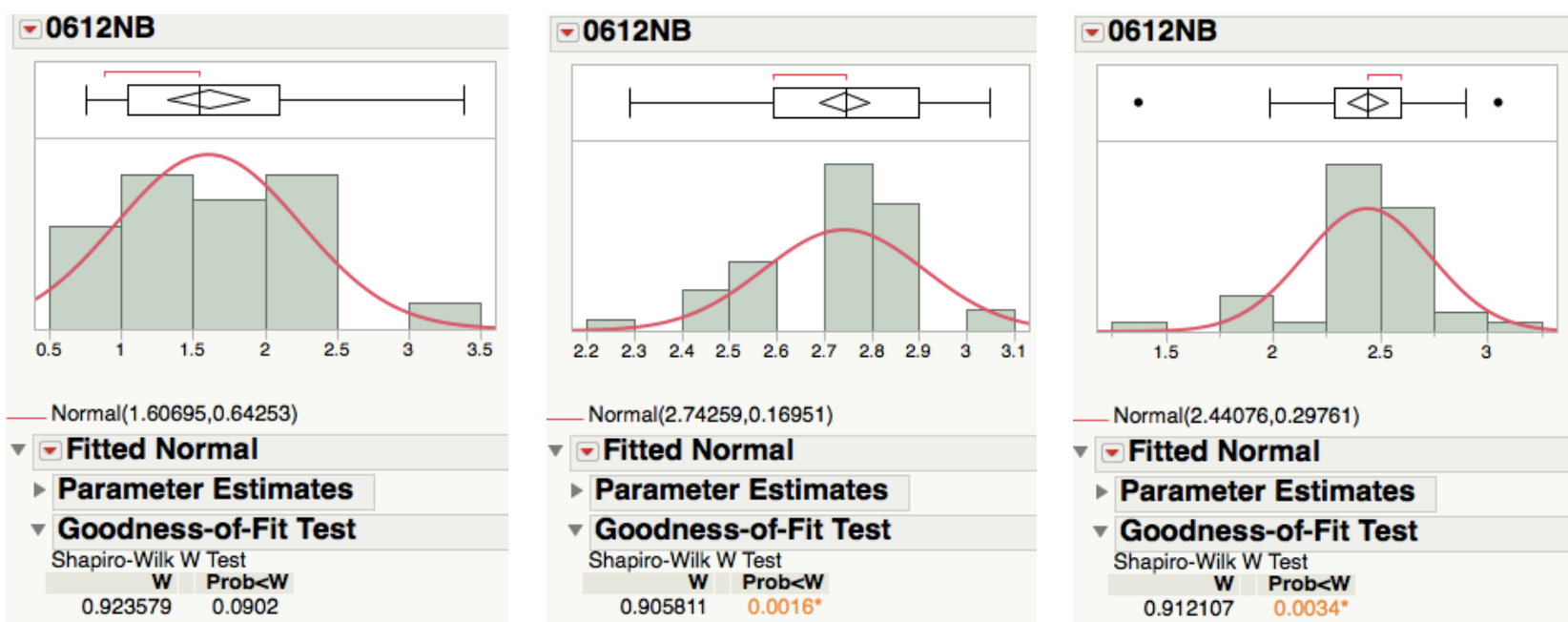

_ Normal(2.74259,0.16951)

- Fitted Normal

- Parameter Estimates

$\checkmark$ Goodness-of-Fit Test

Shapiro-Wilk W Test

$\begin{array}{rr}\text { W } & \text { Prob<W } \\ 0.905811 & 0.0016 *\end{array}$
— Normal(2.44076,0.29761)
- Fitted Normal
- Parameter Estimates
v Goodness-of-Fit Test
Shapiro-Wilk W Test
W
0.912107

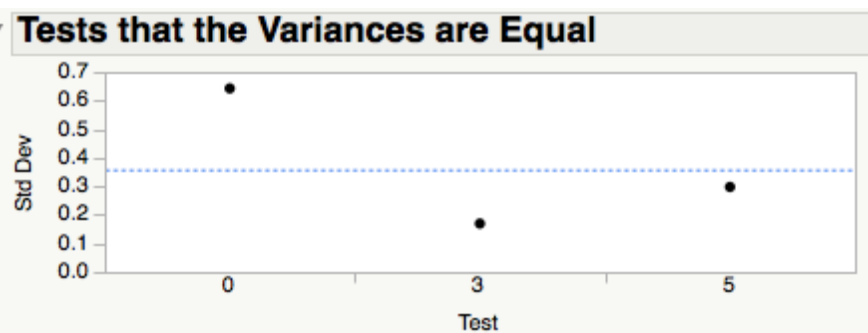

Test

O'Brien[.5]

Brown-Forsythe

Levene

Bartlett

$\begin{array}{rrrr}\text { F Ratio } & \text { DFNum } & \text { DFDen } & \text { Prob }>\text { F } \\ 9.8866 & 2 & 105 & 0.0001^{*} \\ 18.9274 & 2 & 105 & <.0001^{*} \\ 20.7261 & 2 & 105 & <.0001^{*} \\ 27.3582 & 2 & . & <.0001^{*}\end{array}$

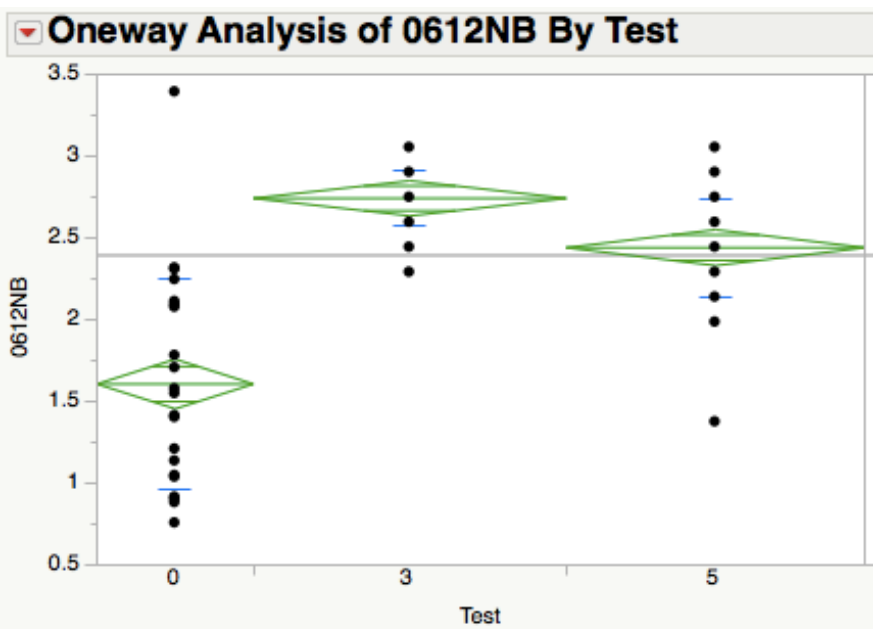

\section{Analysis of Variance}

Source

Test

Error

C. Total

$\begin{array}{rr}\text { DF } & \begin{array}{r}\text { Sum of } \\ \text { Squares }\end{array} \\ 2 & 19.066218 \\ 105 & 13.53675 \\ 107 & 32.602969\end{array}$

Mean Square

9.53311 0.12892

F Ratio Prob > F

$73.9451<.0001 *$

\section{Connecting Letters Report Level \\ Mean \\ 3 \\ 5 \\ 0
A
2.7425909
B $\quad 2.4407619$ \\ C 1.6069545 ,}


Student 11: 0162PF
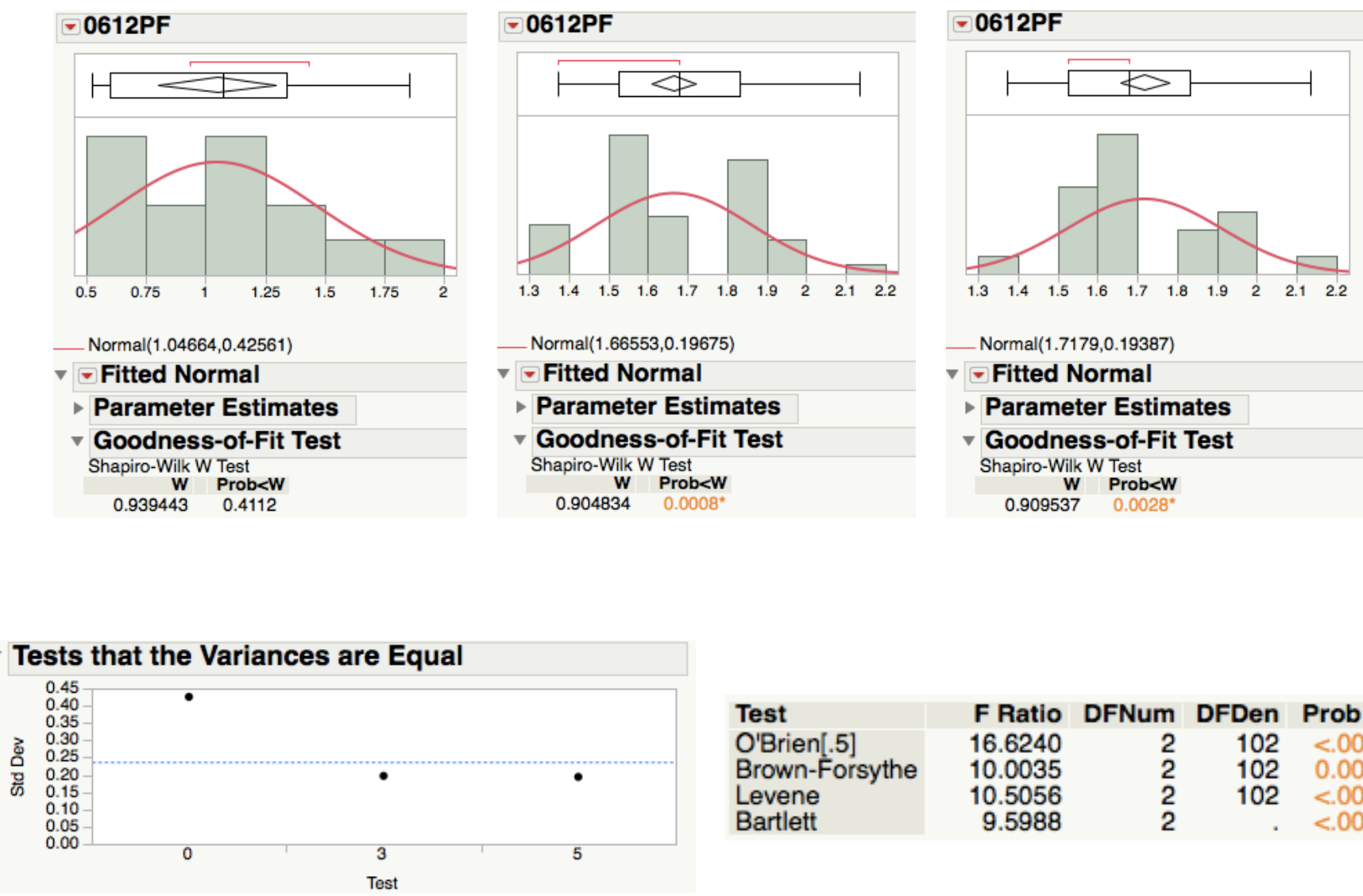

Test

O'Brien[.5]

Brown-Forsythe

Levene

Bartlett

$\begin{array}{rrrr}\text { F Ratio } & \text { DFNum } & \text { DFDen } & \text { Prob }>\text { F } \\ 16.6240 & 2 & 102 & <.0001^{*} \\ 10.0035 & 2 & 102 & 0.0001^{*} \\ 10.5056 & 2 & 102 & <.0001^{*} \\ 9.5988 & 2 & . & <.0001^{*}\end{array}$

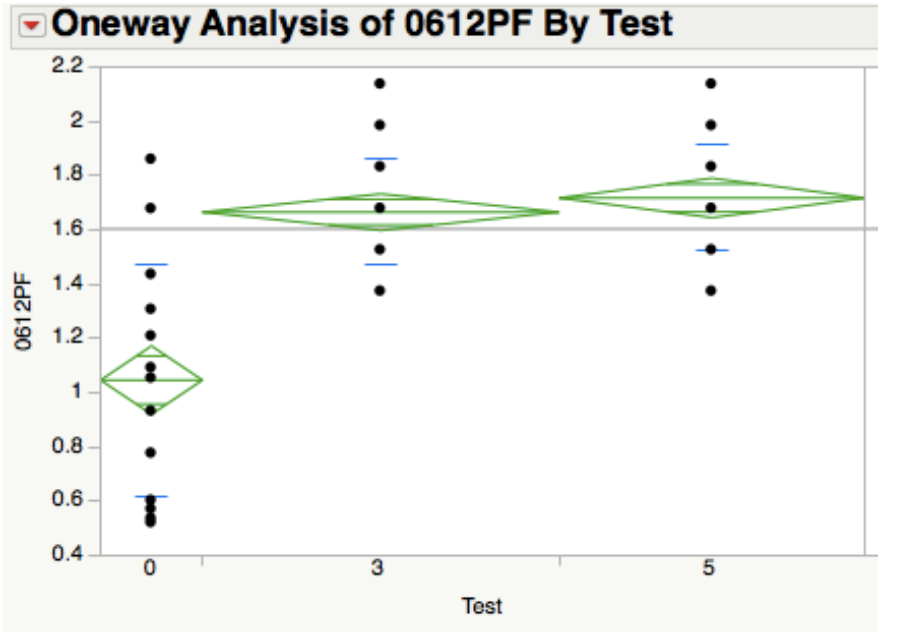

\begin{tabular}{|c|c|c|c|c|c|}
\hline \multicolumn{6}{|c|}{ Analysis of Variance } \\
\hline $\begin{array}{l}\text { Source } \\
\text { Test } \\
\text { Error }\end{array}$ & $\begin{array}{r}\text { DF } \\
2 \\
102\end{array}$ & $\begin{array}{r}\text { Sum of } \\
\text { Squares } \\
5.079493 \\
5.753907\end{array}$ & $\begin{array}{r}\text { Mean Square } \\
2.53975 \\
0.05641\end{array}$ & $\begin{array}{l}\text { F Ratio } \\
45.0223\end{array}$ & $\begin{array}{r}\text { Prob }>\mathbf{F} \\
<.0001^{*}\end{array}$ \\
\hline $\begin{array}{l}\text { Error } \\
\text { C. Tot }\end{array}$ & $\begin{array}{l}102 \\
104\end{array}$ & 10.833400 & & & \\
\hline
\end{tabular}

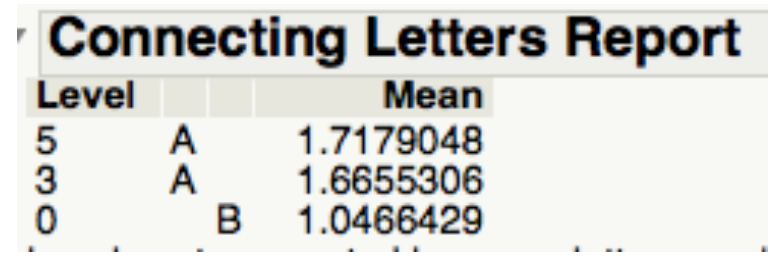


Student 12: 0612RK
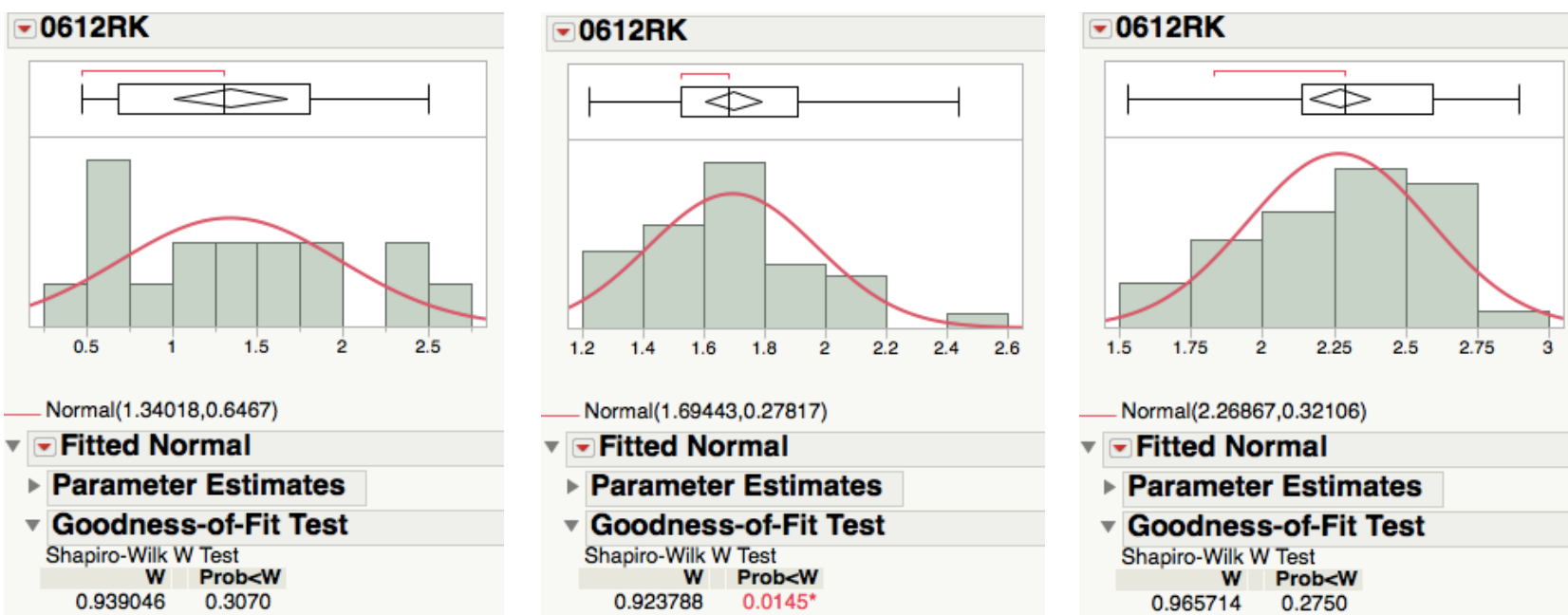

_ Normal(2.26867,0.32106)

v Fitted Normal

- Parameter Estimates

v Goodness-of-Fit Test

Shapiro-Wilk W Test

$\begin{array}{rc}\text { W } & \text { Prob }<\text { W } \\ 0.965714 & 0.2750\end{array}$

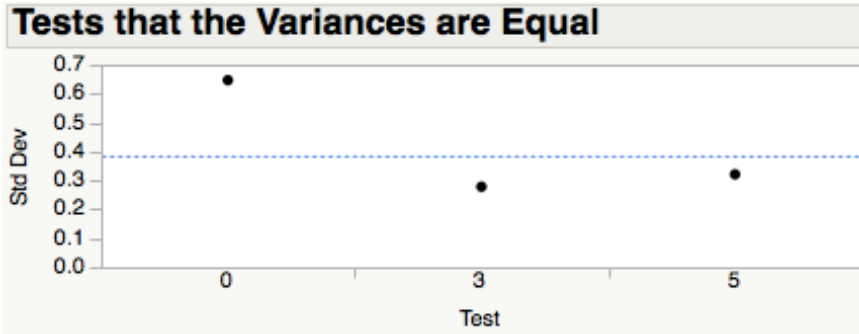

Test

O'Brien[.5]

Brown-Forsythe Levene Bartlett
F Ratio

16.4769

13.4191

13.8024

10.3037
DFNum DFDen Prob $>$ F

$290<0001$ "

$290<0001$

$90<0001$
- Oneway Analysis of 0612RK By Test

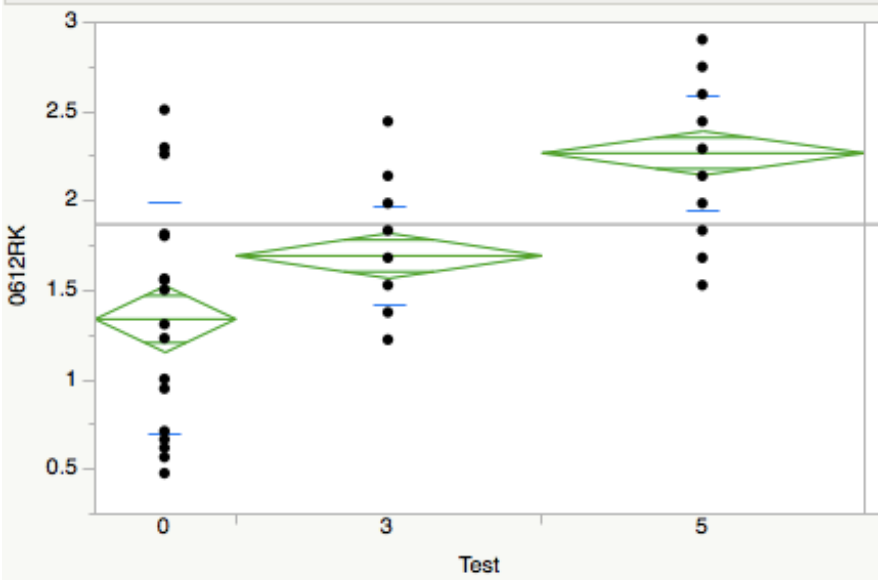

Analysis of Variance

\begin{tabular}{|l|r|r|r|r|r|}
\hline Source & DF & $\begin{array}{r}\text { Sum of } \\
\text { Squares }\end{array}$ & Mean Square & F Ratio & Prob $>$ F \\
Test & 2 & 12.111055 & 6.05553 & 40.6889 & $<.0001$ * \\
Error & 90 & 13.394248 & 0.14882 & & \\
C. Total & 92 & 25.505303 & & &
\end{tabular}

Connecting Letters Report Level Mean

5

3

0

A

1.6944324
C $\quad 1.3401765$ 
Student 13: 0612SS
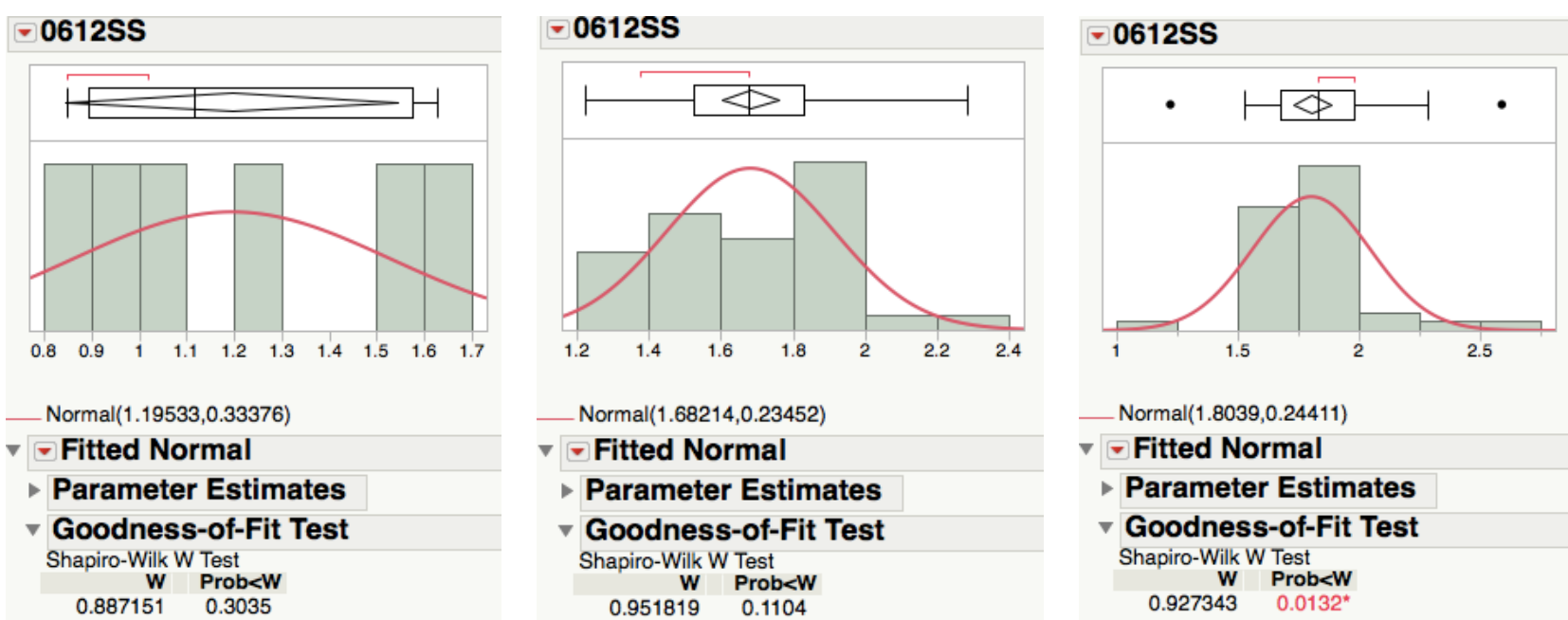

_ Normal(1.8039,0.24411)

$\checkmark$ Fitted Normal

- Parameter Estimates

- Goodness-of-Fit Test

Shapiro-Wilk W Test

$\begin{array}{rr}\text { W } & \text { Prob }<W \\ 0.927343 & 0.0132^{*}\end{array}$

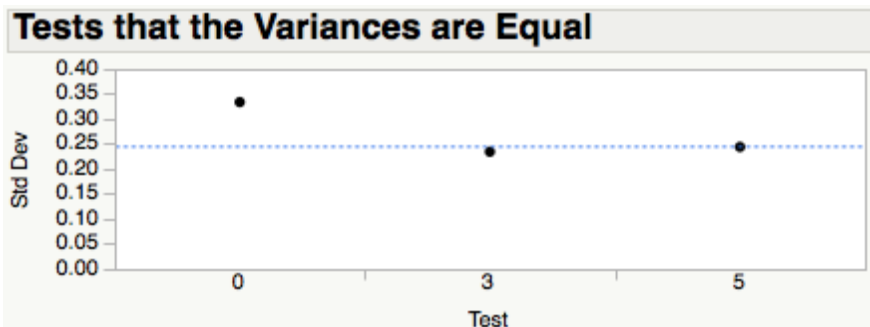

Test

O'Brien[.5]

Brown-Forsythe

Levene

Bartlett

$\begin{array}{rrrc}\text { F Ratio } & \text { DFNum } & \text { DFDen } & \text { Prob > F } \\ 0.8346 & 2 & 80 & 0.4378 \\ 1.0188 & 2 & 80 & 0.3657 \\ 0.9900 & 2 & 80 & 0.3761 \\ 0.6328 & 2 & & 0.5311\end{array}$

\section{- Oneway Analysis of 0612SS By Test}

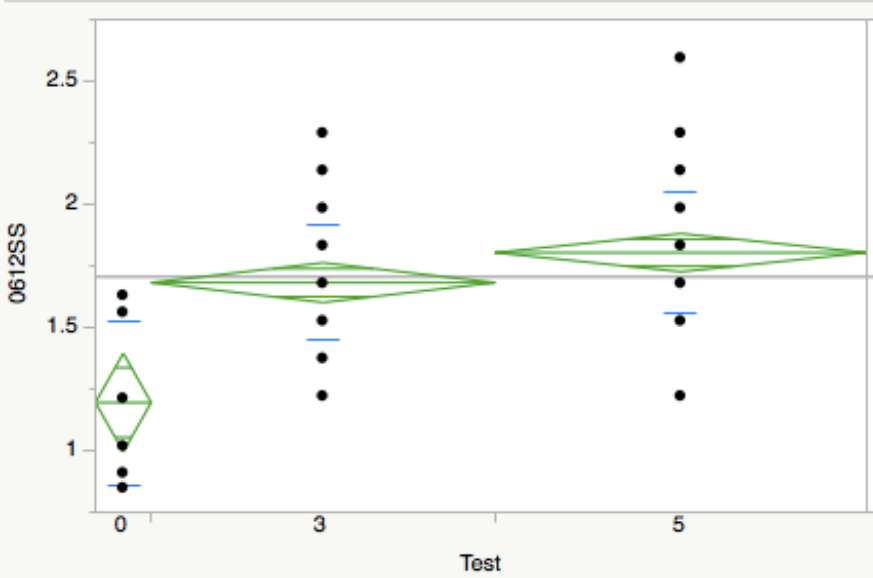

- Analysis of Variance

\begin{tabular}{l|r|r|r|r|r|}
\hline Source & DF & $\begin{array}{r}\text { Sum of } \\
\text { Squares }\end{array}$ & Mean Square & F Ratio & Prob $>$ F \\
\hline Test & 2 & 1.9691202 & 0.984560 & 16.2038 & $<.0001$ * \\
Error & 80 & 4.8608993 & 0.060761 & & \\
C. Total & 82 & 6.8300194 & & &
\end{tabular}

\section{Connecting Letters Report}

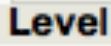

$$
\text { Mean }
$$

5

3

A

1.8039000

A

1.6821351

0

B 1.1953333 
Student 14: 0613JL
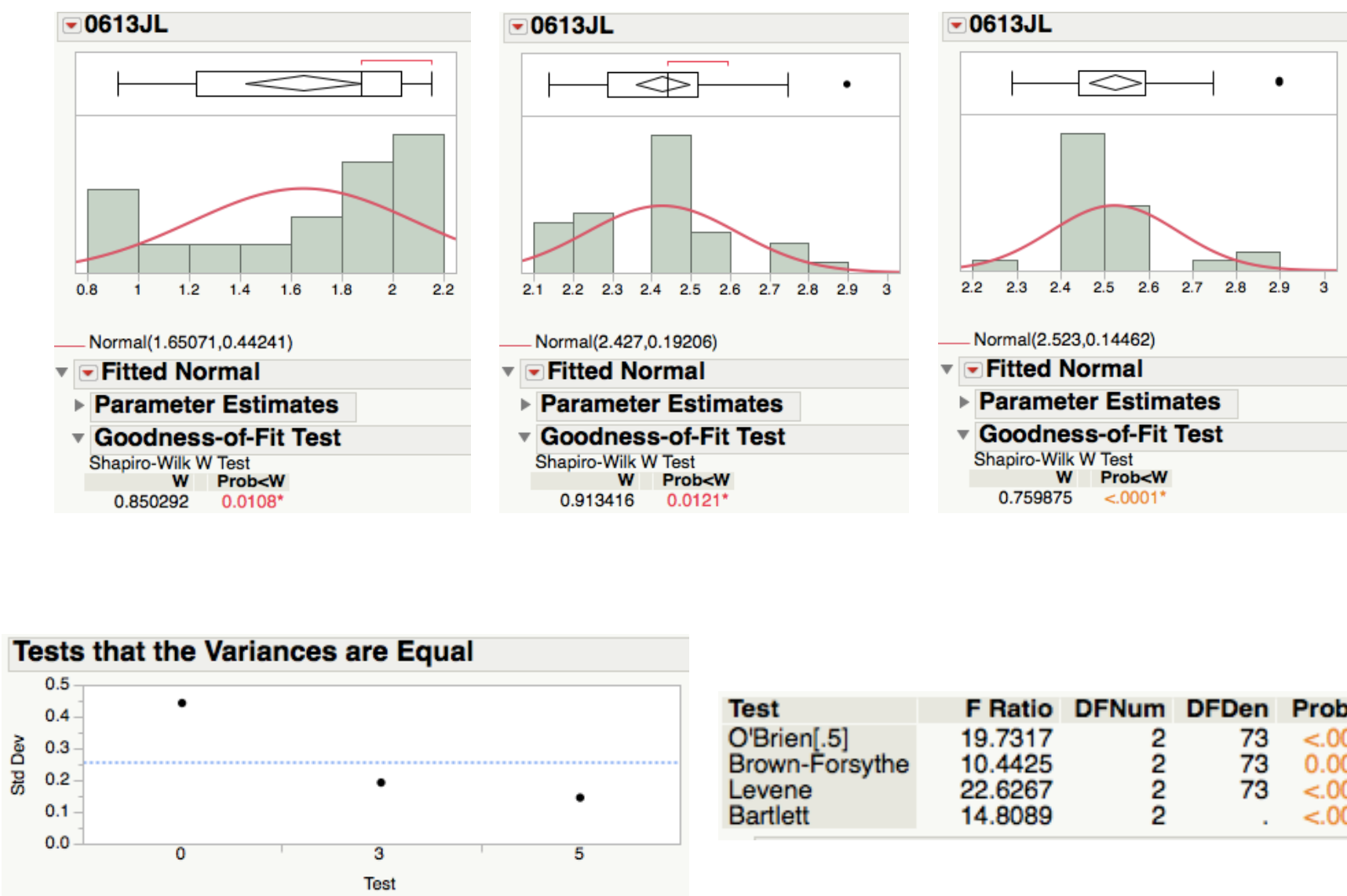

Test
O'Brien[.5]
Brown-Forsythe
Levene
Bartlett

Oneway Analysis of 0613JL By Test

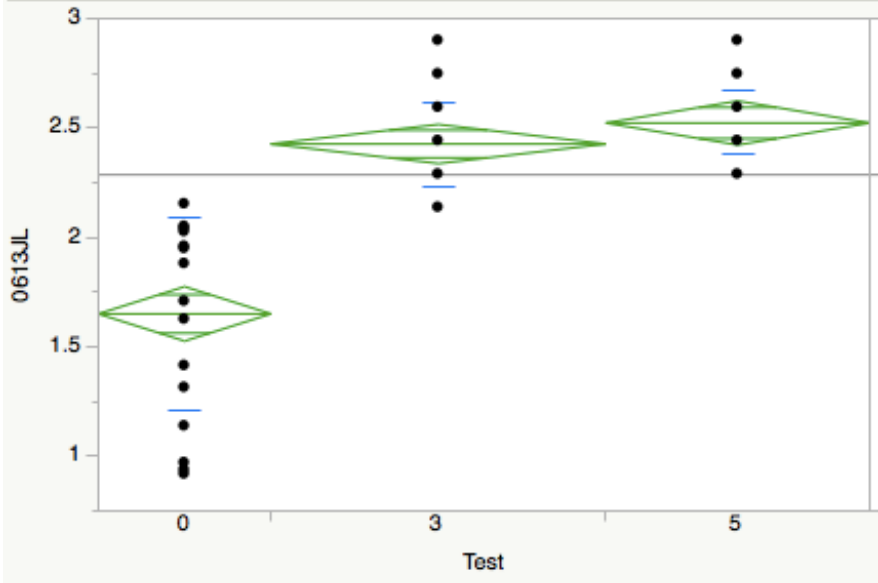

Analysis of Variance

\begin{tabular}{|c|c|c|c|c|c|}
\hline Source & DF & $\begin{array}{l}\text { Sum of } \\
\text { Squares }\end{array}$ & Mean Square & F Ratio & Prob $>$ F \\
\hline $\begin{array}{l}\text { Test } \\
\text { Error } \\
\text { C. Total }\end{array}$ & $\begin{array}{r}2 \\
73 \\
75\end{array}$ & $\begin{array}{r}8.977641 \\
4.834892 \\
13.812532\end{array}$ & $\begin{array}{r}4.48882 \\
0.06623\end{array}$ & 67.7748 & $<.0001^{*}$ \\
\hline
\end{tabular}

\section{- Connecting Letters Report} Level

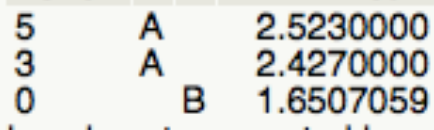


Student 15: 0613JS
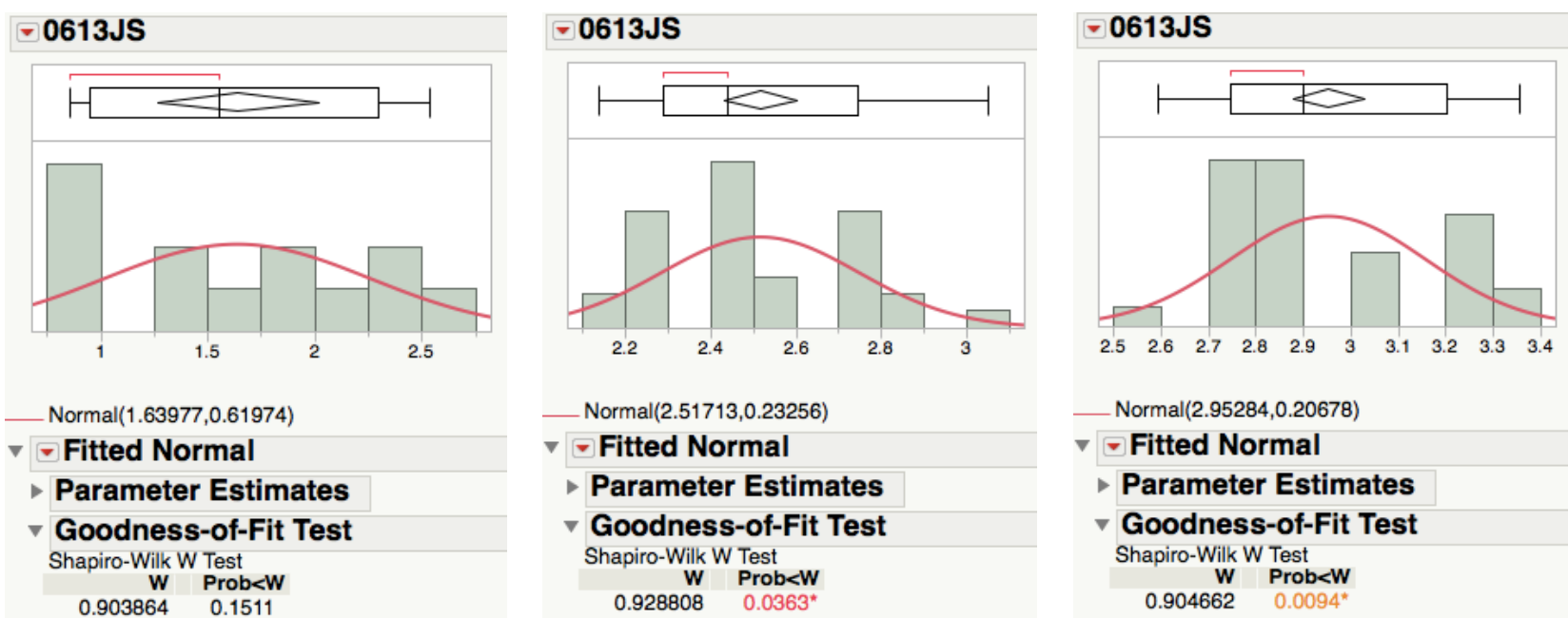

Normal(2.95284,0.20678)

- Fitted Normal

- Parameter Estimates

$\checkmark$ Goodness-of-Fit Test

Shapiro-Wilk W Test

$\begin{array}{rr}\text { W } & \text { Prob }<W \\ 0.904662 & 0.0094^{\prime \prime}\end{array}$

\section{Tests that the Variances are Equal}

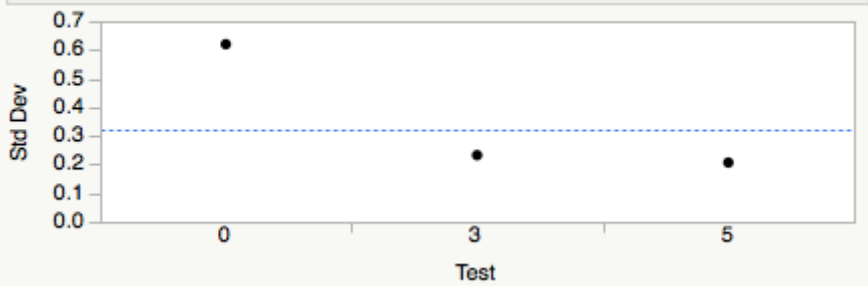

Test
O'Brien[.5]
Brown-Forsythe
Levene
Bartlett

$\begin{array}{rrrr}\text { F Ratio } & \text { DFNum } & \text { DFDen } & \text { Prob }>\text { F } \\ 31.8002 & 2 & 73 & <.0001^{*} \\ 18.8298 & 2 & 73 & <.0001^{*} \\ 26.1257 & 2 & 73 & <.0001^{*} \\ 15.1724 & 2 & . & <.0001^{*}\end{array}$

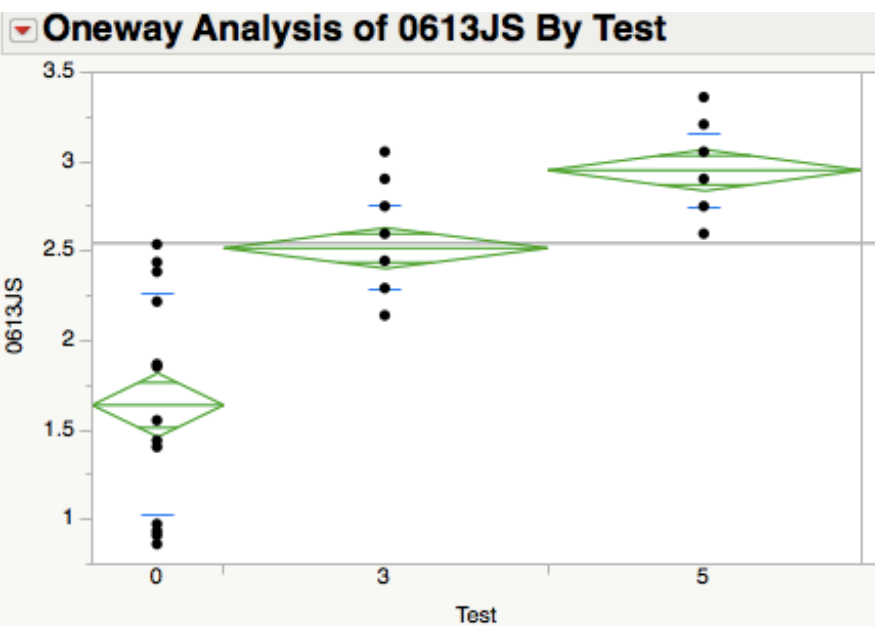
Analysis of Variance

\begin{tabular}{|l|r|r|r|r|r|}
\hline Source & DF & $\begin{array}{r}\text { Squ of } \\
\text { Squares }\end{array}$ & Mean Square & F Ratio & Prob > F \\
\hline Test & 2 & 15.833921 & 7.91696 & 76.3639 & $<.0001$ * \\
Error & 73 & 7.568214 & 0.10367 & & \\
C. Total & 75 & 23.402135 & & &
\end{tabular}

\section{Level 5 A 3 0

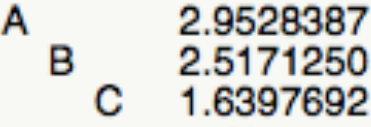

Connecting Letters Report 
Student 16: 0613MB
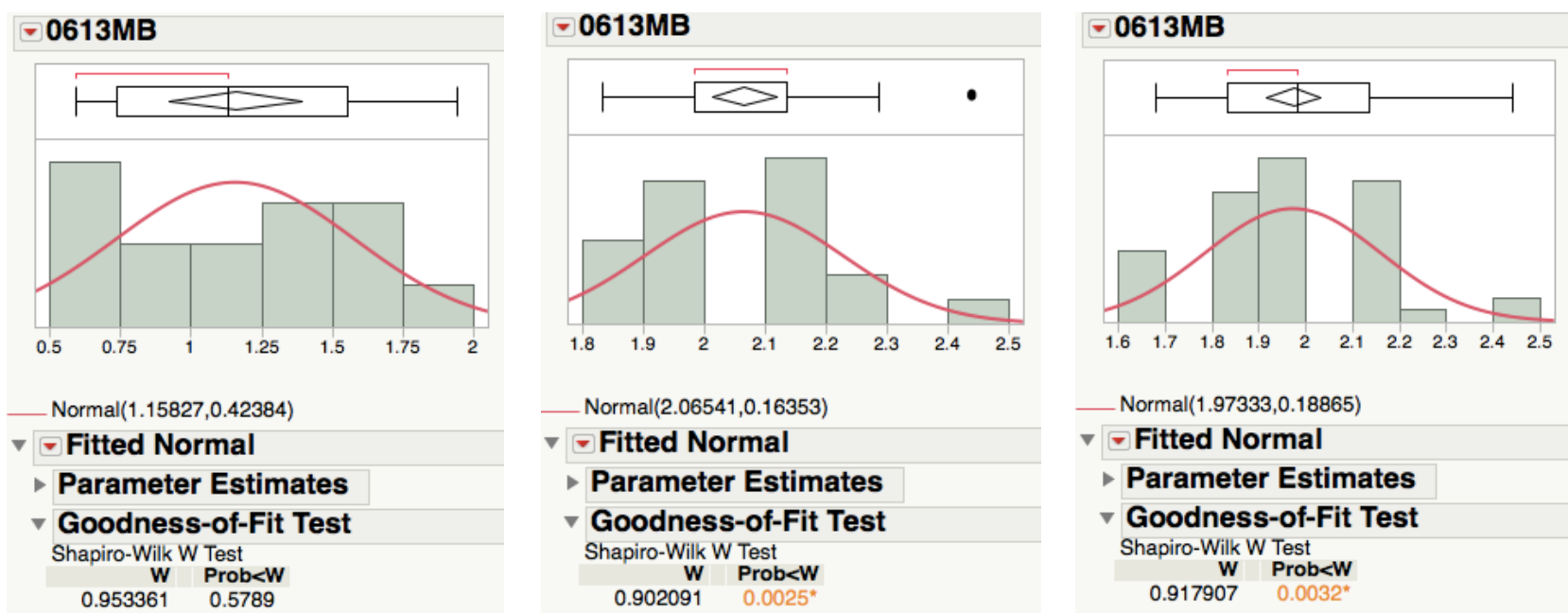

Normal(1.97333,0.18865)

- Fitted Normal

- Parameter Estimates

- Goodness-of-Fit Test

Shapiro-Wilk W Test $\begin{array}{rr}\text { W } & \text { Prob<W } \\ 0.917907 & 0.0032^{*}\end{array}$

\section{Tests that the Variances are Equal}

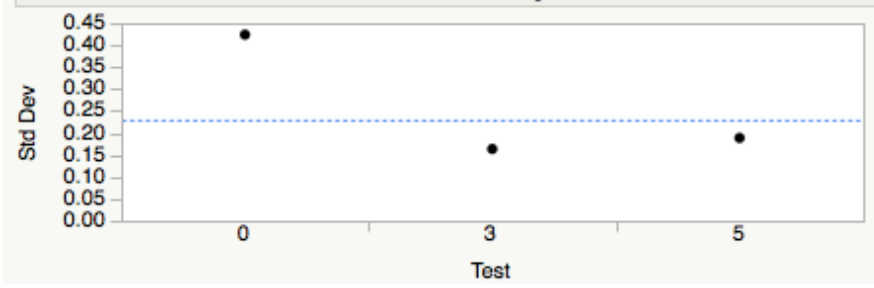

Test

O'Brien[.5]

Brown-Forsythe Levene Bartlett
F Ratio 20.5078

14.3113

16.6897

13.0952
DFNum DFDen Prob $>F$

$\begin{array}{rrr}\text { m } & \text { DFDen } & \text { Prob > F } \\ 2 & 97 & <.0001^{*} \\ 2 & 97 & <.0001^{*} \\ 2 & 97 & <.0001^{*} \\ 2 & & .0001^{*}\end{array}$

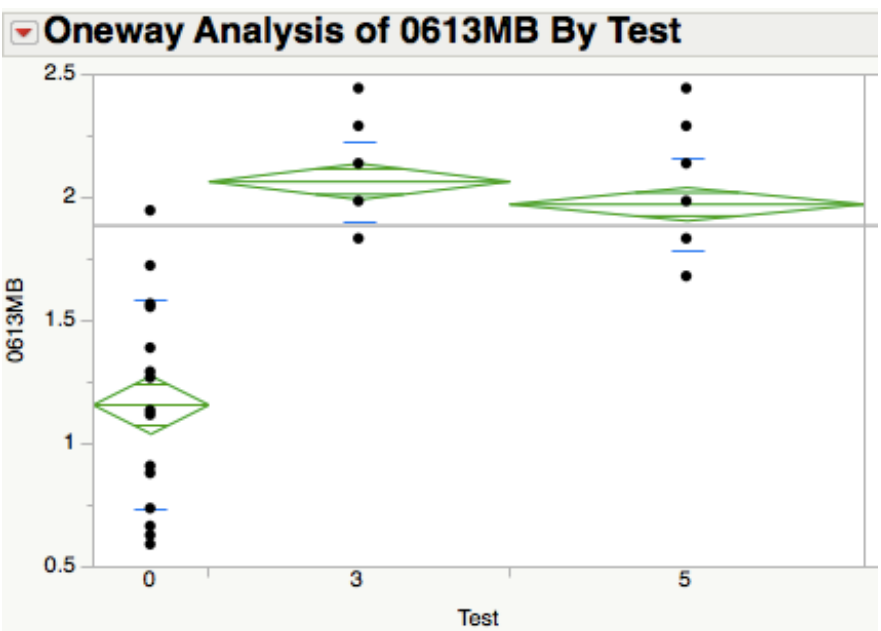

\begin{tabular}{|c|c|c|c|c|c|}
\hline \multicolumn{6}{|c|}{ Analysis of Variance } \\
\hline Source & DF & $\begin{array}{r}\text { Sum of } \\
\text { Squares }\end{array}$ & Mean Square & F Ratio & Prob $>F$ \\
\hline $\begin{array}{l}\text { Test } \\
\text { Error } \\
\text { C. Total }\end{array}$ & $\begin{array}{r}2 \\
97 \\
99\end{array}$ & $\begin{array}{r}9.549963 \\
5.132634 \\
14.682598\end{array}$ & $\begin{array}{l}4.77498 \\
0.05291\end{array}$ & 90.2408 & $<.0001^{*}$ \\
\hline
\end{tabular}

\section{Connecting Letters Report} Level

3

5

A

Mean

2.0654103

0

A

B 1.1582667 
Student 17: 0613MP
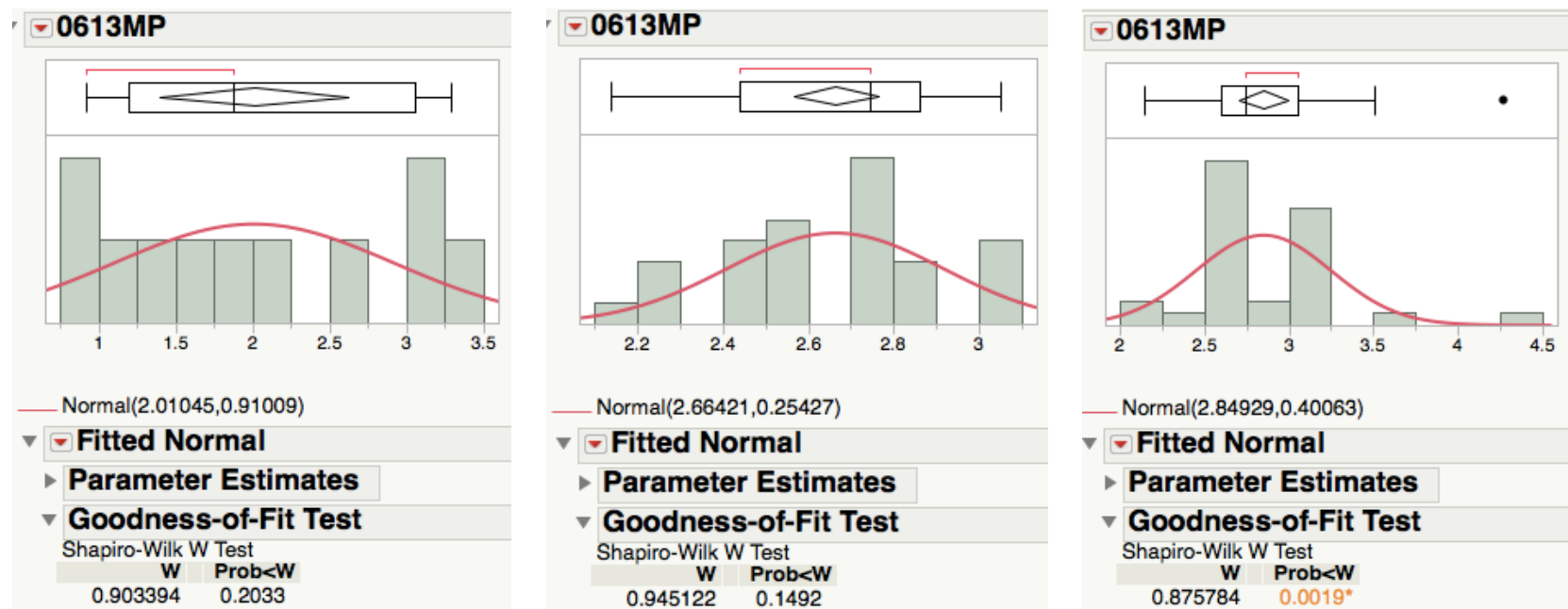

_ Normal(2.84929,0.40063)

$\checkmark$ Fitted Normal

- Parameter Estimates

- Goodness-of-Fit Test Shapiro-Wilk W Test

$\begin{array}{rr}\text { W } & \text { Prob }<W \\ 0.875784 & 0.0019^{*}\end{array}$

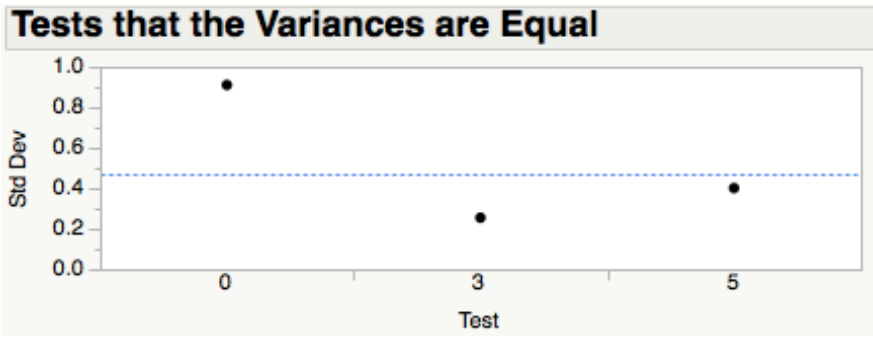

Test

O'Brien[.5]

Brown-Forsythe

Levene

Bartlett

$\begin{array}{rrrr}\text { F Ratio } & \text { DFNum } & \text { DFDen } & \text { Prob > F } \\ 17.3506 & 2 & 67 & <.0001^{*} \\ 15.2489 & 2 & 67 & <.0001^{*} \\ 19.6849 & 2 & 67 & <.0001^{*} \\ 14.4922 & 2 & . & <.0001^{*}\end{array}$

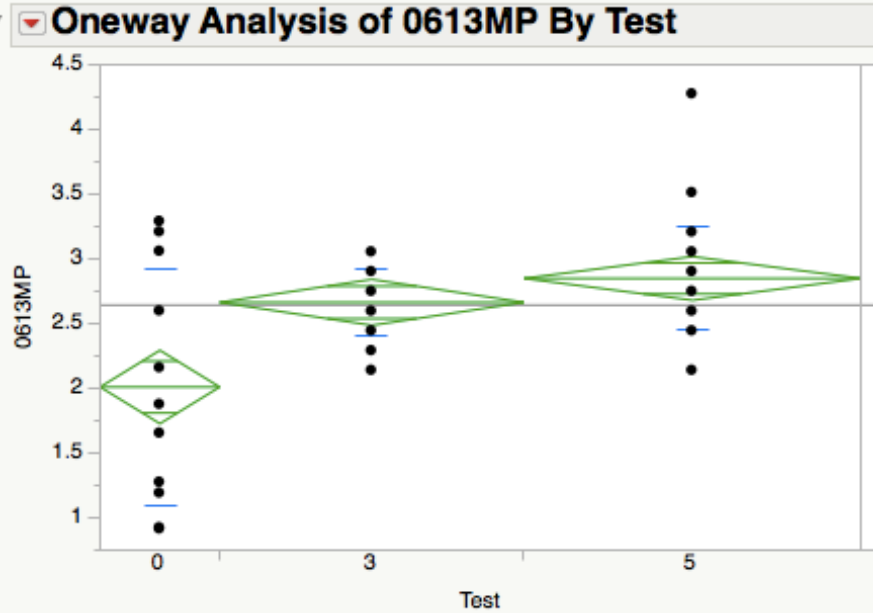

- Analysis of Variance

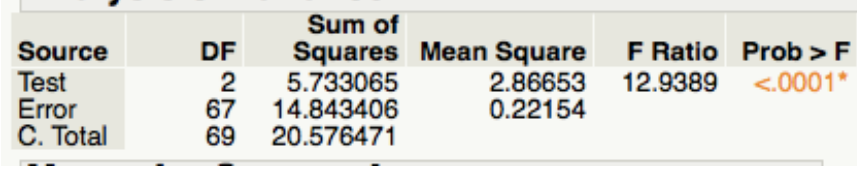

\section{Connecting Letters Report} Level

$5 \quad$ A 2.8492903

$\begin{array}{lll}3 & \text { A } & 2.6642143\end{array}$

O B 2.0104545 
Student 18: 0613MPO
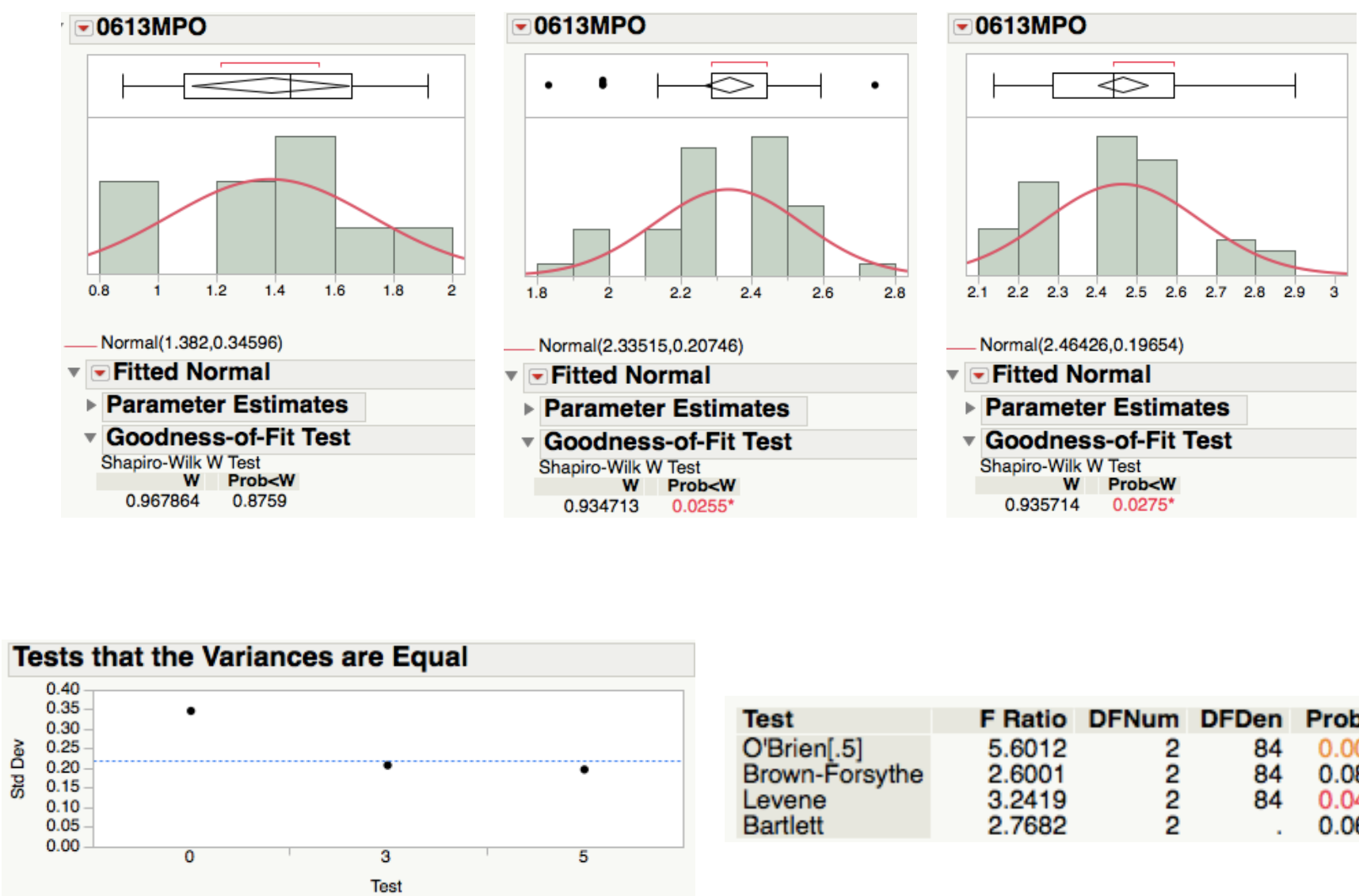

Test

O'Brien[.5]

Brown-Forsythe Levene Bartlett

$\begin{array}{rrrl}\text { F Ratio } & \text { DFNum } & \text { DFDen } & \text { Prob > F } \\ 5.6012 & 2 & 84 & 0.0052^{*} \\ 2.6001 & 2 & 84 & 0.0802 \\ 3.2419 & 2 & 84 & 0.0440^{*} \\ 2.7682 & 2 & . & 0.0628\end{array}$

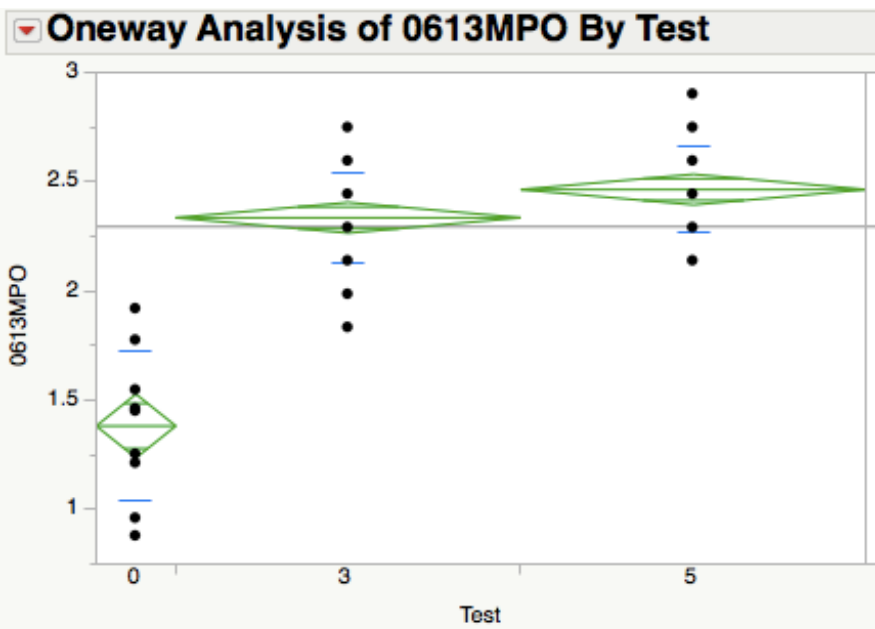

\begin{tabular}{|c|c|c|c|c|c|}
\hline \multicolumn{6}{|c|}{ Analysis of Variance } \\
\hline $\begin{array}{l}\text { Source } \\
\text { Test } \\
\text { Error } \\
\text { C. Total }\end{array}$ & $\begin{array}{r}\text { DF } \\
2 \\
84 \\
86\end{array}$ & $\begin{array}{r}\text { Sum of } \\
\text { Squares } \\
8.682235 \\
4.060899 \\
12.743133\end{array}$ & $\begin{array}{r}\text { Mean Square } \\
4.34112 \\
0.04834\end{array}$ & $\begin{array}{l}\text { F Ratio } \\
89.7963\end{array}$ & $\begin{array}{c}\text { Prob }>\mathbf{F} \\
<.0001^{*}\end{array}$ \\
\hline
\end{tabular}

\section{- Connecting Letters Report Level Mean 5 3 $\begin{array}{lll}\text { A } & & 2.4642564 \\ \text { B } & 2.3351538 \\ & \text { C } & 1.3820000\end{array}$}


Student 19: 0613MS
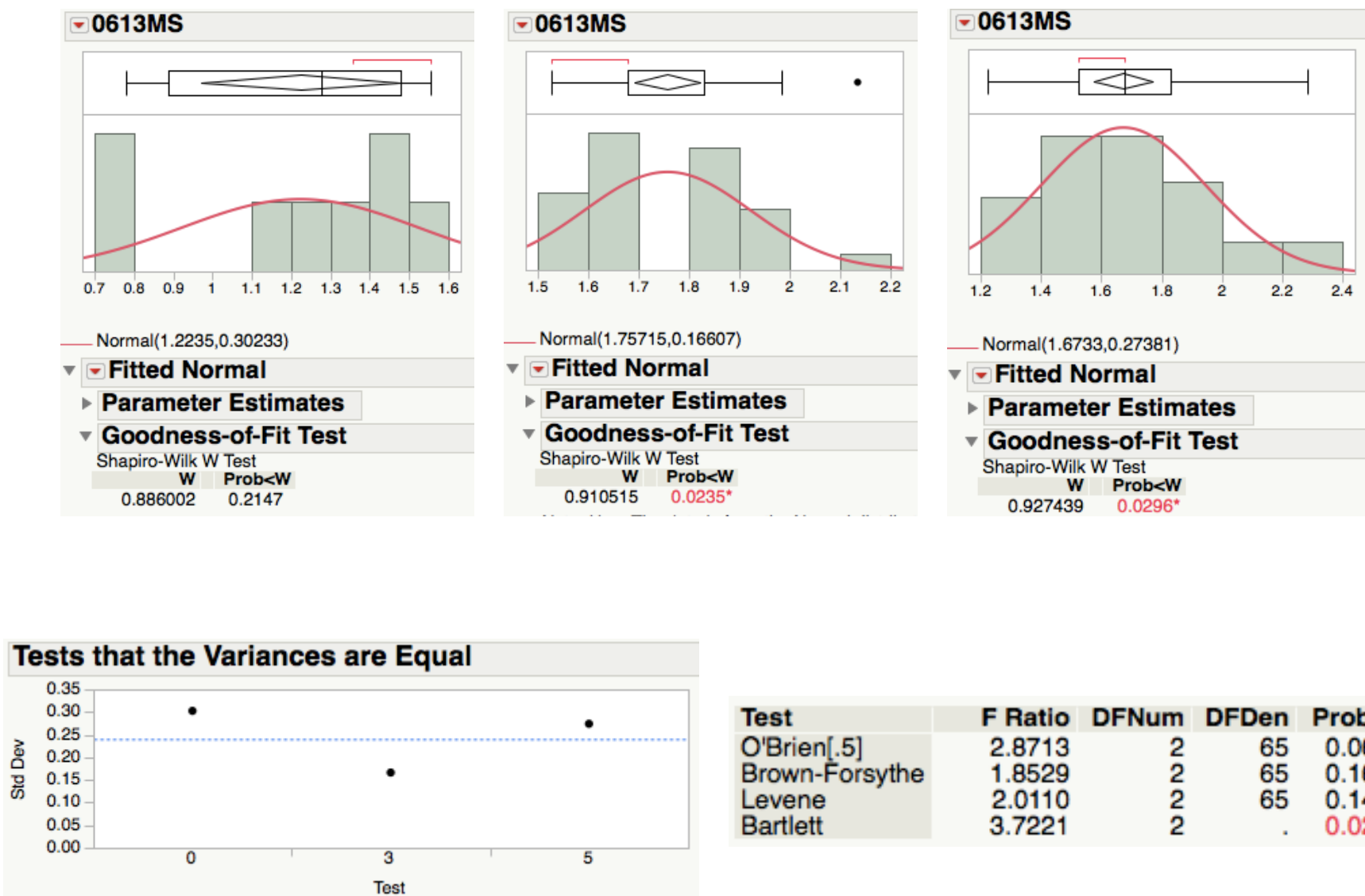

Test

O'Brien[.5]

Brown-Forsythe

Levene

Bartlett

$\begin{array}{rrrc}\text { F Ratio } & \text { DFNum } & \text { DFDen } & \text { Prob > F } \\ 2.8713 & 2 & 65 & 0.0638 \\ 1.8529 & 2 & 65 & 0.1650 \\ 2.0110 & 2 & 65 & 0.1421 \\ 3.7221 & 2 & . & 0.0242^{*}\end{array}$

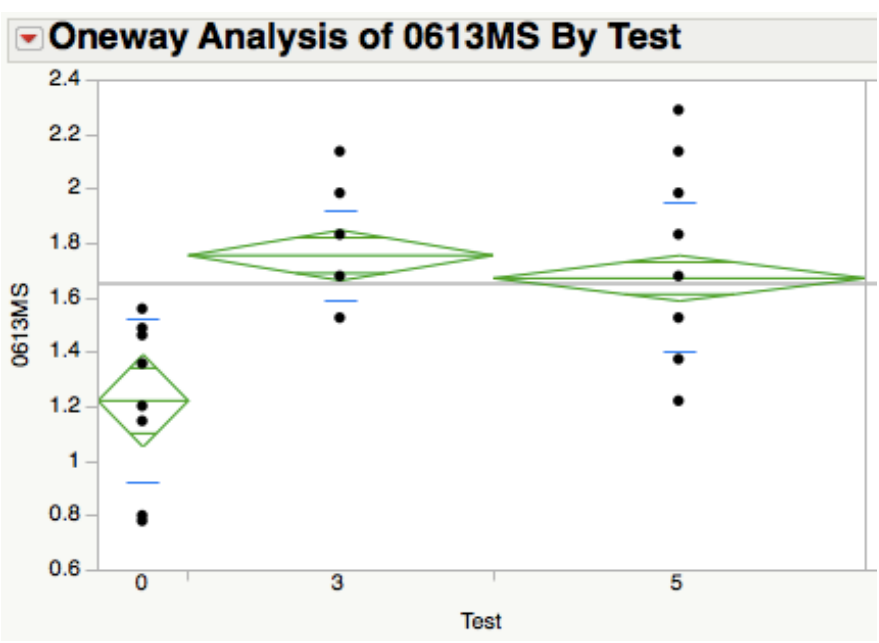

\begin{tabular}{|l|r|r|r|r|r|}
\multicolumn{6}{|l|}{ Analysis of Variance } \\
Sum of & & & \\
\hline Source & DF & $\begin{array}{r}\text { Squares } \\
\text { Mean Square }\end{array}$ & F Ratio & Prob $>$ F \\
\hline Test & 2 & 1.7821985 & 0.891099 & 15.4211 & $<.0001$ * \\
Error & 65 & 3.7559784 & 0.057784 & & \\
C. Total & 67 & 5.5381769 & & & \\
\hline
\end{tabular}

\section{Connecting Letters Report} Level 3

5

$\begin{array}{lrr}\text { A } & 1.7571481 \\ \text { A } & 1.6733030 \\ \text { B } & 1.2235000\end{array}$ 
Student 20: 0613NN
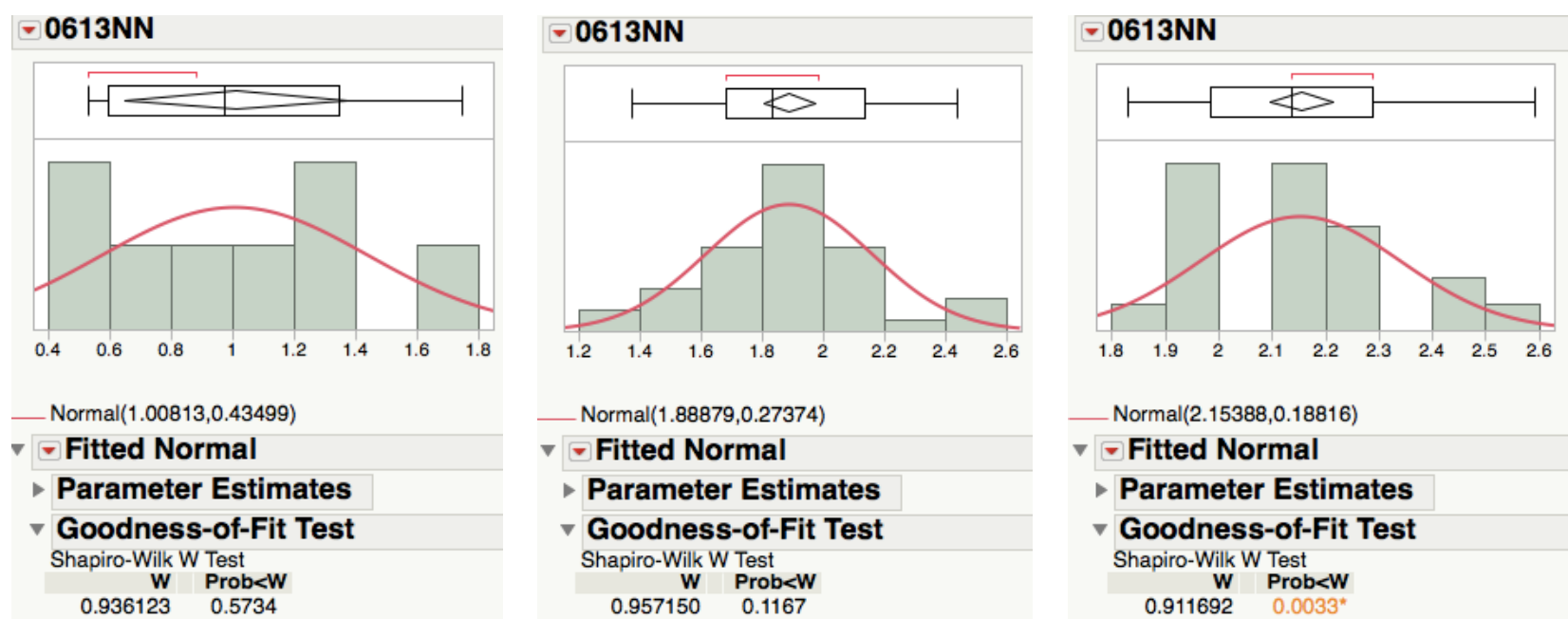

\section{Tests that the Variances are Equal}

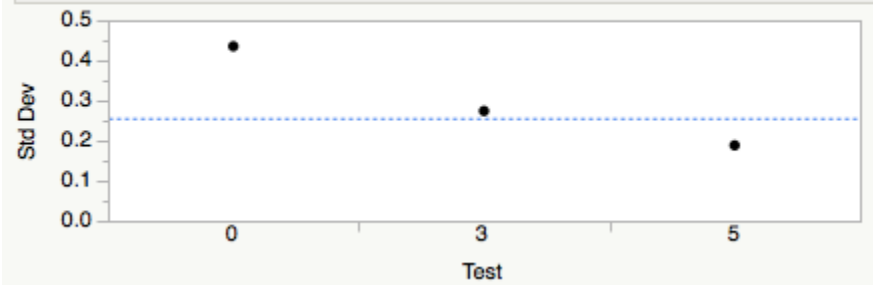

Test

O'Brien[.5]

Brown-Forsythe

Levene

Bartlett

$\begin{array}{rrrr}\text { F Ratio } & \text { DFNum } & \text { DFDen } & \text { Prob }>\text { F } \\ 9.2705 & 2 & 89 & 0.0002^{*} \\ 7.0050 & 2 & 89 & 0.0015^{*} \\ 7.9145 & 2 & 89 & 0.0007^{*} \\ 6.1010 & 2 & . & 0.0022^{*}\end{array}$

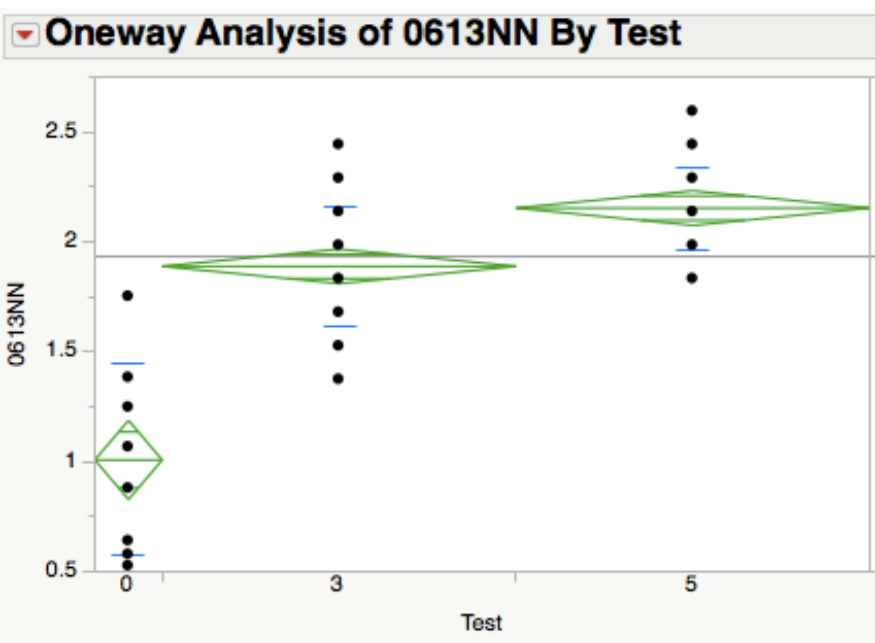

\begin{tabular}{|c|c|c|c|c|c|}
\hline \multicolumn{6}{|c|}{ Analysis of Variance } \\
\hline $\begin{array}{l}\text { Source } \\
\text { Test } \\
\text { Esror }\end{array}$ & $\begin{array}{r}\text { DF } \\
2 \\
89\end{array}$ & $\begin{array}{r}\text { Sum of } \\
\text { Squares } \\
8.974364 \\
5848264\end{array}$ & $\begin{array}{r}\text { Mean Square } \\
4.48718\end{array}$ & $\begin{array}{l}\text { F Ratio } \\
68.2868\end{array}$ & $\begin{array}{l}\text { Prob }>F \\
<.0001 *\end{array}$ \\
\hline & 91 & $\begin{array}{r}.040204 \\
14.822628\end{array}$ & & & \\
\hline
\end{tabular}

\section{Connecting Letters Report Level}

$5 \quad \mathrm{~A}$

3

0 
Age/Gender Study

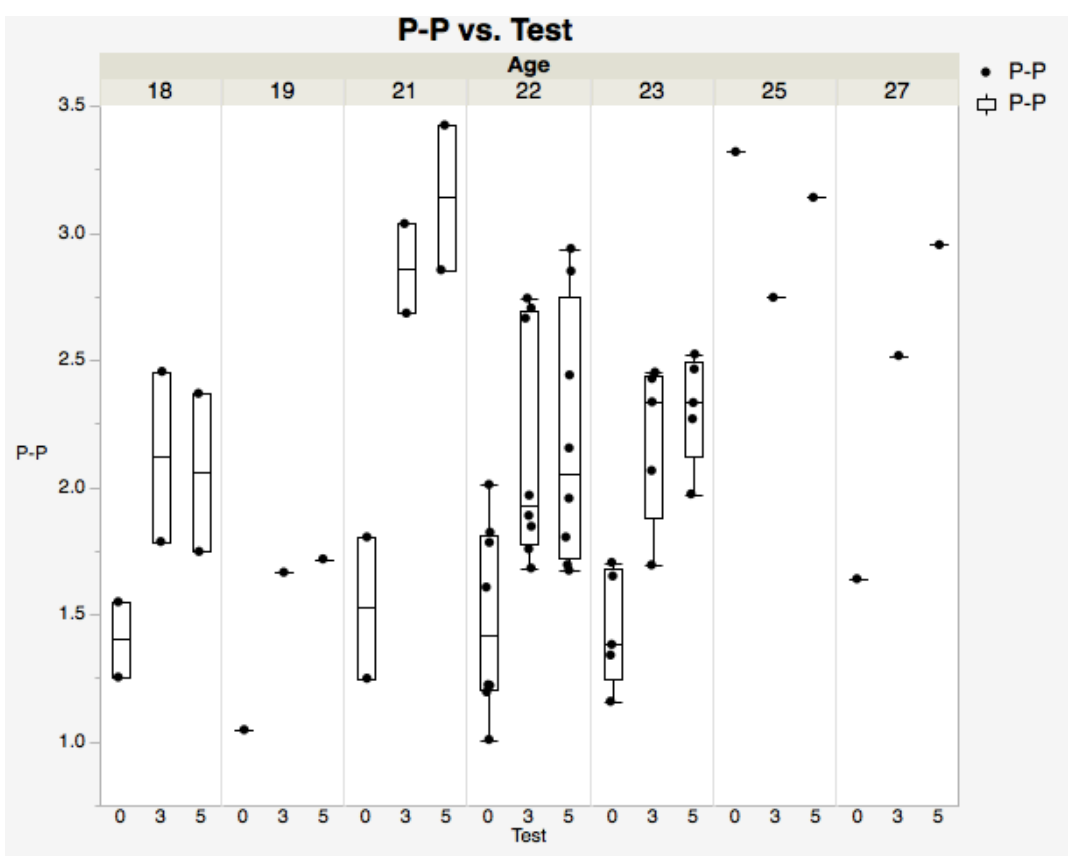

\begin{tabular}{|l|l|r|}
\hline & & \\
\hline Age & Mean & 22 \\
& Std Dev & 2.042 \\
& Min & 18 \\
& Max & 27 \\
\hline
\end{tabular}

P-P vs. Test

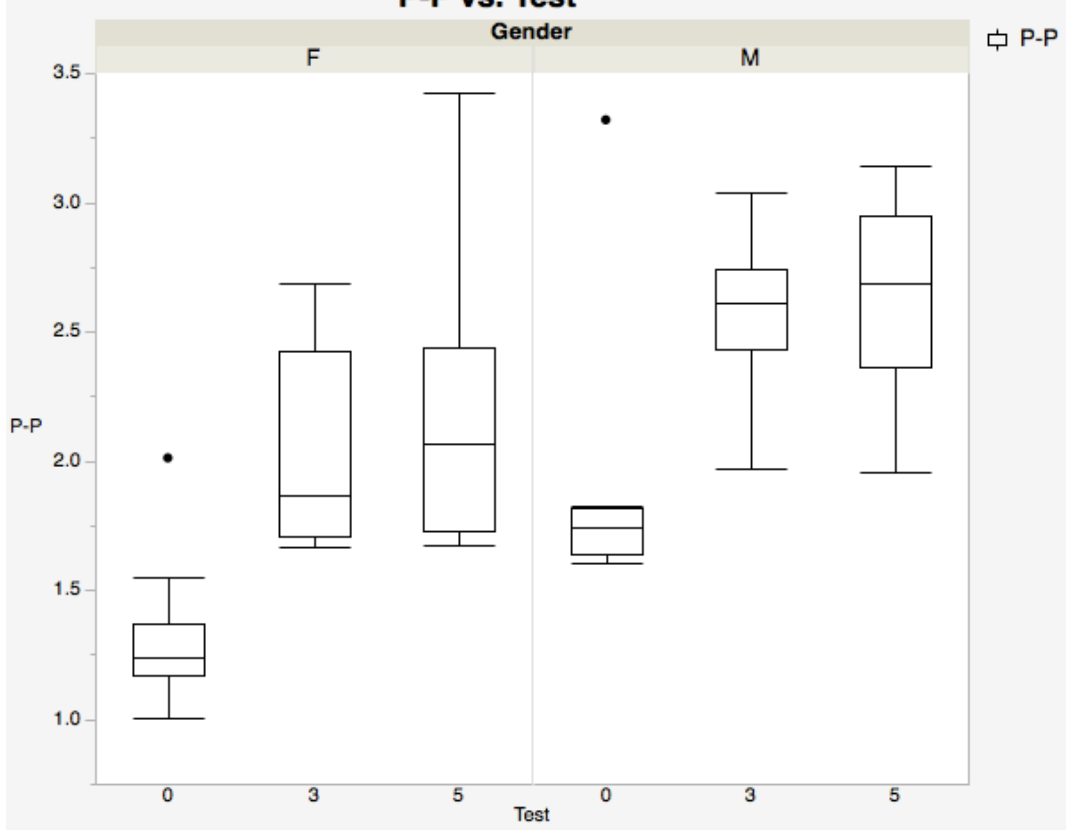

\begin{tabular}{|l|l|l|r|r|r|}
\hline \multicolumn{2}{|l|}{} & \multicolumn{3}{|c|}{ Test } \\
\hline Gender & & & $\mathbf{0}$ & $\mathbf{3}$ & $\mathbf{5}$ \\
\hline F & P-P & N & 12 & 12 & 12 \\
& & Mean & 1.303 & 2.044 & 2.178 \\
M & & Std Dev & 0.265 & 0.388 & 0.539 \\
& P-P & 8 & 8 & 8 \\
& & Mean & 1.916 & 2.574 & 2.642 \\
& & Std Dev & 0.572 & 0.315 & 0.396 \\
\hline
\end{tabular}


Age/Gender Study (continued)

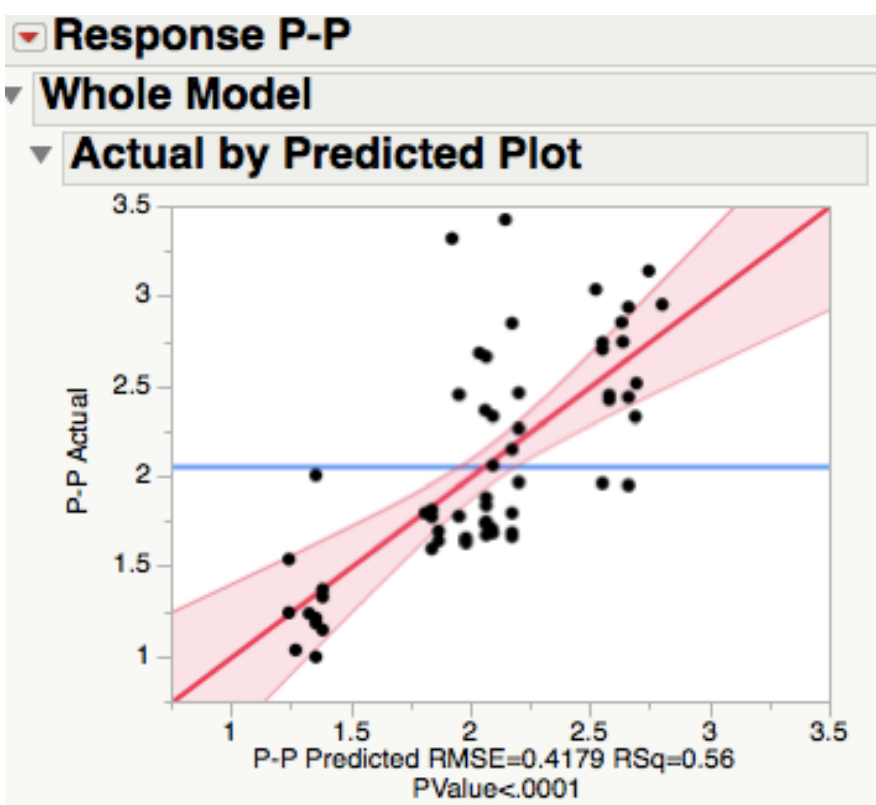

\begin{tabular}{|c|c|c|c|c|}
\hline \multicolumn{5}{|c|}{ Analysis of Variance } \\
\hline & DF & $\begin{array}{l}\text { Sum of } \\
\text { Squares }\end{array}$ & Mean Square & F Ratio \\
\hline Model & $\begin{array}{r}4 \\
55\end{array}$ & $\begin{array}{r}12.134994 \\
9.607463\end{array}$ & $\begin{array}{l}3.03375 \\
0.17468\end{array}$ & $\begin{array}{r}17.3673 \\
\text { Prob > F }\end{array}$ \\
\hline & 59 & 21.742457 & & $<.0001^{*}$ \\
\hline
\end{tabular}

\begin{tabular}{|c|c|c|c|c|}
\hline \multicolumn{5}{|c|}{ Parameter Estimates } \\
\hline \multicolumn{5}{|c|}{$\begin{array}{lll} & \text { Earameter Estimates } \\
\text { Term } & \text { Estimate Ero }\end{array}$} \\
\hline & 1.4866414 & & & \\
\hline & & & & $<. O C$ \\
\hline & 0.0 & & $\begin{array}{l}2.62 \\
0.94\end{array}$ & $\begin{array}{l}0.0114^{*} \\
0.3519\end{array}$ \\
\hline & & 0.061 & -3.91 & $0.0003^{*}$ \\
\hline
\end{tabular}

, Effect Tests

\begin{tabular}{lrrrrr|} 
Source & Nparm & DF & $\begin{array}{r}\text { Sum of } \\
\text { Squares }\end{array}$ & F Ratio & Prob > F \\
Test & 2 & 2 & 7.8473642 & 22.4620 & $<.0001^{*}$ \\
Age & 1 & 1 & 0.1539844 & 0.8815 & 0.3519 \\
Gender & 1 & 1 & 2.6695753 & 15.2826 & $0.0003^{*}$
\end{tabular}

\section{Residual by Predicted Plot}

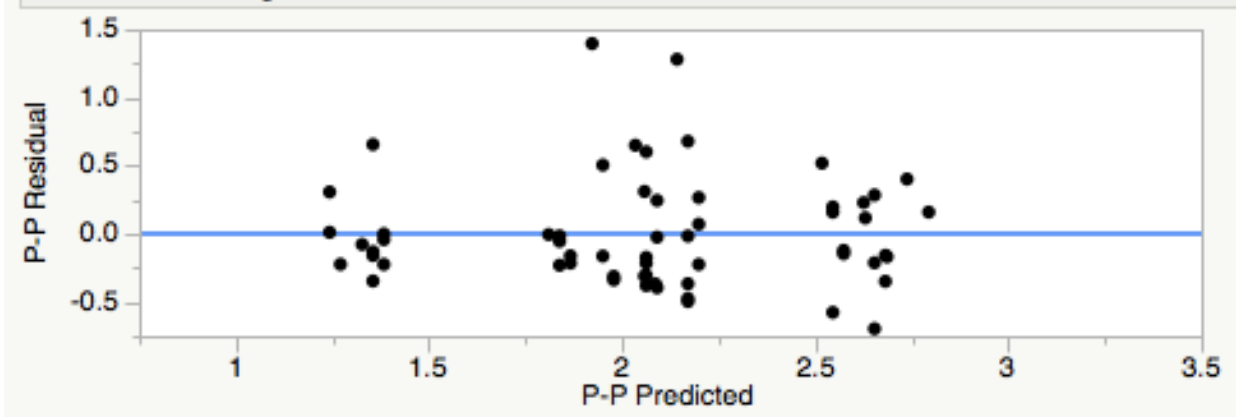


Combined Student Data

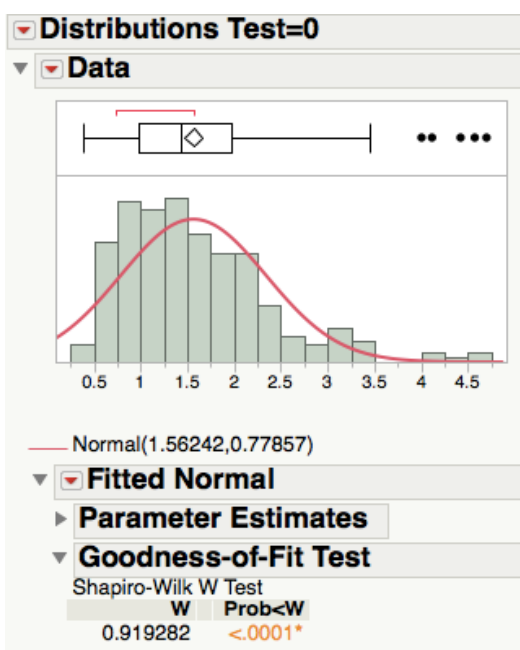

- Distributions Test=3
- Data

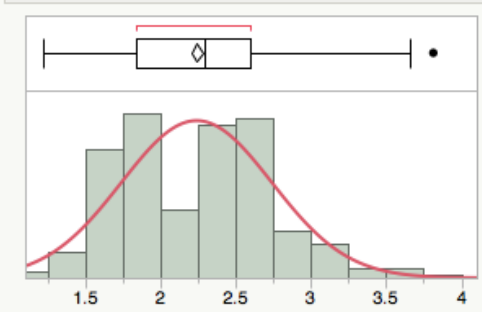

Normal(2.23858,0.50087)

v Fitted Normal

- Parameter Estimates

$\checkmark$ Goodness-of-Fit Test Shapiro-Wilk W Test
W Prob $<$ W $0.974170<.0001 *$

\section{- Distributions Test=5 \\ $\checkmark$ Data}

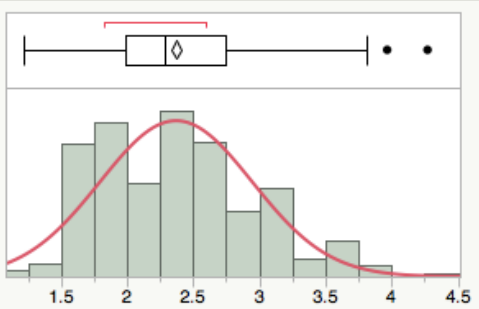

Normal $(2.3718,0.57639)$

- Fitted Normal

- Parameter Estimates

$\checkmark$ Goodness-of-Fit Test

Shapiro-Wilk W Test

W Prob $<$ W

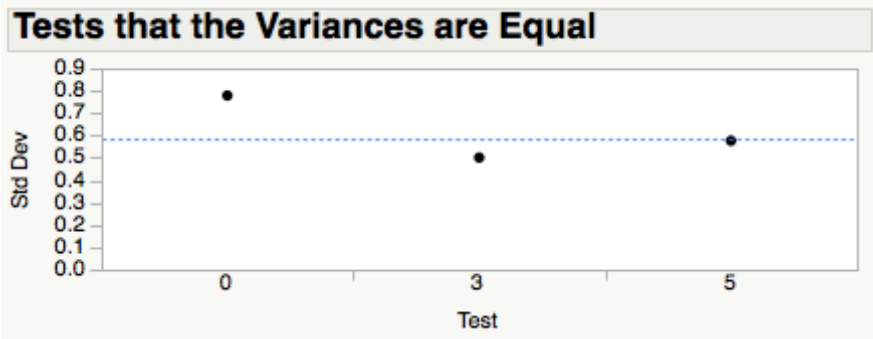

- Oneway Analysis of Data By Test

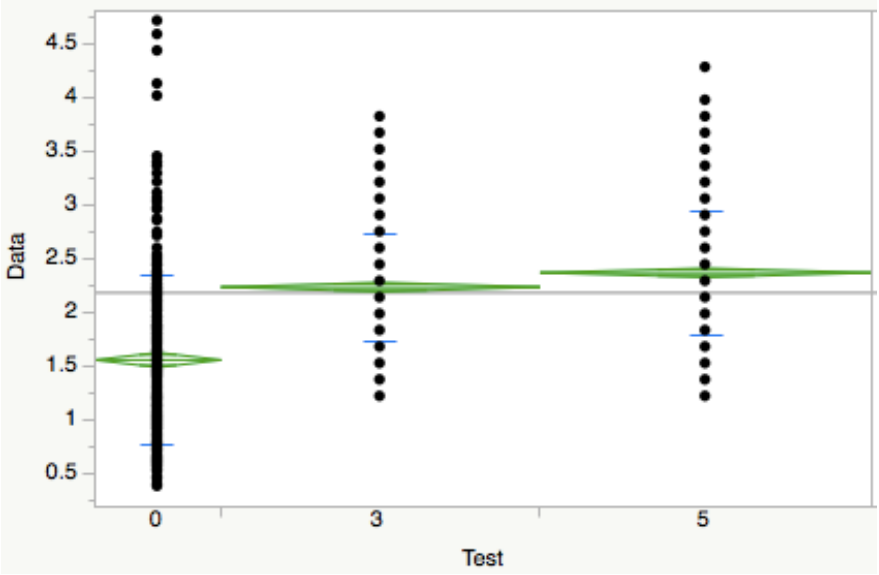

Test

O'Brien[.5]

Brown-Forsythe

Levene

Bartlett

$\begin{array}{rrrr}\text { F Ratio } & \text { DFNum } & \text { DFDen } & \text { Prob > F } \\ 37.3630 & 2 & 1730 & <.0001^{*} \\ 21.2385 & 2 & 1730 & <.0001^{*} \\ 26.1797 & 2 & 1730 & <.0001^{*} \\ 43.5502 & 2 & . & <.0001^{*}\end{array}$

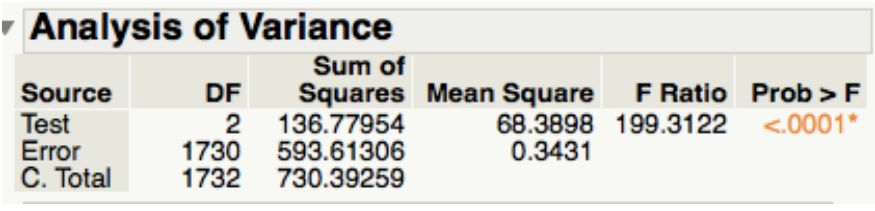

- Connecting Letters Report Level

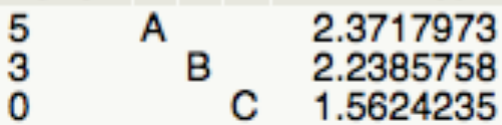




\begin{tabular}{|c|c|c|c|c|c|c|c|c|c|c|}
\hline \# & $\begin{array}{l}\text { GEN } \\
\text { DER }\end{array}$ & AGE & SBP & DBP & BPM & $\begin{array}{c}\text { CUFF } \\
\text { TIGHT } \\
\text { (CM) }\end{array}$ & $\begin{array}{c}50 \\
\text { SUPRA } \\
\text { SYSTO } \\
\text { LIC } \\
\end{array}$ & $\begin{array}{c}\text { BASELIN } \\
\mathbf{E}\end{array}$ & 3 MINUTE & 5 MINUTE \\
\hline 1 & M & 21 & 129 & 67 & 76 & 14 & 179 & 0612JLB & 0612JL3M2 & 0612JL5M1 \\
\hline 2 & $\mathrm{~F}$ & 22 & 125 & 67 & 81 & 14 & 175 & 0612SSB & 0612SS3M2 & 0612SS5M1 \\
\hline 3 & $\mathrm{~F}$ & 22 & 117 & 76 & 94 & 13 & 167 & 0612EKB & 0612EK3M2 & 0612EK5M1 \\
\hline 4 & M & 22 & 121 & 61 & 66 & 7 & 171 & 0612BKB & 0612BK3M1 & 0612BK5M2 \\
\hline 5 & M & 25 & 119 & 66 & 75 & 10 & 169 & 0612JFB & 0612JF3M1 & 0612JF5M2 \\
\hline 6 & $\mathrm{~F}$ & 23 & 107 & 64 & 80 & 12.5 & 157 & 0612RKB & 0612RK3M1 & 0612RK5M2 \\
\hline 7 & $\mathrm{~F}$ & 21 & 112 & 66 & 80 & 13.5 & 162 & 0612JKB & 0612JK3M2 & 0612JK5M1 \\
\hline 8 & $\mathrm{~F}$ & 19 & 99 & 64 & 80 & 13.5 & 149 & 0612PFB & 0612PF3M1 & 0612PF5M2 \\
\hline 9 & $\mathrm{~F}$ & 18 & 117 & 66 & 101 & 11 & 167 & $0612 \mathrm{KVB}$ & 0612KV3M2 & 0612KV5M1 \\
\hline 10 & $\mathrm{~F}$ & 18 & 110 & 58 & 56 & 12 & 160 & 0612BРB & 0612BР3M2 & 0612BР5M1 \\
\hline 11 & M & 23 & 149 & 95 & 102 & 1 & 199 & 0612BJB & 0612BJ3M1 & 0612BJ5M2 \\
\hline 12 & M & 22 & 127 & 72 & 89 & 4 & 177 & 0612NBB & 0612NB3M1 & 0612NB5M2 \\
\hline 13 & M & 22 & 137 & 79 & 77 & 9 & 187 & 0612GLB & 0612GL3M2 & 0612GL5M1 \\
\hline 14 & M & 23 & 133 & 75 & 62 & 5.5 & 183 & 0613JLB & 0613JL3M2 & 0612JL25M1 \\
\hline 15 & $\mathrm{~F}$ & 23 & 128 & 74 & 86 & 11.5 & 178 & 0613MBB & 0613MB3M2 & 0613MB5M1 \\
\hline 16 & $\mathrm{~F}$ & 22 & 103 & 60 & 61 & 15 & 153 & 0613MPB & 0613MP3M1 & 0613MP5M2 \\
\hline 17 & $\mathrm{~F}$ & 23 & 121 & 71 & 84 & 13.5 & 171 & $\begin{array}{c}\text { 0613MPO } \\
\text { B }\end{array}$ & $\begin{array}{c}\text { 0613MPO3M } \\
2\end{array}$ & 0613MPO5M1 \\
\hline 18 & $\mathrm{~F}$ & 22 & 122 & 80 & 88 & 12 & 172 & $0613 \mathrm{NNB}$ & 0613NN3M1 & 0613NN5M2 \\
\hline 19 & $\mathrm{~F}$ & 22 & 121 & 77 & N/A & 8.5 & 171 & 0613MSB & 0613MS3M1 & 0613MS5M2 \\
\hline 20 & $\mathrm{M}$ & 27 & 107 & 59 & 61 & 12 & 157 & 0613JSB & 0613JS3M1 & 0613JS5M2 \\
\hline
\end{tabular}

